ORNL/TM-13683

OAK RIDGE NATIONAL LABORATORY
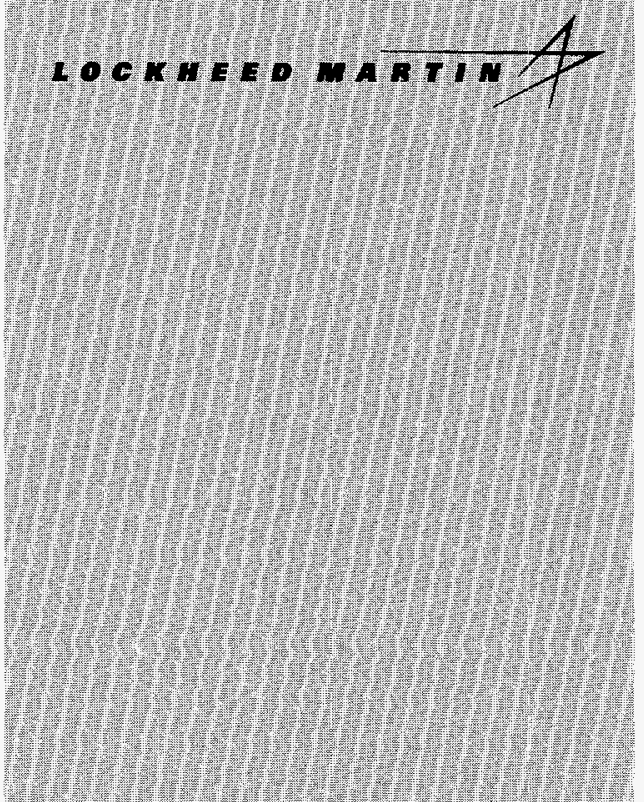

Heter.
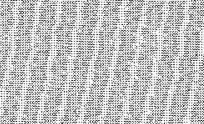

).

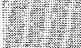

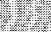

1)

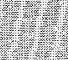

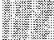

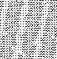

(2)

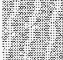

\section{(y)}

\section{MANIGED AND OPERATED BY}

LOCKHEED MARTIN ENERGY RESEARCH CORPCRATION FOA THE UNTED STATES

DEPARTIENT OF ENERGY

\section{CAVITATION BUBBLE NUCLEATION BY ENERGETIC PARTICLES}
1150

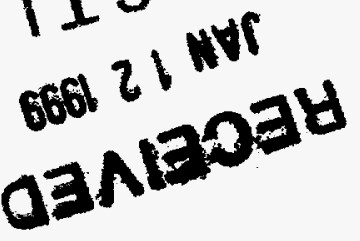
C. D. West 
This report has been reproduced from the best available copy.

Reports are available to the public from the following source.

National Technical Information Service

5285 Port Royal Road

Springfield, VA 22161

Telephone 703-605-6000 (1-800-553-6847)

TDD 703-487-4639

Fax 703-605-6900

E-mail orders@ntis.fedworld.gov

Web site http://www.ntis.gov/ordering.htm

Reports are available to U.S. Department of Energy (DOE) employees, DOE contractors, Energy

Technology Data Exchange (ETDE) representatives, and International Nuclear Information System

(INIS) representatives from the following source.

Office of Scientific and Technical Information

P.O. Box 62

Oak Ridge, TN 37831

Telephone 423-576-8401

Fax 423-576-5728

E-mail reports@ adonis.osti.gov

Web site http://www.osti.gov/products/sources.html

Reports produced after January 1, 1996, are generally available via the DOE Information Bridge.

Web site $h$ ttp://www.doe.gov/bridge 


\section{DISCLAIMER}

This report was prepared as an account of work sponsored by an agency of the United States Government. Neither the United States Government nor any agency thereof, nor any of their employees, make any warranty, express or implied, or assumes any legal liability or responsibility for the accuracy, completeness, or usefulness of any information, apparatus, product, or process disclosed, or represents that its use would not infringe privately owned rights. Reference herein to any specific commercial product, process, or service by trade name, trademark, manufacturer, or otherwise does not necessarily constitute or imply its endorsement, recommendation, or favoring by the United States Government or any agency thereof. The views and opinions of authors expressed herein do not necessarily state or reflect those of the United States Government or any agency thereof. 


\section{DISCLAIMER}

Portions of this document may be illegible in electronic image products. Images are produced from the best available original document. 


\title{
CAVITATION BUBBLE NUCLEATION BY ENERGETIC PARTICLES
}

\author{
C. D. West
}

Date published: December 1998

\author{
Prepared by \\ OAK RIDGE NATIONAL LABORATORY \\ Oak Ridge, Tennessee 37831 \\ managed by \\ LOCKHEED MARTIN ENERGY RESEARCH CORP. \\ for the \\ U.S. DEPARTMENT OF ENERGY \\ under contract DE-AC05-96OR22464
}




\section{CONTENTS}

LIST OF FIGURES $\ldots \ldots \ldots \ldots \ldots \ldots \ldots \ldots \ldots \ldots \ldots \ldots \ldots \ldots \ldots \ldots \ldots \ldots \ldots$

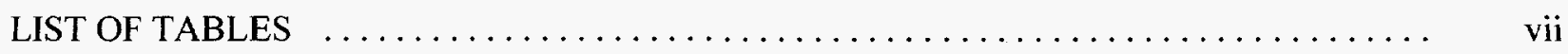

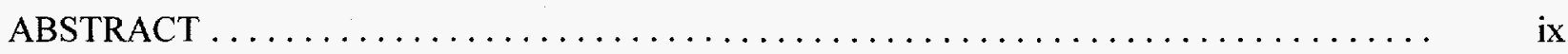

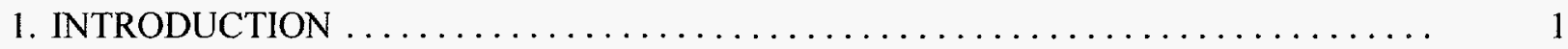

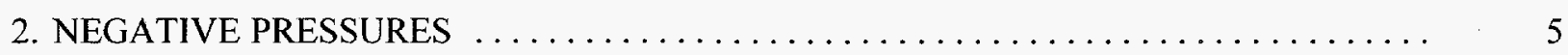

3. EXPERIMENTAL MEASUREMENTS $\ldots \ldots \ldots \ldots \ldots \ldots \ldots \ldots \ldots \ldots \ldots \ldots \ldots$

4. RIEPE AND HAHN'S BUBBLE CHAMBER MEASUREMENTS AND THEORY . . . . . 9

5. HAHN'S SPINNER RESULTS-A MAJOR PUZZLE $\ldots \ldots \ldots \ldots \ldots \ldots \ldots \ldots \ldots \ldots \ldots$

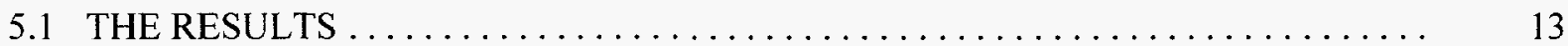

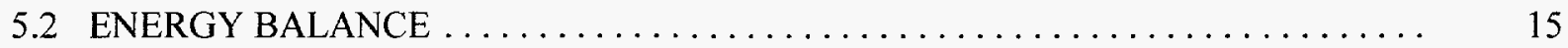

6. CAVITATION BUBBLE NUCLEATION $\ldots \ldots \ldots \ldots \ldots \ldots \ldots \ldots \ldots \ldots \ldots \ldots \ldots \ldots$

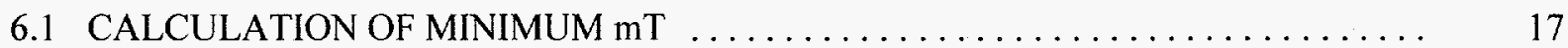

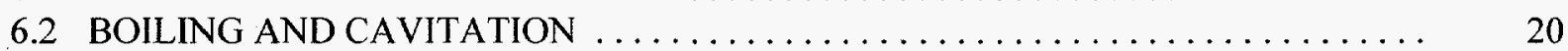

6.3 INITIATION OF BUBBLE FORMATION IN COLD LIQUIDS $\ldots \ldots \ldots \ldots \ldots \ldots . \quad 21$

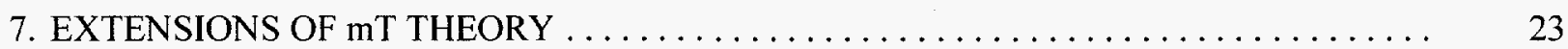

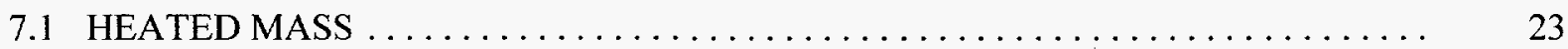

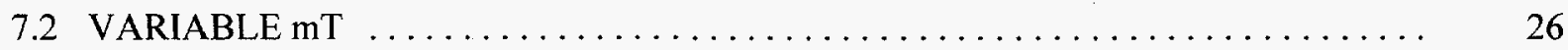

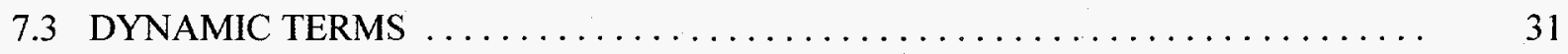

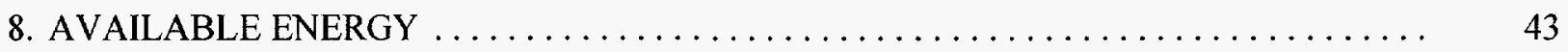

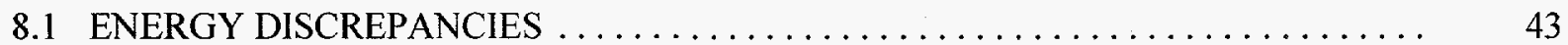

8.2 LINEAR RATE OF ENERGY LOSS $\ldots \ldots \ldots \ldots \ldots \ldots \ldots \ldots \ldots \ldots \ldots \ldots \ldots \ldots \ldots \ldots \ldots$

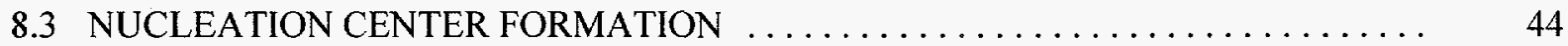

8.4 CALCULATION OF CAVITATION THRESHOLD $\ldots \ldots \ldots \ldots \ldots \ldots \ldots \ldots .48$

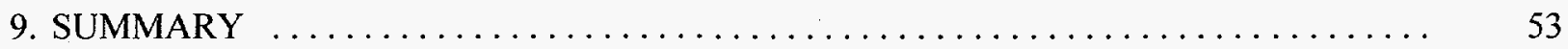

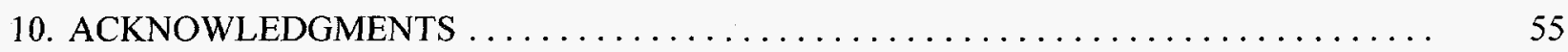

11. REFERENCES $\ldots \ldots \ldots \ldots \ldots \ldots \ldots \ldots \ldots \ldots \ldots \ldots \ldots \ldots \ldots \ldots \ldots \ldots \ldots \ldots \ldots \ldots \ldots$

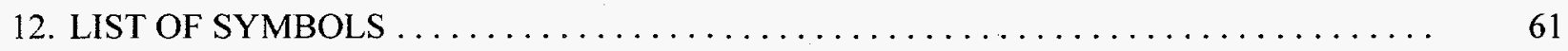

APPENDIX A. MEASUREMENTS OF THE PRESSURE THRESHOLD FOR BUBBLE NUCLEATION BY VARIOUS PARTICLES IN VARIOUS LIQUIDS $\ldots \ldots \ldots \ldots \ldots \ldots$ A

APPENDIX B. EFFECT OF SURFACE CURVATURE ON ENTHALPY

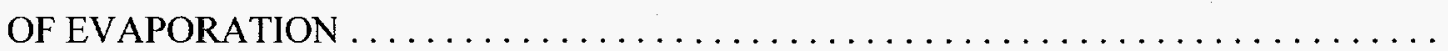


APPENDIX C. CALCULATIONS ON RIEPE AND HAHN'S BUBBLE CHAMBER EXPERIMENT RESULTS AND COMPARISONS

WITH THEIR CALCULATIONS

C-1

APPENDIX D. AN ADDITIONAL SURFACE ENERGY TERM? $\ldots \ldots \ldots \ldots \ldots \ldots \ldots \ldots$ D-1

APPENDIX E. FLUID PROPERTIES FOR EVALUATIONS OF ENERGY

TERMS AND PRESSURE THRESHOLD FOR HAHN'S SPINNER

EXPERIMENTS

E-1 


\section{LIST OF FIGURES}

Page

1 Rotating pyrex glass capillary tube $\ldots \ldots \ldots \ldots \ldots \ldots \ldots \ldots \ldots \ldots \ldots \ldots \ldots \ldots \ldots \ldots \ldots$

2 The expansive (LHS) and compressive (RHS) pressures on bubbles filled with a constant (mass $\times$ temperature) of vapor $\ldots \ldots \ldots \ldots \ldots \ldots \ldots \ldots \ldots \ldots \ldots \ldots$

3 Expansive and compressive pressure when $P_{\text {vap }}$ is three times $P_{\text {neg }} \ldots \ldots \ldots \ldots \ldots \ldots$

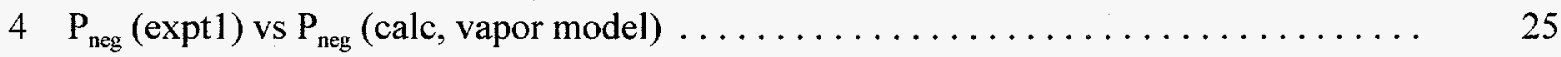

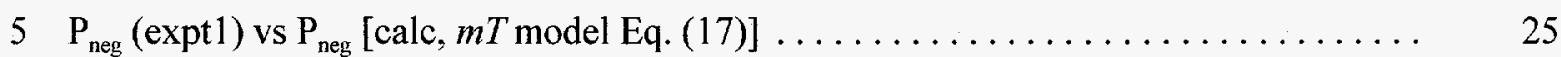

$6 \quad P_{\text {neg }}$ (expt1) vs $P_{\text {neg }}[\mathrm{calc}, m T$ model, Eq. (27)], cyclohexanol excluded $\ldots \ldots \ldots \ldots \ldots . \quad 30$

$7 \quad P_{\text {neg }}\left(\right.$ expt1) vs $P_{\text {neg }}$ [calc, $m T$ model, Eq. (27)], cyclohexanol included $\ldots \ldots \ldots \ldots \ldots$

$8 \quad \mathrm{P}_{\text {neg }}$ (expt1) vs $\mathrm{P}_{\text {neg }}$ [calc, variable, $m T$ dynamic model, Eqs. (44) and (50)] $\ldots \ldots \ldots \quad 42$

9 Unit diameter cylinders and spheres of the same volume $\ldots \ldots \ldots \ldots \ldots \ldots \ldots$

$10 \quad \mathrm{P}_{\text {neg }}$ (expt1) vs $\mathrm{P}_{\text {neg }}$ [calc, variable, $m T$ model, Eq. (64), using EAN] $\ldots \ldots \ldots \ldots \ldots .50$ 


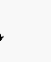




\section{LIST OF TABLES}

Page

1 Reipe and Hahn: Energy balance with recoils from ${ }^{210}$ Po decay $\ldots \ldots \ldots \ldots \ldots \ldots$

2 Results from Hahn's spinner experiments $\ldots \ldots \ldots \ldots \ldots \ldots \ldots \ldots \ldots \ldots \ldots \ldots$

3 Liquid and vapor properties for calculations of bubble formation energy in

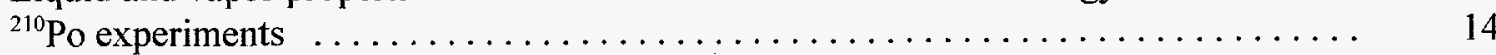

4 Energy terms (in keV) for Hahn's spinner liquids nucleated by ${ }^{210}$ Po recoils $\ldots \ldots \ldots \quad 15$

5 Operating temperatures, superheat limits, and enthalpies in Riepe and Hahn

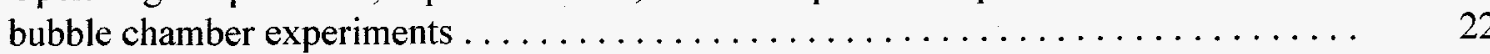

6 Operating temperatures, critical temperatures, and enthalpies in Hahn's

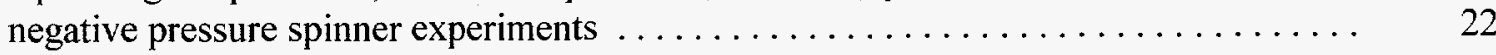

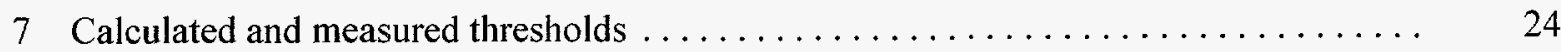

8 Equation (25) results with and without the $T d \sigma / d T$ term $\ldots \ldots \ldots \ldots \ldots \ldots \ldots \ldots$

9 Correlation coefficients with and without the $T d \sigma / d T$ term $\ldots \ldots \ldots \ldots \ldots \ldots \ldots$

10 Initial internal energy, surface energy, and PV work $\ldots \ldots \ldots \ldots \ldots \ldots \ldots \ldots \ldots \ldots$

11 Effect of dynamic terms on the calculated threshold $\ldots \ldots \ldots \ldots \ldots \ldots \ldots \ldots \ldots$

12 Calculated thresholds, equilibrium radius, and unconditional growth radii ....... 39

13 Comparison of $r_{\mathrm{eq}}, r^{*}$, and $R_{\mathrm{o}} \ldots \ldots \ldots \ldots \ldots \ldots \ldots \ldots \ldots \ldots \ldots \ldots \ldots \ldots \ldots \ldots \ldots \ldots \ldots \ldots \ldots$

14 Threshold calculated from Eqs. (44) and (50) $\ldots \ldots \ldots \ldots \ldots \ldots \ldots \ldots \ldots \ldots \ldots \ldots$

15 Energy available for bubble formation $\ldots \ldots \ldots \ldots \ldots \ldots \ldots \ldots \ldots \ldots \ldots \ldots \ldots \ldots$

16 Calculated and measured cavitation thresholds $\ldots \ldots \ldots \ldots \ldots \ldots \ldots \ldots \ldots \ldots$

17 Evolution of the model $\ldots \ldots \ldots \ldots \ldots \ldots \ldots \ldots \ldots \ldots \ldots \ldots \ldots \ldots \ldots \ldots \ldots \ldots \ldots$

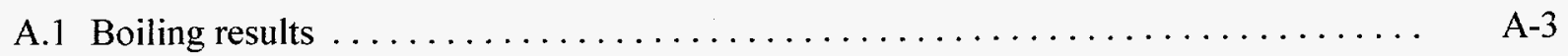

A.2 Negative pressure results $\ldots \ldots \ldots \ldots \ldots \ldots \ldots \ldots \ldots \ldots \ldots \ldots \ldots \ldots \ldots \ldots \ldots \ldots \ldots$

C.1 Calculated parameters of critical bubbles $\ldots \ldots \ldots \ldots \ldots \ldots \ldots \ldots \ldots \ldots \ldots \ldots \ldots$ 


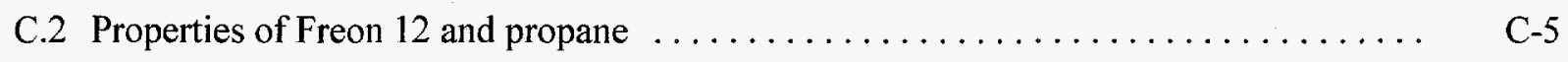

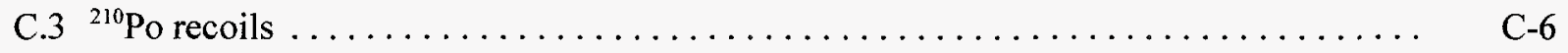

D.1 Extension of West figures and columns in Table C.3 $\ldots \ldots \ldots \ldots \ldots \ldots \ldots \ldots \ldots \ldots$

E.1 Liquid and vapor properties; $10-5-98 \ldots \ldots \ldots \ldots \ldots \ldots \ldots \ldots \ldots \ldots \ldots \ldots \ldots \ldots \ldots \ldots \ldots$ 


\begin{abstract}
In the early sixties, experimental measurements using a bubble chamber confirmed quantitatively the thermal spike theory of bubble nucleation by energetic particles: the energy of the slow, heavy alpha decay recoils used in those experiments matched the calculated bubble nucleation energy to within a few percent. It was a triumph, but was soon to be followed by a puzzle. Within a couple of years, experiments on similar liquids, but well below their normal boiling points, placed under tensile stress showed that the calculated bubble nucleation energy was an order of magnitude less than the recoil energy.

Why should the theory work so well in the one case and so badly in the other? How did the liquid, or the recoil particle, "know" the difference between the two experiments? Another mathematical model of the same physical process, introduced in 1967, showed qualitatively why different analyses would be needed for liquids with high and low vapor pressures under positive or negative pressures. But, the quantitative agreement between the calculated nucleation energy and the recoil energy was still poor-the former being smaller by a factor of two to three.

In this report, the 1967 analysis is extended and refined: the qualitative understanding of the difference between positive and negative pressure nucleation, "boiling" and "cavitation" respectively, is retained, and agreement between the negative pressure calculated to be needed for nucleation and the energy calculated to be available is much improved. A plot of the calculated negative pressure needed to induce bubble formation against the measured value now has a slope of 1.0 , although there is still considerable scatter in the individual points.
\end{abstract}




\section{INTRODUCTION}

Under normal conditions, most liquids have rather well-defined freezing and boiling points. However, it is well known that clean liquids can be supercooled or superheated, finally changing phase only considerably below the freezing, or above the boiling, point. The superheating effect is easily demonstrated with a clean glass of previously boiled water and a microwave oven. However, I do not recommend the experiment, because the final boiling event is fairly violent: liquid water at atmospheric pressure and, say, $125^{\circ} \mathrm{C}$ contains a lot of stored energy - almost one-fifth of that stored as chemical energy in the same volume of gunpowder, for example, and enough to flash about $5 \%$ of its mass into steam immediately, increasing the volume of that $5 \%$ more than a thousandfold.

Superheating is put to good use in the bubble chamber, invented by Donald Glaser and for which he was awarded the Nobel prize for physics in 1960. His first demonstration of particle tracks, in the early 1950 s, involved a small glass bulb on the end of a long tube (Glaser 1958 and 1964). The apparatus was filled with diethyl ether, and the few $\mathrm{mL}$ in the bulb part was kept at $135^{\circ} \mathrm{C}$ or above, the rest of the system being at room temperature. The normal boiling point of diethyl ether at atmospheric pressure is only $34^{\circ} \mathrm{C}$, but a piston pressurized the system, keeping even the ether in the bulb above its saturation pressure of about $13 \mathrm{~atm}$ and offering it no temptation to boil. However, when the pressure was released by moving the piston with a hand crank, the ether in the bulb was more than $100^{\circ} \mathrm{C}$ above its boiling point. Even so, there was a significant delay before general boiling occurred, and during that period, atomic particles (e.g., cosmic rays) passing through the bulb could be seen, by high-speed photography, to leave a track of small, but growing, bubbles. Stereo photographs of the bulb allowed the particle's path to be reconstructed. It was like a Wilson cloud chamber, but with a medium whose density was the order of $1 \mathrm{~kg} / \mathrm{L}$ instead of only 1 to $100 \mathrm{~g} / \mathrm{L}$, and therefore gave a much greater chance of interacting within the volume of the chamber with an energetic particle.

Progress was rapid. In less than seven years, bubble chambers had grown from Glaser's tiny demonstration to the status of major, high-tech hardware: Berkeley had a 6-ft bubble chamber filled with $500 \mathrm{~L}$ of liquid hydrogen!

All of these machines worked on the same principle: the pressure on a suitable liquid was dropped suddenly from above the saturation value to below it, so that bulk boiling became energetically favorable. In so called "clean" bubble chambers like Glaser's first glass model, the liquid could remain in the superheated state for seconds, or longer, awaiting a particle whose path would then be outlined as a trail of bubbles. If the particle decayed, or interacted with an atom in the bubble chamber medium, the paths of the reaction products would also be rendered visible.

"Dirty" bubble chambers, including all of the biggest chambers, were those with structures or materials (such as seals and fasteners around the windows, and the piston) that would always nucleate boiling-like the rough, porous ceramic disks that used to be placed in kettles and pans to prevent the "bumping" that was, in fact, superheating and subsequent violent boiling - as soon as the pressure was dropped. The bubbles nucleated in that way eventually would repressurize the system to somewhere close to the saturation pressure, thus removing the superheat and rendering the chamber insensitive to incoming particles. However, the growth rate of the bubbles was slow enough that there was still a period of sensitivity lasting at least several milliseconds, before the pressure became too high.

One major disadvantage of the bubble chamber was that it could not be triggered. In a cloud chamber, on the other hand, the droplets making up the tracks in a supercooled, and therefore supersaturated, gas/vapor mixture are nucleated along the line of electric charges left by the incoming particle. Those charges remain separated long enough that a cloud chamber can be depressurized after the incoming particle has arrived and still show tracks. This means that interesting events can be identified by electronic detectors, such as Geiger or scintillation counters, placed outside the chamber in various coincidence/anticoincidence arrangements, and depressurization can be triggered if, but only if, such an event is detected. 
No one ever succeeded in triggering a bubble track chamber in that way, or even in measuring the lifetime of whatever nucleation centers are left in a subcooled (i.e., pressurized) bubble chamber liquid by the incoming particles. Glaser and Rahm (1955) showed that the lifetime of the radiation-induced nucleation centers in a bubble chamber (meaning the length of time that a nucleation center created under pressure and temperature conditions unfavorable to growth, which Glaser referred to as a "latent image," remains capable of forming a bubble if conditions later become favorable) was not more than $1 \mathrm{~ms}$, or in some cases less than $0.1 \mathrm{~ms}$. They argued that it might be less than a few microseconds. West and Howlett (1968) reported experiments with very rapidly (ultrasonically) depressurized liquids that showed the lifetime of latent nucleation centers to be less than $2 \mu \mathrm{s}$.

Some experiments, in which a small, clean, isopentane bubble chamber was placed in a waveguide where it could be zapped with a $2-\mu \mathrm{s}$ microwave pulse from a $250-\mathrm{kW}$ magnetron (Bertanza et al. 1956) reported that boiling could be triggered after a particle had passed through. The chamber was depressurized, but not enough to show tracks; as a clean chamber, it could remain in this state for a significant period. During that period, a microwave pulse was initiated on detection of coincident signals in two Geiger-Muller (G.M.) counters, one above and one below the chamber, indicating that a particle had passed through the superheated isopentane. "In a certain range of temperature (from $80^{\circ} \mathrm{C}$ upwards) microwaves in coincidences with G.M. counters always give rise to boiling, whereas microwaves alone never do (of course, counter coincidences alone do not give rise to any boiling). . ..." Without knowledge of the delays in the electronics and of the microwave pulse rise time, which the reference does not supply, one cannot estimate the lifetime of the nucleation centers between their creation by the particle and their growth beginning during the microwave pulse. Furthermore, there are some puzzling aspects to the results (e.g., the bubbles photographed in the boiling liquid were few and scattered-no tracks were seen.

Years after bubble chambers were in common use, debate on the bubble nucleation mechanism continued. Glaser originally thought that the mechanism might be similar to the cloud chamber, depending upon ionization and electric charge effects, and others pursued the same idea. Eventually, a different theory gained general acceptance; its most eloquent and influential expression is probably found in a paper written by Seitz (1958), although by that time Glaser too had arrived at a similar viewpoint. In Seitz' theory, kinetic energy is transferred to the atoms and molecules of the medium, thus raising the temperature locally, producing '. . . highly localized hot regions, or 'temperature spikes,' within the liquid that literally explode into bubbles of larger than critical size, which can grow through evaporation of the superheated liquid." There is a critical size, beyond which the bubble can grow indefinitely, because the surface tension, $\sigma$, of the liquid effectively acts as an additional pressure, equal to $2 \sigma / r$, tending to collapse the bubble. If the difference between the vapor pressure inside the bubble and the pressure outside it is greater than $2 \sigma / r$, the bubble can continue to grow; i.e., the condition for growth is

$$
P_{v a p}>P_{e x t}+2 \sigma / r
$$

where $P_{e x t}$ is the pressure in the liquid after the chamber has been depressurized. The critical radius is therefore

$$
r_{c r i t}=\frac{2 \sigma}{P_{\text {vap }}-P_{\text {ext }}}
$$


Seitz also calculated that the heat within the spherical thermal spike dissipated by conduction, losing all but a fraction $1 / \mathrm{e}$ of the initial heat content in a time $\tau$, called the relaxation time, determined by the radius of the spike and the thermal diffusivity of the medium

$$
\tau=r^{2} / 4 D
$$

In a typical calculation for a bubble chamber liquid (hydrogen or propane) sensitive to minimum ionization particles, $\tau$ is the order of $10^{-11}$ to $10^{-10} \mathrm{~s}$ for a spike of the critical radius defined by Eq. (1).

Such a time was much too short for it to be practical to heat or depressurize the liquid chamber after particles were detected by external counters (i.e., there seemed to be no way in which a bubble chamber could be triggered by thermal or mechanical means). However, Rice-Evans (1973) proposed applying a fast-rising, high-gradient electric field to an already superheated liquid. The principle was that although the thermal spike would have dissipated before the pulse was applied, electrons and ions along the particle track would remain separated for longer and could be accelerated by the field, causing very localized heating and bubble nucleation. As far as I know, no such chamber was built, unless the Bertanza et al. results were due to an effect of this kind. 



\section{NEGATIVE PRESSURES}

In 1956, Pless and Plano reported the successful construction and operation of a small, "clean" isopentane bubble chamber in which the liquid was actually placed under a negative pressure (i.e., tensile stress) in the expansion process.

The idea of a negative pressure is a little strange at first, but it is an entirely respectable, and quite common, phenomenon (e.g., Donny 1846; Berthelot 1850; Worthington 1892). For example, at the base of a tree, the sap is at approximately atmospheric pressure (a cut does not cause sap to spurt out or air to be sucked in). At the top of, say, a hundred-foot tree, the sap is at almost -2 atm because the pressure in a column of liquid water falls by 1 atm for every $34 \mathrm{ft}$ of vertical height.

I can almost feel the readers' skepticism, but in fact there is a simple, convincing demonstration (Scholander et al. 1965). From the ground, a marksman with a rifle shoots through a twig near the top of a tall tree. The severed twig falls to the ground and, upon examination, it is found that the sap has retracted from the cut some distance into the capillaries. The twig is now placed into a pressure chamber with the cut end protruding, through a cuff seal, into the air. The pressure in the chamber is increased, and sap is forced out of the twig. The gauge pressure in the chamber needed to bring the surface of the sap level with the cut end is the same as the negative pressure that was in the liquid-filled capillaries of the twig at the instant that it was severed.

Evidently the capillaries of a tree are "clean" in the same sense as Glaser's first bubble chamber [i.e., their surface does not nucleate bubbles of vapor or of dissolved air in the sap, except under extreme conditions of negative pressure due to rapid loss of water from the leaves (Milburn and Johnson 1966)]. Likewise, Pless and Plano (1956) found that isopentane "will not boil from clean glass surfaces, even under a negative pressure as great as 6 atm. However, it boils quite readily from brass. Ethylene glycol $\left(\mathrm{C}_{6} \mathrm{H}_{6} \mathrm{O}_{2}\right)$, on the other hand, does not boil from brass under these same conditions." They devised an apparatus in which isopentane was in contact only with glass, while only ethylene glycol, which is immiscible with isopentane, came in contact with the brass and rubber of the moving piston device that was used to depressurize the system. They were able to produce negative pressures in excess of $4 \mathrm{~atm}$, while the isopentane, at $120^{\circ} \mathrm{C}$, had a vapor pressure of about 11 atm so that $P_{\text {vap }}-P_{\text {ext }} \approx 15 \mathrm{~atm}$.

Incidentally, in their 1956 paper Pless and Plano also supported a thermal, rather than electric, charge basis for bubble nucleation.

B. Hahn (1961) measured the threshold (negative pressure) for nucleation of bubbles by $\alpha$-decay recoils, fast neutrons, and gamma rays in various liquids under negative pressures. He achieved the negative pressures using a modification of a very simple method first, I think, used by Reynolds (Worthington 1892) and improved by Briggs (1949) In Hahn's experiments, a glass capillary tube with bent-back ends was rapidly rotated about an axis through its center (Fig. 1). The pressure over the free surface of the liquid near the ends of the capillary tube is atmospheric, but there is a pressure gradient along the tube, this time a much steeper one than in our tree because the radial acceleration in a centrifuge at high rotational speeds is much greater than the acceleration due to earth's gravity. In some liquids, negative pressures of more than 100 atm can easily be produced near the center of the tube. Hahn found that recoils from the decay of $\alpha$-emitters dissolved in the liquid under test were very effective at nucleating bubbles, and even at room temperature the threshold in isopentane was only -3.3 bars.

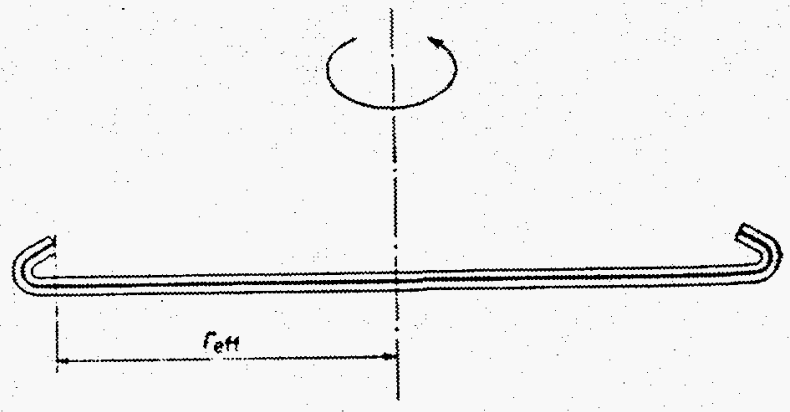

Fig. 1. Rotating pyrex glass capillary tube (Hahn 1961). 
Another way of producing negative pressures in a liquid is to subject it to high-intensity sound waves. It is not difficult to achieve sound pressure amplitudes of several atmospheres in some liquids, and such an amplitude imposed on a static pressure of, say, 1 atm will put the liquid under negative pressure during most of the negative-going half of the cycle.

In several experiments (Lieberman 1959; Hughes 1960; Sette and Wanderlingh 1962; Hahn and Peacock 1963), evidence was found of bubble formation, nucleated by energetic particles, in ultrasonically excited liquids. Sette and Wanderlingh's experiments showed that neutron irradiation could lower the cavitation threshold in water for several hours after the irradiation took place-this is in the strongest possible contrast to the no-memory behavior of bubble chambers. As far as I know, the nature of Sette's long-lived, radiation-induced nucleation centers has never been definitely identified, although the effect was verified in experiments by Finch (1964).

A dictionary definition of cavitation (below) is bubble formation under reduced pressures, which would not differentiate between, for example, the ultrasonic cavitation bubbles mentioned in the last paragraph and the boiling of liquid hydrogen in the Berkeley bubble chamber.

Webster's Third New International Dictionary
Cavitation ... 1a: the formation of partial vacuums in a
liquid esp. as a result of the passage
through it of a swiftly moving solid body
(as a propeller blade) or of high
frequency soundwaves
1b: the pitting and wearing away of solid
surfaces (as metal or concrete) as a result
of the collapse of those vacuums

I do not know that there is any formal demarcation between the phenomena of boiling and cavitation, but I believe that many workers in the field have a sense that "cavitation" refers to "cold" liquids, those at such a temperature that the vapor pressure is small compared with the absolute value of the external pressure. In this sense, Pless and Plano's negative pressure isopentane bubble chamber at $120^{\circ} \mathrm{C}\left(P_{\text {vap }} \approx\right.$ 11 bars, $\Delta P \approx 4$ bars) is in the boiling category, but Hahn's spinner measurements on the same liquid at $20^{\circ} \mathrm{C}\left(P_{\text {vap }} \approx 0.8\right.$ bars, $\Delta P \approx 3.3$ bars $)$ represent cavitation. In a later section, a boundary line between the two categories of radiation-induced bubble formation will be quantified and seen to have some physical significance.

It should be noted that in other kinds of experiments, cavitation bubbles may contain significant amounts of permanent gas, although in this report I am not addressing that situation. 


\section{EXPERIMENTAL MEASUREMENTS}

G. Riepe (then a graduate student) and B. Hahn carried out a wonderful series of experiments with a temperature-controlled bubble chamber specially designed to hold the pressure nearly constant for a long period (up to $100 \mathrm{~ms}$ ) following the expansion. Using two different liquids, Freon 12 at several different temperatures between $30^{\circ} \mathrm{C}$ and $80^{\circ} \mathrm{C}$ and propane at $18.5^{\circ} \mathrm{C}$, they measured the pressure drop necessary to nucleate bubbles by individual recoils from the $\alpha$-decay of ${ }^{210}$ Polonium, and of ${ }^{212}$ Bismuth and ${ }^{212}$ Polonium (also known as Thorium $\mathrm{C}$ and Thorium $\mathrm{C}^{\prime}$ ). The results in Appendix A are measured from the graphs published in their paper (Riepe and Hahn 1961). Riepe and Hahn also measured the threshold for bubble formation by dissolved ${ }^{37} \mathrm{Ar}$, which decays and releases an Auger electron with an energy of $2.3 \mathrm{keV}$.

The alpha-decay results are probably the easiest to analyze, because all of the recoil energy, but very little of the alpha's energy, is deposited in a small region, so that the energy available for bubble nucleation may be reasonably easily, but not necessarily accurately, estimated.

El-Nagdi and Harris (1971) carried out another clever experiment. To permit a higher superheat in the bulk of the hot liquid in a dirty bubble chamber, they cooled the walls of the chamber just before depressurizing it. With correct timing, a layer of colder liquid could be created around the walls while an interior core of hot liquid remained in the middle of the chamber. They measured the threshold (i.e., the superheat at which boiling began) in liquids irradiated by fast neutrons from an accelerator source.

Dietrich and Cornolly (1973), using a small, specially built, water bubble chamber measured the superheat needed for uranium fission fragments to nucleate bubbles.

Apfel (1979) developed a very different form of the bubble chamber, a most elegant and interesting idea, specifically for use as a neutron dosimeter. In Apfel's Superheated Drop Detector, very many uniform, small ( $\sim 100 \mu \mathrm{m}$ to $1 \mathrm{~mm}$ ) droplets of a liquid whose normal boiling point is below room temperature are suspended in a gel. At room temperature and pressure, each and every small drop is superheated and is a miniature, one-shot, clean bubble chamber. Apfel (1979) and Lo and Apfel (1988) reported on a series of experiments in which the superheated drops were irradiated with monochromatic - or nearly so-neutron beams of different energies, and the number of droplets that turned to vapor, per unit time and volume, was measured. In some cases, where only fast neutron knock-ons were believed capable of nucleating bubble formation, there was a fairly well defined threshold of neutron energy for droplet vaporization.

Besides Hahn's negative pressure results with the spinner, thresholds for prompt neutron-induced ultrasonic cavitation (i.e., cavitation not involving the unexplained delayed effect reported by Sette and Wanderlingh and by Finch) were reported by Greenspan and Tscheig (1967).

For the convenience of future researchers in the field, most of the results from the above measurements, converted to a common set of units and presented in a common format, are collected in Appendix A. 



\section{RIEPE AND HAHN'S BUBBLE CHAMBER MEASUREMENTS AND THEORY}

As described above, Riepe and Hahn measured the threshold for bubble formation by alpha-recoils and Auger electrons in a bubble chamber specially designed to have a long $(\sim 100 \mathrm{~ms})$ period of constant, reduced pressure following the rapid ( $4 \mathrm{~ms}$ ) expansion.

They compared the alpha-decay results with calculations based on Seitz' theory. A basis of their calculation is that a static bubble with internal pressure $P_{v r}$ will tend to grow if its radius is $r_{c r i t}$ or greater where

$$
r_{c r i t}=\frac{2 \sigma}{P_{v r}-P_{e x t}}
$$

This is similar to Eq. (1), except that they applied a correction to the vapor pressure inside the bubble to account for the curvature of the bubble surface. Now, it is known that the equilibrium vapor pressure over a tiny droplet is significantly higher than over a plane surface (see Wilson 1951), but Glaser (1958) believed that there was no corresponding effect in bubbles (i.e., no decrease in equilibrium vapor pressure within the concave liquid surface of a small bubble, although Peyrou (1967) argued for such a decrease). In any case, Riepe and Hahn incorporated such an effect into their bubble calculations, hence the appearance of $P_{v r}$ instead of $P_{v a p}$ in Eq. (3). Their formula for the ratio of the equilibrium vapor pressure over a plane surface, $P_{v a p}$, to that over the surface of radius $\mathrm{r}_{\text {crit }}, P_{v r}$, was

$$
\ln \left(P_{v a p} / P_{v r}\right)=\frac{M w t}{R T \rho_{\ell}} \cdot \frac{2 \sigma}{r_{c r i t}}
$$

$R$ is the gas constant; $\rho_{\ell}$ is the density of the liquid (mass/unit volume). $M w t, \sigma$, and $T$ are its molecular weight, surface tension, and temperature, respectively. The calculations in this report use molar, rather than mass, densities, and so the multiplier $M w t$ is not needed here.

The curvature of a small droplet also changes the enthalpy of evaporation, but the effect is very small in the circumstances considered here (see Appendix B) and has been ignored in these calculations.

The measurements were made by expanding the chamber so that the pressure in the liquid, which contained traces of dissolved alpha-emitter or ${ }^{37} \mathrm{Ar}$, fell from its equilibrium vapor pressure, $P_{\text {vap }}$, to some lower pressure, $P_{e x t}$. For small pressure reductions, with a dissolved alpha-emitter, few or no bubbles were seen, but once the $\Delta P=P_{v a p}-P_{e x t}$ exceeded a threshold value, many bubbles were observed in the photographs of the chamber. At any particular $\Delta P$ above the threshold, the number of bubbles in the pictures was linearly proportional to the length of time for which the depressurization lasted. Increasing the $\Delta P$ slightly beyond the threshold gave more bubbles per picture, but further increases of $\Delta P$ beyond about 1.1 times the threshold brought no additional bubbles: apparently a $\Delta P$ only $10 \%$ or so above the threshold was enough to give a bubble for every single alpha-decay taking place in the sensitive region during the depressurized period.

Following Seitz, Riepe and Hahn calculated five different terms in the energy of formation of a critical bubble [Eqs. (5a-5e)]: 


$$
\begin{aligned}
& W_{s l}=\text { surface energy } \quad=4 \pi r_{c r i t}^{2} \sigma \\
& \begin{aligned}
& W_{e}= \text { PV work done by the bubble during expansion }=\frac{4}{3} \pi r_{c r i t}^{3} P_{e x t} \\
& \text { to the critical size }
\end{aligned} \\
& W_{v}=\begin{array}{l}
\text { enthalpy of evaporation of the vapor filling the }=\frac{4}{3} \pi r_{c r i t}^{3} \rho_{v} H_{v} \\
\text { bubble }
\end{array} \\
& W_{4}=\text { kinetic energy given to the liquid moving } \quad=32 \pi D^{2} \rho_{\ell} r_{c r i t} \times\left(\mathrm{Mwt} / 10^{3}\right)^{a} \\
& \text { away as the bubble expands to the critical } \\
& \text { radius } \\
& W_{5}=\text { viscous losses in moving away the liquid as }=64 \pi \eta D r_{c r i t} \\
& \text { the bubble expands }
\end{aligned}
$$

${ }^{a}$ The term Mwt $/ 10^{3}$ is the mass, in $\mathrm{kg}$, of $1 \mathrm{~mol}$; it is needed to convert the density, $\rho_{o}$ from mols $/ \mathrm{m}^{3}$ to $\mathrm{kg} / \mathrm{m}^{3}$ so that the kinetic energy appears in units of joules. This factor was not needed in Riepe and Hahn's paper because they did not use molar enthalpies, densities, specific heats, etc.

For convenience later, I have partially rewritten the Riepe and Hahn equations to use some of Peyrou's (1967) notation. $D$ is the thermal diffusivity; $H$ is the enthalpy of evaporation; and $\eta$ is the viscosity of the liquid.

The dynamic terms, $W_{4}$ and $W_{5}$, were calculated on the assumption that the bubble expands at constant velocity to the critical radius in a time equal to the relaxation time $\tau$ for conductive dissipation of the heat from a spherical thermal spike of radius $r_{c r i t}$ deposited in the bulk liquid.

$$
\tau=r_{c r i t}^{2} / 4 D=r_{c r i t}^{2} c \rho_{\ell} / 4 \lambda
$$

where $D$ is the thermal diffusivity, $=\lambda / \rho_{\ell} c$, of a liquid of thermal conductivity $\lambda$, density $\rho_{\ell}$, and specific heat $c$.

The velocity $v_{c}$ of the bubble wall is taken as the critical radius divided by $\tau$,

$$
\mathrm{v}_{\mathrm{c}} \sim r_{c r i l} / \tau=4 D / r_{c r i l}
$$

In comparing the above energy terms with the available energy, Riepe and Hahn assumed that all the energy deposited in a length equal to the diameter of the critical bubble was available. The alpha-recoils generally had a calculated range, $R_{r}$, less than $2 r_{c r i t}$ and in that case the energy calculated to be lost by the alpha particle in a distance $2 r_{\text {crit }}-R_{r}$ at the beginning of its range was added to the recoil energy. Two sets of results published by Riepe and Hahn are shown in Table 1 . Appendices $C$ and D recalculate these results using more recent values for the liquid properties, with the addition of another energy term proposed by Bugg (1959); the recalculations independently confirm the Riepe and Hahn conclusions.

The ratio of critical radius to velocity, in accordance with Eq. (7), reveals that the thermal relaxation time for these large thermal spikes is $\sim 10^{-8} \mathrm{~s}$. 
Table 1. Reipe and Hahn: Energy balance with recoils from ${ }^{210}$ Po decay

\begin{tabular}{|c|c|c|}
\hline & $\begin{array}{c}\mathrm{CCl}_{2} \mathrm{~F}_{2} \\
\text { at } 29.4^{\circ} \mathrm{C}\end{array}$ & $\begin{array}{c}\mathrm{C}_{3} \mathrm{H}_{8} \\
\text { at } 18.5^{\circ} \mathrm{C}\end{array}$ \\
\hline Threshold $\Delta P^{a}$ & $2.00 \mathrm{~atm}$ & $1.97 \mathrm{~atm}$ \\
\hline Calculated critical radius $r_{c},{ }^{b} \AA$ & $860.8 \AA$ & $829.3 \AA$ \\
\hline Growth velocity $(\max )$ & $3.04 \times 10^{2} \mathrm{~cm} / \mathrm{s}$ & $6.1 \times 10^{2} \mathrm{~cm} / \mathrm{s}$ \\
\hline No. of molecules in critical bubble & $5.55 \times 10^{5}$ & $5.52 \times 10^{5}$ \\
\hline Surface energy, $W_{s I}$ & $4.9 \mathrm{keV}$ & $4.3 \mathrm{keV}$ \\
\hline PV work, $W_{e}$ & $8.7 \mathrm{keV}$ & $8.9 \mathrm{keV}$ \\
\hline Latent heat, $W_{v}$ & $94.7 \mathrm{keV}$ & $89.0 \mathrm{keV}$ \\
\hline Kinetic energy, $W_{4}$ & $0.3 \mathrm{keV}$ & $\sim 0.4 \mathrm{keV}$ \\
\hline Viscous work, $W_{5}$ & $1.8 \mathrm{keV}$ & $\sim 2.6 \mathrm{keV}$ \\
\hline Total energy needed & $110.4 \mathrm{keV}$ & $105.2 \mathrm{keV}$ \\
\hline Recoil range $R_{r}^{c}$ & $651 \AA$ & $1146 \AA$ \\
\hline Recoil energy & $101.0 \mathrm{keV}$ & $101.0 \mathrm{keV}$ \\
\hline Alpha-energy loss (in a distance $2 r_{c r i t}-R_{r}$ ) & $11.6 \mathrm{keV}$ & $2.8 \mathrm{keV}$ \\
\hline Total energy available & $112.6 \mathrm{keV}$ & $103.8 \mathrm{keV}$ \\
\hline
\end{tabular}

${ }^{a}$ Measured by CDW from the graphs in Fig. 6 and in Fig. 10, Riepe and Hahn (1961).

${ }^{b}$ This is the critical radius calculated by correcting the vapor pressure in the bubbles for the curvature effect.

${ }^{c}$ From Table 1 of Riepe and Hahn; based on a formula privately communicated to them by Lindhard and Schiff.

The very close quantitative agreement between the calculations of energy needed and energy available for bubble nucleation by the heavy, slow $\alpha$-recoils is impressive and confirms Seitz' basic theory. In practice, bubble chambers were more usually employed to detect minimum ionization particles, and in those circumstances there are a number of discrepancies between the theory and the observation: for a good discussion of those discrepancies, and some possible reasons, see Section IV in Peyrou (1967). 
. 


\section{HAHN'S SPINNER RESULTS-A MAJOR PUZZLE}

\subsection{THE RESULTS}

As we have seen, the thermal spike theory, as formulated by Seitz, gave a quantitatively accurate explanation of the nucleation of boiling by $\alpha$-decay recoils in propane and Freon 12 . But a surprising thing emerged when Hahn (1961) measured the negative pressure needed to form macroscopic bubbles in some other liquids at temperatures below their normal boiling points from these same particles and from fast neutrons. His 1961 paper simply reported the results from spinner experiments, but a later one (Hahn and Peacock, 1963) noted that in the negative pressure experiments, by both the spinner and ultrasonic methods, the calculated energy needed to form viable nucleation centers, typically $\sim 17 \mathrm{keV}$ for the static terms, was very much lower than the energy, $\sim 100 \mathrm{keV}$, thought to be available within the critical diameter from the recoiling nuclei. With some understatement they wrote, "In contrast to the behavior at positive pressures, as in normal bubble chamber operation, where energy equilibrium was found with the above terms, at negative pressures additional terms seem to play an important role."

Table 2 lists the negative pressure thresholds measured by Hahn and Peacock for bubble formation by $\alpha$-decay (mostly ${ }^{210} \mathrm{Po}$ decay) and some properties of the liquids. These negative pressures correspond to the value $P_{e x t}$ in Eqs. (3) and (5). Using the TK Solver models described in Appendix C, the parameters of critical bubbles under these conditions were calculated and are also listed in Table 2. Table 3 lists the liquid and vapor properties, from the Yaws (1996) data, needed to calculate the Seitz theory energy terms; Appendix E also lists those properties and the ones used, later in this report, for calculations based on a different model.

Table 2. Results from Hahn's spinner experiments (with ${ }^{210}$ Po $\alpha$-decay except as indicated) ${ }^{a}$

\begin{tabular}{|c|c|c|c|c|c|}
\hline Material & Composition & Temp., ${ }^{\circ} \mathrm{C}$ & $\begin{array}{l}\text { Recoil energy } \\
\quad(\mathrm{keV})\end{array}$ & $\begin{array}{l}\text { Measured } P_{\text {neg }} \\
\text { (bars) }\end{array}$ & $\begin{array}{l}\text { Vapor pressure } \\
{[\mathrm{kPa} \text { (Yaws)] }}\end{array}$ \\
\hline Isopentane & $\mathrm{C}_{5} \mathrm{H}_{12}$ & 20 & 101 & 3.344 & 76.7 \\
\hline Freon $113^{b}$ & $\mathrm{C}_{2} \mathrm{C}_{13} \mathrm{~F}_{3}$ & $"$ & 166 & 4.490 & 36.1 \\
\hline Freon 113 & $\mathrm{C}_{2} \mathrm{C}_{\mathrm{C} 3} \mathrm{~F}_{3}$ & $"$ & 101 & 5.207 & 36.1 \\
\hline n-hexane & $\mathrm{C}_{6} \mathrm{H}_{14}$ & ." & $"$ & 6.890 & 16.3 \\
\hline Acetone & $\mathrm{C}_{3} \mathrm{H}_{6} \mathrm{O}$ & $"$ & $"$ & 8.309 & 24.6 \\
\hline Trichloroethylene & $\mathrm{C}_{2} \mathrm{HC}_{13}$ & $"$ & $"$ & 11.754 & 7.75 \\
\hline Ethylene bromide & $\mathrm{C}_{2} \mathrm{H}_{4} \mathrm{Br}_{2}$ & $"$ & $"$ & 22.190 & 1.36 \\
\hline Acetophenone & $\mathrm{C}_{8} \mathrm{H}_{8} \mathrm{O}$ & $20.5^{c}$ & $"$ & 33.235 & 0.037 \\
\hline Cyclohexanol & $\mathrm{C}_{6} \mathrm{H}_{12} \mathrm{O}$ & $23.45^{d}$ & $"$ & 48.740 & 0.088 \\
\hline
\end{tabular}

${ }^{a}$ Results taken from Table A.2.

${ }^{b}$ Result with Th $\left(\mathrm{C}+\mathrm{C}^{\prime}\right) \alpha$; measured from Fig. 2, Hahn 1961.

${ }^{c} \mathrm{Hahn}$ 's paper indicates that all these spinner experiments were carried out at $20^{\circ} \mathrm{C}$, but the normal freezing point of acetophenone is $20.5^{\circ} \mathrm{C}$.

${ }^{d} \mathrm{Hahn}$ 's paper indicates that all these spinner experiments were carried out at $20^{\circ} \mathrm{C}$, but the normal freezing point of cyclohexanol is $23.45^{\circ} \mathrm{C}$. 


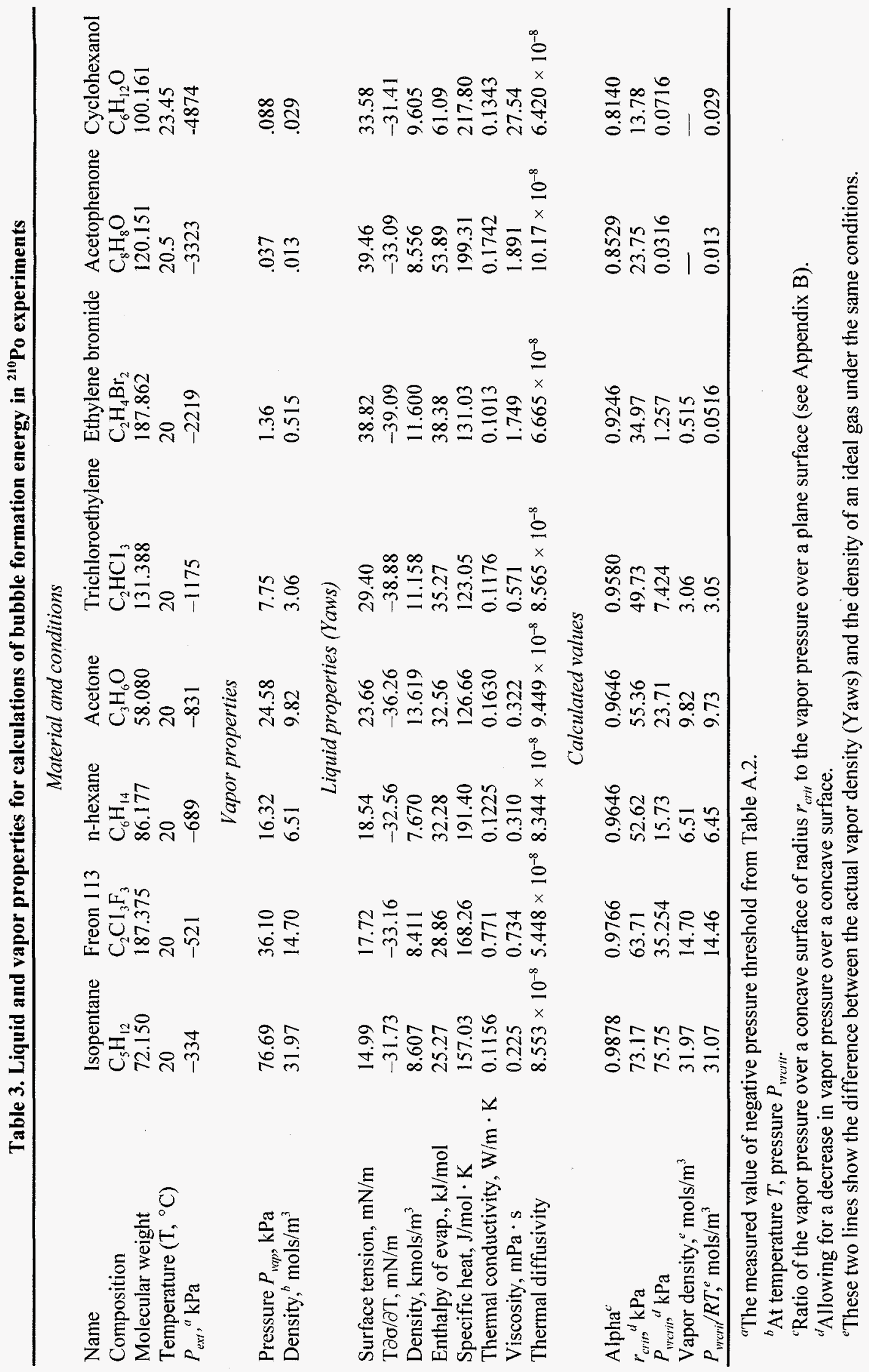




\subsection{ENERGY BALANCE}

Table 4 lists the energy terms for the negative pressure results in the same manner as the bubble chamber results in Table 1 but with Bugg's additional surface energy term (see Appendix D) also included. One sees that indeed the sums of all the energy terms are much less than the energy $(\sim 100 \mathrm{keV})$ of the $\alpha$-recoil, even if the Bugg term is included. The relative contributions of the terms are also very different. For example, the enthalpy of vaporization is generally a minor, rather than a major, term. That is because in cavitating liquids the vapor pressure is, by my definition of cavitation, relatively small, and therefore, the mass of vapor in the critical bubble is small.

In some cases, the critical radius is much smaller than in the bubble chamber, because of the larger pressure difference between the interior of the bubble and the liquid outside it, so that we may imagine that for those liquids the entire recoil energy might not be available in a distance $2 r_{\text {crit. }}$. However, for isopentane and Freon 113, the critical radii are quite comparable with those in the Riepe and Hahn bubble chamber experiments, so that such an effect cannot be the whole explanation for the discrepancy between the calculated energy needed to form the nucleation center and the recoil energy.

Why does a theory that worked so splendidly for the bubble chamber alpha recoil experiments fail so badly when applied to the same particles in similar liquids at lower temperatures?

Table 4. Energy terms (in keV) for Hahn's spinner liquids nucleated by ${ }^{210}$ Po recoils

\begin{tabular}{|c|c|c|c|c|c|c|c|c|}
\hline Term & Isopentane & Freon 113 & n-hexane & Acetone & Trichloroethylene & $\begin{array}{l}\text { Ethylene } \\
\text { bromide }\end{array}$ & Acetophenone & Cyclohexanol \\
\hline$W_{s 1}$ & 6.3 & 5.6 & 4.0 & 5.7 & 5.7 & 3.7 & 1.7 & 0.5 \\
\hline$W_{c}$ & 3.4 & 3.5 & 2.6 & 3.7 & 3.8 & 2.5 & 1.2 & 0.3 \\
\hline $\mathrm{W}_{\mathrm{v}}^{\mathrm{c}}$ & 8.3 & 2.9 & 0.8 & 1.4 & 0.3 & $\sim 0.0$ & $\simeq 0.0$ & $\simeq 0.0$ \\
\hline Subtotal ${ }^{\circ}$ & $\overline{18.0}$ & $\overline{12,0}$ & 7.4 & $\overline{10.8}$ & 9.8 & $\overline{6.2}$ & $\overline{2.9}$ & $\overline{0.8}$ \\
\hline $\mathrm{W}_{\mathrm{s} 2}$ & 13.3 & $\underline{10.6}$ & 7.1 & 8.7 & 7.5 & 3.7 & 1.5 & 0.5 \\
\hline $\begin{array}{l}\text { Subtotal } \\
\text { static terms }\end{array}$ & $\overline{31.3}$ & $\overline{22.6}$ & $\overline{14.5}$ & $\overline{19.5}$ & $\overline{17.3}$ & $\overline{9.9}$ & $\overline{4.4}$ & $\overline{1.3}$ \\
\hline$W_{4}$ & 0.2 & 0.2 & 0.2 & 0.4 & 0.3 & 0.2 & 0.2 & $\sim 0$ \\
\hline$W_{5}^{4}$ & 1.8 & 3.2 & 1.7 & $3: 1$ & 3.1 & 5.1 & 5.8 & $\underline{30.6}$ \\
\hline Total ${ }^{c}$ & $\overline{33.3}$ & 26.0 & 16.4 & 23.0 & 20.7 & 15.2 & $\overline{10.4}$ & 31.9 \\
\hline
\end{tabular}

${ }^{a}$ Riepe and Hahn found that these static terms alone provided a good energy balance for their bubble chamber experiments.

${ }^{b}$ Static terms including Bugg's additional surface energy term.

${ }^{c}$ Static and dynamic terms. 



\section{CAVITATION BUBBLE NUCLEATION}

\subsection{CALCULATION OF MINIMUM mT}

A possible explanation for the difference between boiling and cavitation nucleation events was proposed a few years later (West 1967). It is based on the fact that the Seitz condition $\left(P_{v r}-P_{e x t}>\right.$ $\left.2 \sigma / r_{c r i i}\right)$ is necessary for growth to proceed from $r_{c r i}$, but may not be sufficient to ensure growth up to that radius. Instead of the Seitz condition at the critical radius, the new model required that

$$
P_{i n t}(r)-P_{e x t} \geq 2 \sigma / r
$$

at all stages of growth from the initial ". . highly localized hot regions ..." described by Seitz. $P_{i n t}(r)$ is the pressure in the bubble when its radius is $r$. For the negative pressure case, $P_{e x t}=-P_{n e g}$.

For simplicity, the vapor inside the bubble was treated as an ideal gas, although the last two lines of Table 3 show that it really is not. Then, during the growth

$$
\frac{m(r) T(r) R}{V(r)}+P_{n e g} \geq \frac{2 \sigma}{r}
$$

or

$$
\frac{m(r) T(r) R}{(4 / 3) \pi r^{3}}+P_{n e g}>\frac{2 \sigma}{r}
$$

where $m(r)$ is the mass of gas inside the bubble, and $T(r)$ is its temperature, when the radius is $r$. Note that according to Eq. (9), there is one radius, $r^{*}=2 \sigma / P_{n e g}$, beyond which the bubble would continue to grow even if there were no gas inside it at all.

As a gross oversimplification, suppose first that $m(r) T(r)$ remains constant during the growth. Then at a very small positive $r$, the first term will dominate in Eq. (9), thus satisfying the inequality. At a very large positive $r$, the first and third terms tend to zero, the second term dominates, and again the inequality is satisfied. Figure 2 illustrates this by plotting the left hand side (LHS) and right hand side (RHS) of Eq. (8). Two cases are shown: one in which $P_{n e g}\left(=-P_{e x t}\right)$ is large enough that the inequality is maintained for all $r$ and one in which $P_{n e g}$ is such that, although the inequality is fulfilled at large and small $r$, there is an intermediate region in which it is not and through which the bubble could therefore not grow.

If $m T$ is a constant, the condition that the curves never cross is that the simple cubic equation in $1 / r$,

$$
\frac{3 m T R}{4 \pi} \cdot\left(\frac{1}{r}\right)^{3}-2 \sigma\left(\frac{1}{r}\right)+P_{n e g}=0
$$



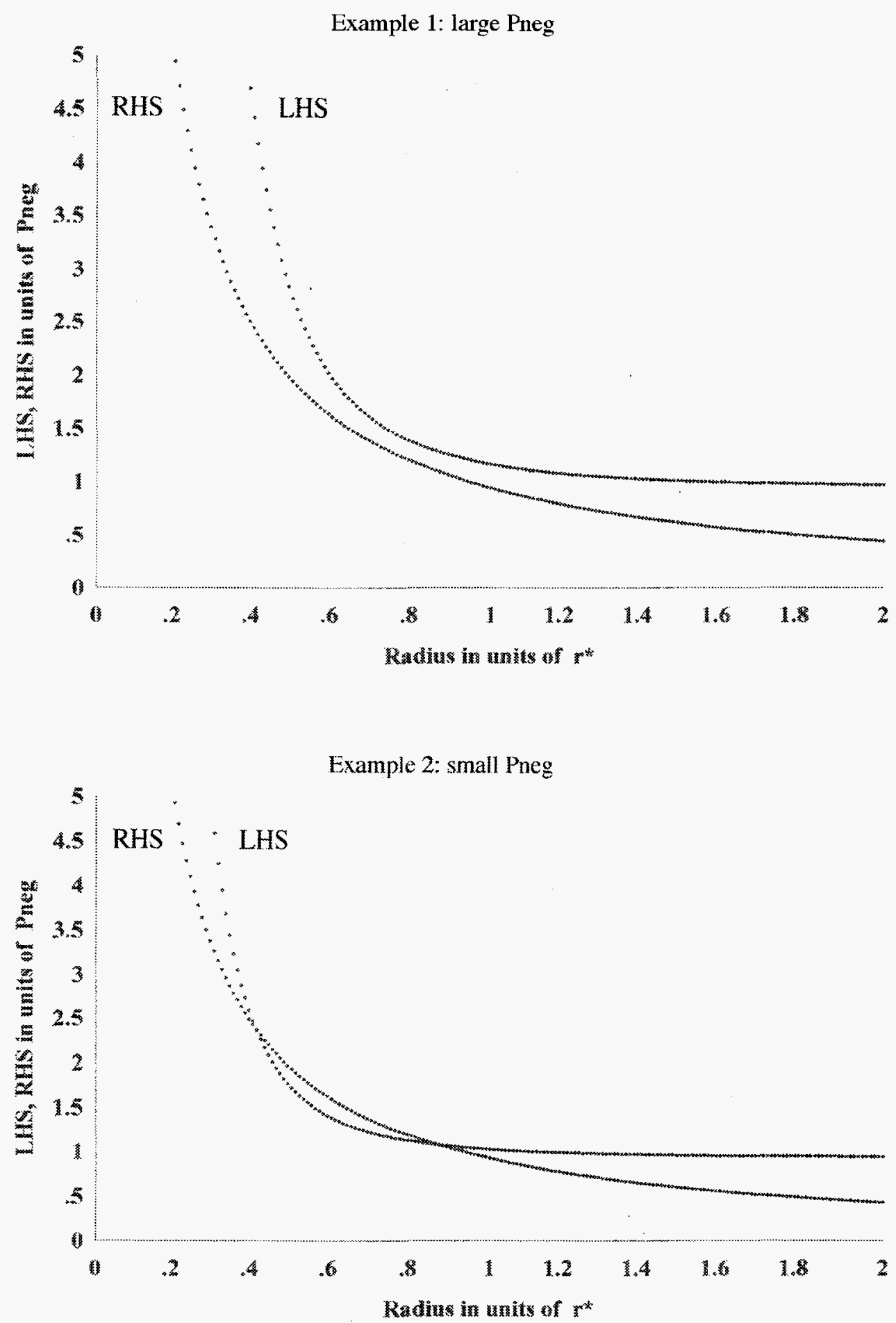

Fig. 2. The expansive (LHS) and compressive (RHS) pressures on bubbles filled with a constant (mass $\times$ temperature) of vapor. 


$$
\left(\frac{1}{r}\right)^{3}-\frac{8 \pi \sigma}{3 m T R}\left(\frac{1}{r}\right)+\frac{4 \pi P_{n e g}}{3 m T R}=0,
$$

does not have the two real, positive roots represented by the two crossing points of the curves in Fig. 2, Example 2. The equation is a reduced cubic (i.e., it is of the form $y^{3}+p y+q=0$ ). The condition that the two real roots are equal, so that the curves touch but do not cross, can be found in older algebra text books; it is that $(p / 3)^{3}+(q / 2)^{2}=0$. If $(p / 3)^{3}+(q / 2)^{2}>0$, the curves in Fig. 2 do not even touch, and the internal pressure always exceeds the sum of the external pressure and the surface tension effect, $2 \sigma / r$. Substituting the coefficients $p$ and $q$ from Eq. (10) provides the condition that the compressive pressures on the bubble never exceed the expansive ones,

$$
m T \geq \frac{128 \pi \sigma^{3}}{81 R P_{n e g}^{2}}
$$

The threshold (i.e., the minimum negative pressure to cause cavitation) would be given by choosing the equality sign, when

$$
P_{n e g}=\sqrt{\frac{128 \pi \sigma^{3}}{81 m T R}}
$$

In Eq. (11), if the equality sign (i.e., the limiting case or threshold) is chosen, then there is one positive radius, and one only, at which the expansive and compressive pressures in Eq. (8) are equal, while at all other real, positive radii, larger or smaller, the expansive pressure is the greater. Cardan's solution to a cubic equation (see Korn and Korn 1968) shows that the radius, $r_{e q}$, at which the two are equal is given by

$$
r_{e q}=\sqrt[3]{\frac{2}{q}}=\frac{4 \sigma}{3 P_{n e g}} .
$$

The pressure, $P_{i n}$, of the ideal gas inside the bubble at that time is equal to $m T R$ divided by its volume,

$$
P_{i n t}=\frac{m T R}{(4 / 3) \pi r_{e q}^{3}}
$$


Substituting for $m T$ from Eq. (11) and for $r_{e q}$ from Eq. (13) yields an expression for the pressure inside the bubble at the equilibrium radius,

$$
P_{\text {int }}\left(r_{e q}\right)=P_{n e g} / 2
$$

a delightfully simple result.

It is interesting, and reassuring, that subsequent—but completely independent-research into the effects of helium generated by transmutation in irradiated solids led to equations that are formally identical to the original $m T$ model of bubbles in liquids. For example, compare Eqs. (13) and (12) above with Eqs. (3) and (10), and Eq. (11), in Mansur et al. (1986).

\subsection{BOILING AND CAVITATION}

Now one can see a possible difference between boiling and cavitation bubbles. If the vapor pressure is low (cavitation case), Eq. (11) must be fulfilled to ensure growth from Seitz' initial small bubble, through the most difficult size (radius around $r_{e q}$ ). But, if the vapor pressure is high (boiling case) and evaporation from the bubble surface prevents the internal pressure from falling below $P_{\text {vap }}$, the LHS of Eq. (9) would look like the curve in the second example of Fig. 2 only until the pressure fell to $P_{\text {vap}}$, when the LHS curve would flatten out, remaining above the RHS curve and thus ensuring continued growth, as shown in Fig. 3, which is the same as Fig. 2, second example, except that the vapor pressure, which was much less than $P_{n e g} / 2$ in Fig. 2 , is now set to $P_{\text {vap }}=3 \times P_{n e g}$. Physically, what has been done in Fig. 3 is to maintain $m(r) T(r)$ constant only until $P(r)$ falls to $P_{\text {vap }}$, at which time evaporation from the bubble surface adds more vapor, increasing $m$ enough to keep the pressure constant. The effect is to hold the internal pressure higher than $P_{n e g} / 2$, the minimum equilibrium pressure at the most difficult stage of growth around $r_{e q}$.

Obviously, this is a grossly oversimplified model, but it demonstrates why there might be a qualitative difference in the nucleation energetics of boiling and cavitation. From this model, one would expect that in any negative-pressure experiment showing a negative-pressure threshold for bubble

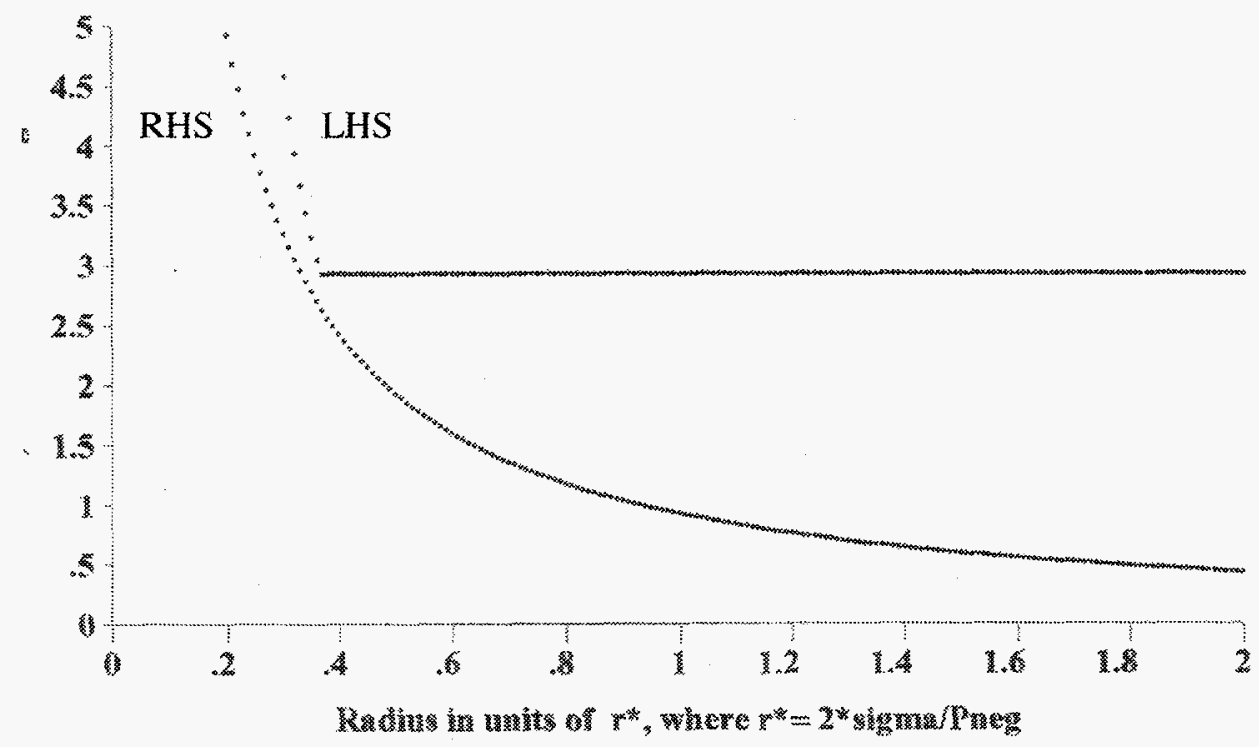

Fig. 3. Expansive and compressive pressures when Pvap is three times Pneg (small Pneg, large Pvap). 
nucleation of less than twice the vapor pressure, and in all positive pressure experiments, the Seitz and the Riepe and Hahn approaches based on vapor pressure would be applicable. The model described in this section would be needed to explain the experiments showing a negative-pressure threshold of more than twice the vapor pressure, which, as seen in Table 2, include all of Hahn's reported spinner results.

\subsection{INITIATION OF BUBBLE FORMATION IN COLD LIQUIDS}

Measurements of the superheat limit (i.e., the maximum temperature to which a liquid can be taken before vapor bubbles are spontaneously nucleated) are usually made by allowing a droplet of the test liquid to rise slowly through a bath of another, immiscible liquid with higher density and a higher boiling point, such as glycerin or sulfuric acid (see Apfel 1972 or Carey 1992).

A temperature gradient is maintained in the bath so that the temperature at the bottom is lower than, and at the top is much higher than, the boiling point of the liquid under test.

The droplets are small enough, typically $\sim 1 \mathrm{~mm}$ diam, and purified enough that the probability of an inhomogeneous nucleation center, such as a speck of dust, being found in any particular droplet is low. They are also small enough, and rise slowly enough, to be in equilibrium with the temperature of the liquid immediately surrounding them. Observing the position at which the rising droplets explode into vapor, and knowing the bath temperature as a function of depth, one can find the superheat at which homogeneous nucleation occurred. By superimposing an acoustic standing wave on the static pressure in the bath, the method can be extended to negative pressures (Apfel 1971).

Experiments of this kind reveal that a typical positive pressure superheat limit for organic liquids is in the range of $0.85 T_{\text {crii }}-0.9 T_{\text {criti }}$, where $T_{\text {cri }}$ is the critical temperature of the substance (Carey 1992). This is the case over a wide range of pressures, up to $10 \%$ or more of the critical pressure.

For high sensitivity, bubble chambers are normally operated $1 / 2$ to $2 / 3$ of the way between the boiling point and the critical point: at a higher temperature-called the foam limit in bubble chamber jargon - spontaneous or homogeneous nucleation fills the chamber with bubbles upon depressurization, whether any radiation traverses it or not.

Under bubble chamber conditions, the enthalpy of evaporation is more than the enthalpy required to raise the temperature of the liquid in Seitz' thermal spike from the operating temperature to $0.9 T_{\text {crit }}$, so that if enough energy is deposited to form the vapor in a bubble of critical size, we may think that the liquid in the spike is raised above the superheat limit and will indeed boil. This is shown in Table 5.

However, homogeneous nucleation is a statistical process, originating in the density fluctuations that arise and disappear over a scale a few molecules across. The typical droplet, which might contain $10^{19}-10^{20}$ molecules and whose temperature is slowly varying (increasing) at a rate $\sim 1 \mathrm{deg} / \mathrm{s}$, will have a high probability of spontaneous nucleation before the superheat threshold is exceeded by more than a fraction of a degree. The Seitz thermal spike on the other hand contains only $10^{5}-10^{6}$ molecules (see Table 1), and in order to have a high probability of spontaneous boiling within the $10^{-8} \mathrm{~s}$ or so before the heat is dissipated into the surrounding liquid, the initial temperature must be not just within $10 \%$ of the critical temperature, as is the case for the slowly heated macroscopic drops, but much closer. Therefore, I now assume that, in practice, the thermal spike must both be of greater than a critical size, calculated below, and heated to the critical point.

In the case of "cold" (i.e., cavitating) liquids, the enthalpy needed to raise the liquid temperature from the operating point to the critical point is actually greater than the enthalpy of evaporation (see Table 6). The amount of energy needed to promote a high probability of nucleation within the volume of the thermal spike is therefore sufficient to evaporate that entire volume of liquid. 
Table 5. Operating temperatures, superheat limits, and enthalpies in Riepe and Hahn bubble chamber experiments

\begin{tabular}{|c|c|c|c|c|c|}
\hline \multirow{2}{*}{ Material } & \multirow{2}{*}{ Composition } & \multirow{2}{*}{$\begin{array}{c}\text { Operating temp., } \\
T_{o p}, \mathrm{~K}\end{array}$} & \multirow{2}{*}{$\begin{array}{l}\text { Superheat limit } \\
\quad 0.9 T_{\text {crii }}, \mathrm{K}\end{array}$} & \multicolumn{2}{|c|}{ Enthalpies, $\mathrm{kJ} / \mathrm{mol}$} \\
\hline & & & & $H_{v a p}$ & $\mathrm{H}\left(0.9 T_{c r i t}\right)-\mathrm{H}\left(T_{o p}\right)$ \\
\hline Freon 12 & $\mathrm{CCl}_{2} \mathrm{~F}_{2}$ & 303 & 347 & 16.5 & 5.7 \\
\hline Propane & $\mathrm{C}_{3} \mathrm{H}_{8}$ & 292 & 333 & 15.2 & 5.1 \\
\hline
\end{tabular}

Table 6. Operating temperatures, critical temperatures, and enthalpies in Hahn's negative pressure spinner experiments

\begin{tabular}{lccccc}
\hline \multirow{2}{*}{ Material } & Composition & $\begin{array}{c}\text { Operating temp., } \\
T_{\text {op }} \mathrm{K}\end{array}$ & \multicolumn{2}{c}{ Critical temp., } & \multicolumn{2}{c}{ Enthalpies, $\mathrm{kJ} / \mathrm{mol}$} \\
\cline { 5 - 6 } & & 293 & 487 & 28.9 & 45.0 \\
Freon 113 & $\mathrm{C}_{2} \mathrm{Cl}_{3} \mathrm{~F}_{3}$ & 294 & 701 & 53.9 & 112.6 \\
\hline
\end{tabular}




\section{EXTENSIONS OF mT THEORY}

\subsection{HEATED MASS}

The above observation suggests a way to estimate the initial value of $m T$ in Eq. (9) or Eq. (11). If $E_{a v}$, the energy available for bubble nucleation, is known, one can calculate the number of moles of liquid, $M_{o}$, initially at $T_{a m b}$, that could be raised to the critical point, or very close to it. Within that heated fluid, homogeneous nucleation would take place, resulting in its entire mass turning into a bubble of heated vapor,

$$
M_{o}=E_{a v} / H_{c a},
$$

where $H_{c a}$ is the difference in enthalpy per mole between the liquid at $T_{a m b}$ and at $T_{c r i t}$. The value of $H$ is not very dependent on pressure, and I simply used the difference between the values at $T_{a m b}, 1 \mathrm{~atm}$, and $T_{\text {crit }} P_{\text {crii }}$ in making this calculation (a more exact course would be to take the enthalpy difference between $P_{n e g}, T_{a m b}$, and the critical point, but enthalpy data for negative pressure conditions were not available).

Some sophisticated simulations of interface and bubble formation in small volumes of liquid heated to the critical point by radiation are reported by Sun, Chu, and Apfel (1992 a and b). Their simulations include many more factors than Eq. (16), and are much more rigorous, realistic, and complete models, capable of providing insights and predictions concerning many aspects of the early stages of bubble formation and the fate of the energy deposited by the incoming particle. In this report, I have chosen to simplify, or oversimplify, the physical model so that general algebraic solutions can be found.

For the present, assume that all of the recoil energy is available, but neglect any contribution from the alpha particle (i.e., write $E_{a v}=E_{\text {recoii }}$ ). Also, consider only static energy terms (but remember that Table 4 shows that the dynamic terms would be very important for cyclohexanol).

With these assumptions, it is easy to calculate the threshold negative pressure for alpha-recoilinduced cavitation by the $m T$ method and by using the Riepe and Hahn approach.

However, a modification of the model used by West (1967) is introduced here to reflect the fact that close to the critical point, as the initial mass of heated fluid is in this new version of the $m T$ model, the ratio of mass to volume (i.e., the density) can be very different from the ideal gas value of P/RT. Accordingly in Eq. (9), (10), and therefore (12), the value of $R T$ is replaced by $P_{\text {crit }} / \rho_{\text {crit }}$ Equation (12) for the threshold pressure becomes

$$
P_{n e g}=\sqrt{\frac{128 \pi \sigma^{3} H_{c i}}{81 E_{\text {recoil }} P_{c r i i} / \rho_{c r i t}}} .
$$

Since, from Eq. (16) $E_{\text {recoil }} / H_{c a}=M_{o}$, the mass of fluid heated to the critical point, Eq. (17a) can be rewritten as

$$
P_{n e g}=\sqrt{128 \pi \sigma^{3} / 81 P_{c r i t} V_{o}} \text {, }
$$


where $V_{o}=M_{o} / \rho_{\text {crit }}$ is the volume of the mass $M_{o}$ at the critical pressure and temperature. It is reassuring to note that if the fluid were to behave as an ideal gas, even at the critical point, Eqs. (17b) and (12) would be identical.

It is easy to show that the two equal real roots of the equation, where the surface tension forces are in equilibrium with the internal pressure and the external, negative pressure, are given by

$$
r=r_{e q}=\frac{4 \sigma}{3 P_{n e g}},
$$

just as in Eq. (13).

In order to calculate the threshold from the Seitz/Riepe model, one needs to know the vapor pressure. Because the vapor pressure is relatively low in the case of cavitation, according to my definition, in these particular calculations I have neglected its small dependence on bubble radius.

The results from the $m T$ and Seitz/Riepe models are compared in Table 7.

Inspection of Table 7 shows that Eq. (17), based on the simple $m T$ model, follows the trend of the experimental results reasonably well, although the predicted thresholds are consistently low by a factor of about 1.5 to 2.8 (excluding the very high viscosity cyclohexanol, since only static terms were included in the calculations). The vapor pressure model is much less consistent, with the predicted thresholds low by a factor of 3-15 and not even in the same rank order as the measured values. This observation is quantified by making a least squares fit of the measured values and the two sets of calculated data (excluding the cyclohexanol results). See Figs. 4 and 5. The $\mathrm{R}^{2}$ correlation coefficients are vastly

Table 7. Calculated and measured thresholds

\begin{tabular}{|c|c|c|c|c|c|}
\hline \multirow{2}{*}{ Material } & \multirow{2}{*}{$\begin{array}{c}H_{c a} \\
\mathrm{~kJ} / \mathrm{mol}\end{array}$} & \multirow{2}{*}{$\begin{array}{c}\text { Recoil energy, } \\
\text { keV }\end{array}$} & \multicolumn{2}{|c|}{$\begin{array}{l}\text { Calculated threshold (bars) for } \\
\text { different models }\end{array}$} & \multirow{2}{*}{$\begin{array}{c}\text { Measured } \\
\text { threshold } \\
\text { (bars) }\end{array}$} \\
\hline & & & Seitz/Reipe ${ }^{a}$ & Eq. (17) & \\
\hline Isopentane & 39.78 & 101 & 1.13 & 1.99 & 3.34 \\
\hline Freon 113 & 44.97 & 166 & 1.20 & 2.05 & 4.49 \\
\hline Freon 113 & 44.97 & 101 & 1.49 & 2.63 & 5.21 \\
\hline n-hexane & 59.25 & 101 & 1.43 & 3.22 & 6.89 \\
\hline Acetone & 39.87 & 101 & 2.26 & 4.06 & 8.31 \\
\hline Trichloroethylene & 47.07 & 101 & 2.22 & 5.40 & 11.75 \\
\hline Ethylene bromide & 63.88 & 101 & 2.64 & 8.94 & 22.19 \\
\hline Acetophenone & 112.61 & 101 & 2.53 & 12.13 & 22.23 \\
\hline Cyclohexanol $^{b}$ & 99.95 & 101 & 2.00 & 9.81 & 48.74 \\
\hline
\end{tabular}

${ }^{a}$ Using only the three static energy terms $\left(W_{s l}, W_{e}, W_{v}\right)$ of the Riepe and Hahn bubble chamber calculations.

${ }^{b}$ This liquid has a very high viscosity compared with the others. 


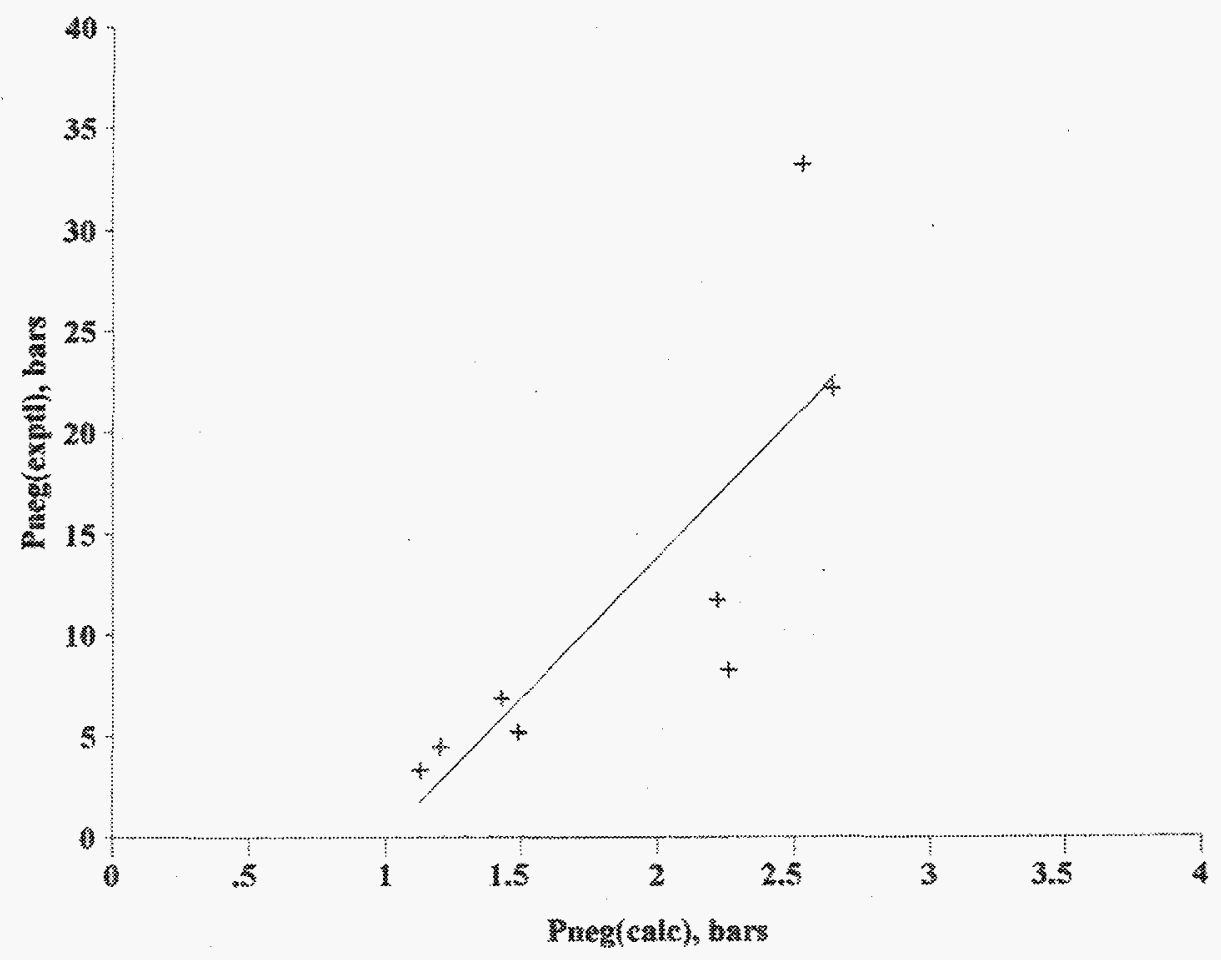

Fig. 4. $P_{\text {neg }}\left(\operatorname{exptl)}\right.$ vs $P_{\text {neg }}$ (calc, vapor model). Static terms only. Cyclohexonal excluded. $R^{\wedge} 2=0.658$.

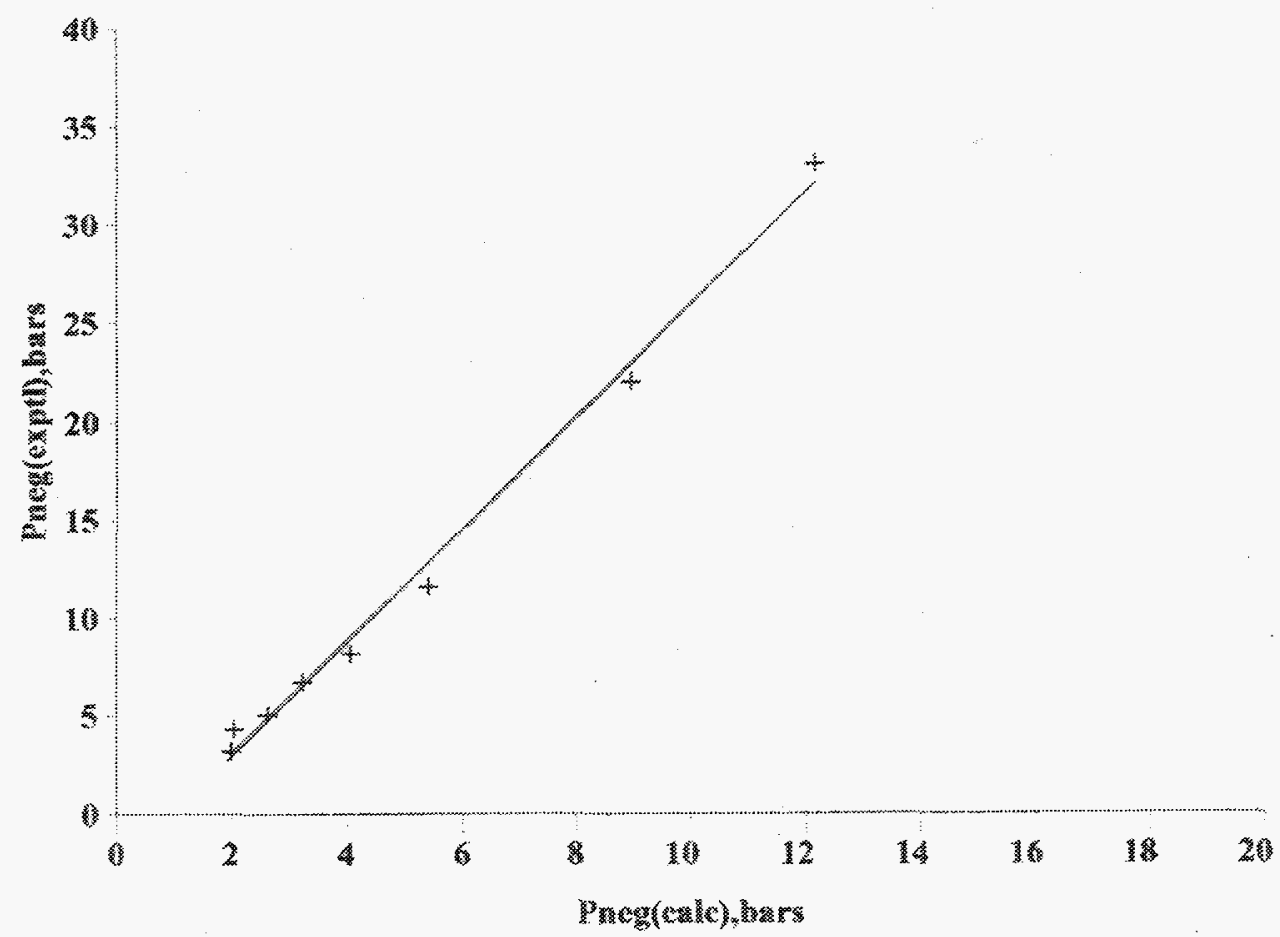

Fig. 5. $P_{\text {neg }}$ (exptl) vs $P_{\text {neg }}$ [calc, mT model, Eq. (17)]. Static terms only. Cyclohexonal excluded. $R^{\wedge} 2=0.993$. 
different at 0.993 for the $m T$ calculations, but only 0.658 for the vapor pressure-based results. This seems to indicate that the Seitz thermal nucleation model can be applied in all cases, but the algebraic form of it that explains Riepe's positive pressure bubble chamber measurements is indeed not applicable to the different physical circumstances of Hahn's cavitation experiments.

\subsection{VARIABLE mT}

In fact, the simplifying assumption in R-5486 (West 1967) that $m T$ remains constant during the initial expansion of the nucleation center is inconsistent with the physical model being used. For the ideal gas considered in the basic $m T$ model, a constant value of $m T$ implies a constant internal energy. But, the growth is pictured as an adiabatic process, which means that the difference between the additional surface energy and the PV work done by the external, negative pressure during growth must be drawn from the internal energy of the gas within the bubble, thereby reducing $m T$ as the expansion proceeds. Fortunately, especially when only these static terms are being considered, the mathematical expression of the $m T$ model can be readily modified to accommodate an approximate representation of this effect.

In general, internal energy is equal to enthalpy minus PV, so the initial internal energy, $U_{o}$, of the nucleation center is given by

$$
U_{o}=E_{\text {recoil }}-P_{\text {crit }} V_{o}
$$

At a stage during the expansion when the bubble radius is $r$ and its volume $V(r)=(4 / 3) \pi r^{3}$, the internal energy will have fallen by an amount equal to the work done on the growing bubble. So

$$
\begin{aligned}
& U(r)=U_{o}-\left(W_{s 1}+W_{s 2}\right)-W_{e} \\
& =U_{o}-4 \pi r^{2} \sigma_{e f f}+P_{n e g} V(r),
\end{aligned}
$$

where only static terms are included and $\sigma_{e f f}=\sigma-T \partial \sigma / \partial T$ to include the additional surface energy term proposed by Bugg. If the Bugg term is not applicable, one would simply write $\sigma_{e f f}=\sigma$.

For an ideal gas, pressure is proportional to the internal energy per unit volume, so

$$
P_{i n t}(r)=P_{c r i t} \cdot \frac{U(r) / V(r)}{U_{o} / V_{o}}
$$

Now substitute for $U(r)$ from Eq. (20),

$$
P_{i n t}(r)=\frac{P_{c r i t} V_{o}}{U_{o} V(r)} \cdot\left[U_{o}-4 \pi r^{2} \sigma_{e f f}+P_{n e g} V(r)\right] .
$$


Using this value for $P(r)$ in Eq. (8) and substituting $(4 / 3) \pi r^{\hat{3}}=V(r)$ yields

$$
\frac{P_{c r i t} V_{o}}{U_{o}}\left(\frac{3}{4 \pi} \cdot \frac{U_{o}}{r^{3}}-3 \sigma_{e f f} \cdot \frac{1}{r}+P_{n e g}\right)+P_{n e g}-\frac{2 \sigma}{r} \geq 0
$$

or

$$
\begin{gathered}
\left(\frac{1}{r}\right)^{3}-2 \sigma \cdot \frac{4 \pi}{3 P_{c r i t} V_{o}} \cdot\left(1+\frac{3}{2} \cdot \frac{P_{c r i t} V_{o}}{U_{o}} \cdot \frac{\sigma_{e f f}}{\sigma}\right)\left(\frac{1}{r}\right) \\
+P_{n e g} \cdot \frac{4 \pi}{3 P_{c r i t} V_{o}} \cdot\left(1+\frac{P_{c r i t} V_{o}}{U_{o}}\right) \geq 0 .
\end{gathered}
$$

Choosing the equality sign will give an equation whose roots correspond to the intersection(s) of the Fig. 2 curves. This equation is also a reduced cubic, and substitution of the coefficients into the condition $(p / 3)^{3}+(q / 2)^{2}=0$ gives a threshold, or minimum value of $P_{n e g}$, for continued growth of the bubble:

$$
\begin{gathered}
(2 \sigma)^{3} \cdot\left(\frac{4 \pi}{3 P_{c r i t} V_{o}}\right)^{3} \cdot\left(1+\frac{3}{2} \frac{P_{c r i t} V_{o}}{U_{o}} \frac{\sigma_{e f f}}{\sigma}\right)^{3} \cdot\left(\frac{1}{3}\right)^{3} \\
=P_{n e g}^{2} \cdot\left(\frac{4 \pi}{3 P_{c r i t} V_{o}}\right)^{2} \cdot\left(1+\frac{P_{c r i t} V_{o}}{U_{o}}\right)^{2} \cdot\left(\frac{1}{2}\right)^{2}
\end{gathered}
$$

or

$$
P_{n e g}=\sqrt{\frac{128 \pi \sigma^{3}}{81 P_{c r i t} V_{o}}} \cdot\left[1+(3 / 2)\left(P_{c r i t} V_{o} / U_{o}\right)\left(\sigma_{e f f} / \sigma\right)\right]^{3 / 2} \cdot \frac{1}{1+P_{c r i t} V_{o} / U_{o}} .
$$

The first term on the RHS is the same as the constant $m T$ solution, Eq. (17b). The second term is the correction for the loss of internal energy, and therefore pressure, to overcome the surface tension and adiabatically form a new surface. The third term is a correction to the second one, representing the contribution of energy by the PV work of the external negative pressure.

At this point, it is in order to confess a hidden approximation in the third term. Setting the PV work equal to $P_{n e g} \cdot V(r)$ implies that the integral of $P d V$ has been taken from zero to $r$. One could make an argument that the integration interval should begin not at zero, but at the radius of a sphere with the 
initial volume $V_{o}$. Such a correction can be made, but usually turns out to be small (see the discussion of Table 10, below) and, in my opinion it is not worth the added algebraic complication in Eq. (25).

As usual for a reduced cubic with $(p / 3)^{3}+(q / 2)^{2}=0$, there are two equal real roots (i.e., values of $1 / r$ for which the equality in Eq. (24) is satisfied. The value of those roots is $\sqrt[3]{2 / q}$ (Korn and Korn 1968). Therefore, the value of $r$ at which the bubble is in static equilibrium at the threshold negative pressure is $\sqrt[3]{2 / q}$, so

$$
r_{e q}=\sqrt[3]{\frac{2}{q}}=\sqrt[3]{\frac{3 P_{c r i t} V_{o}}{2 \pi P_{n e q}\left(1+P_{c r i t} V_{o} / U_{o}\right)}}
$$

Equation (25) can be manipulated to

$$
P_{c r h l} V_{o}=\frac{128 \pi \sigma^{3}}{81 P_{n e g}^{2}} \frac{\left[1+(3 / 2)\left(\sigma_{c f f} / \sigma\right)\left(P_{c r i t} V_{o} / U_{o}\right)\right]^{3}}{\left(1+P_{c r i l} V_{o} / U_{o}\right)^{2}},
$$

and when this is substituted into the above expression for $r_{e q}$, the result is

$$
r_{e q}=\sqrt[3]{\frac{64}{27} \cdot \frac{\sigma^{3}}{P_{n e g}^{3}} \cdot \frac{\left[1+(3 / 2)\left(\sigma_{e f f} / \sigma\right)\left(P_{c r i t} V_{o} / U_{o}\right)\right]^{3}}{\left(1+P_{c r i t} V_{o} / U_{o}\right)}}
$$

or

$$
r_{e q}=\frac{4 \sigma}{3 P_{n e g}} \cdot \frac{1+(3 / 2)\left(\sigma_{e f f} / \sigma\right) P_{c r i t} V_{o} / U_{o}}{1+P_{c r i t} V_{o} / U_{o}} .
$$

The first term in this expression is the same as the equilibrium radius in the constant $m T$ cases, Eq. (13). The second term, which is slightly greater than unity, accounts for the lower internal pressure arising from the loss of internal energy during growth that is described by Eq. (22).

To investigate the effect of the $T d \sigma / d T$ term, Eq. (26) was calculated with $\sigma_{e f f}=\sigma-T d \sigma / d T$ and with $\sigma_{e f f}=\sigma$. The results are shown in Table 8, again omitting cyclohexanol.

When the two sets of calculations, one with and one without the $T d \sigma / d T$ term, are fitted to the measured results, the correlation coefficients are as seen in Table 9. 
Table 8. Equation (25) results with and without the $T d \sigma / d T$ term

\begin{tabular}{|c|c|c|c|c|}
\hline \multirow[b]{2}{*}{ Material } & \multirow{2}{*}{$\begin{array}{c}\text { Recoil energy, } \\
\text { keV }\end{array}$} & \multicolumn{2}{|c|}{ Calculated threshold, bars } & \multirow{2}{*}{$\begin{array}{l}\text { Measured threshold } \\
\text { (bars) }\end{array}$} \\
\hline & & $\begin{array}{c}T d \sigma / \mathrm{dT} \\
\text { included }\end{array}$ & $\begin{array}{c}T d \sigma / d T \\
\text { not included }\end{array}$ & \\
\hline Isopentane & 101 & 2.316 & 2.060 & 3.344 \\
\hline Freon 113 & 101 & 2.336 & 2.115 & 4.490 \\
\hline Freon 113 & 166 & 2.994 & 2.711 & 5.207 \\
\hline n-hexane & 101 & 3.547 & 3.031 & 6.890 \\
\hline Acetone & 101 & 4.544 & 4.188 & 8.309 \\
\hline Trichloroethylene & 101 & 6.031 & 5.587 & 11.754 \\
\hline Ethylene bromide & 101 & 9.664 & 9.197 & 22.190 \\
\hline Acetophenone & 101 & 12.619 & 12.322 & 33.235 \\
\hline
\end{tabular}

Table 9. Correlation coefficients with and without the $T d \sigma / d T$ term

\begin{tabular}{lc}
\hline \multicolumn{1}{c}{$\sigma_{e f f}$} & $R^{2}$ \\
\hline$\sigma-T d \sigma / d T$ & 0.987 \\
$\sigma$ & 0.992 \\
\hline
\end{tabular}

Both correlation coefficients are high, but the simple $\sigma$ version (i.e., without the $T d \sigma / d T$ term) is a better straight-line fit. That term is therefore now omitted from Eq. (25), leading to

$$
\begin{aligned}
& P_{n e g}=\sqrt{\frac{128 \pi \sigma^{3}}{81 P_{c r i t} V_{o}}} \cdot \frac{\left[1+(3 / 2)\left(P_{c r i t} V_{o} / U_{o}\right)\right]^{3 / 2}}{\left(1+P_{c r i t} V_{o} / U_{o}\right)} \\
& =\sqrt{\frac{128 \pi \sigma^{3} H_{c a}}{81 E_{\text {recoil }} P_{c r i t} / \rho_{c r i t}}} \cdot \frac{\left[1+(3 / 2)\left(P_{c r i t} V_{o} / U_{o}\right)\right]^{3 / 2}}{\left(1+P_{c r i t} V_{o} / U_{o}\right)} \text {. }
\end{aligned}
$$

The $\sigma_{e f f} / \sigma$ term should be omitted from Eq. (26) as well. Results calculated from Eq. (27) are plotted in Fig. 6.

A comparison of Tables 7 and 8 shows that while including the effect of varying internal energy may have led to a more self-consistent physical model, it has made little quantitative difference to the predicted thresholds. 


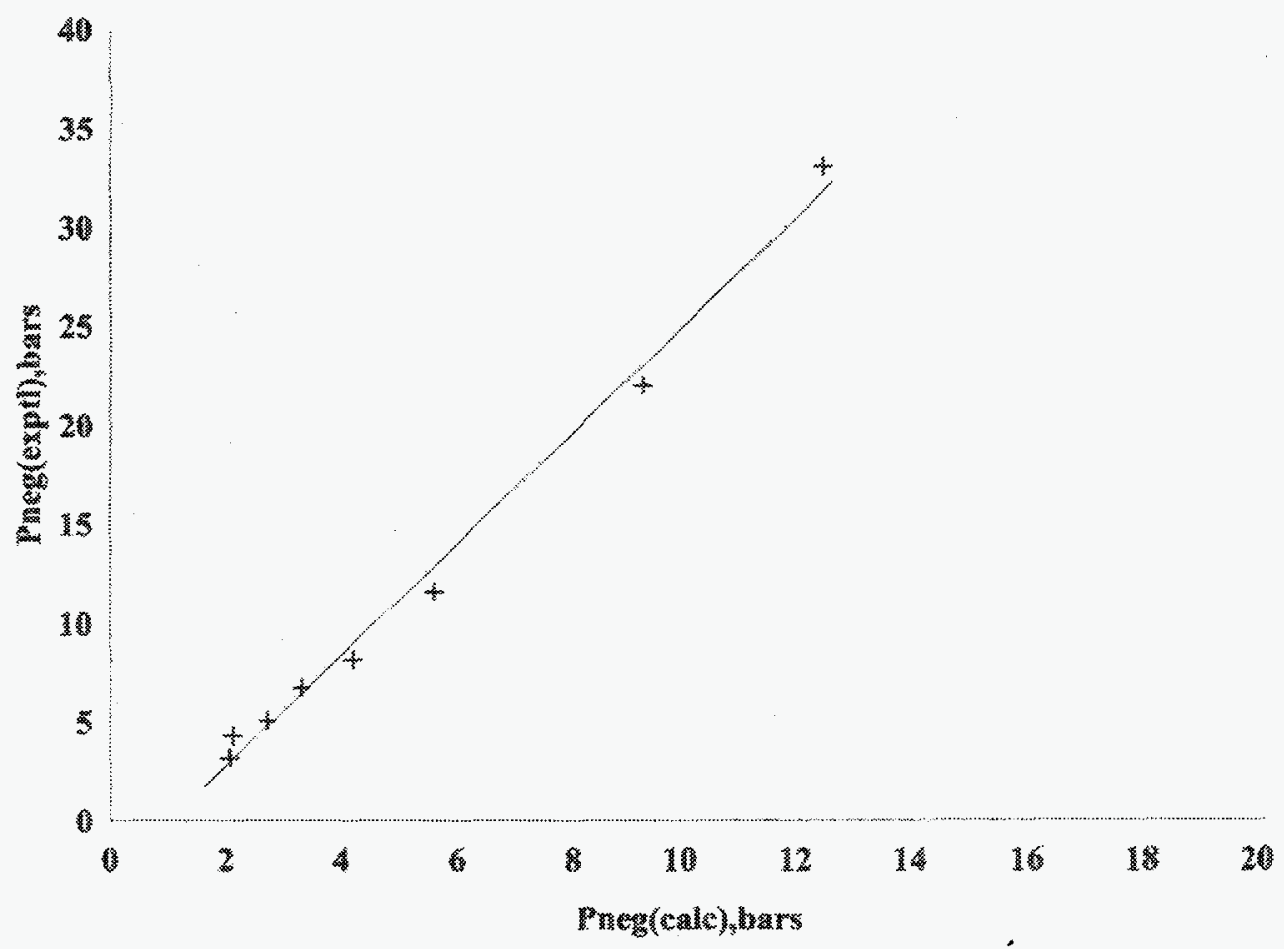

Fig. 6. $P_{\text {neg }}$ (exptl) vs $P_{\text {neg }}$ [calc, mT model, Eq. (27)]. Static terms only. Cyclohexonal excluded. $\mathrm{R}^{\wedge} 2=0.992$.

The reason that the differences between the results from Eq. (17) and from Eq. (27) are so small is surprising, to me at least: only a very small fraction $(\sim 5 \%)$ of the thermal energy deposited by the recoiling particles is actually used to form new surface area on the expanding bubble.

A simple numerical calculation illustrates this; the algebraic demonstration is tedious and long. The basis of the calculation is Eq. (19), but for the reasons given above, the $W_{s 2}$ term is omitted. The integrations of surface energy and PV work are again approximated by beginning the integration at zero radius. Equation (19) becomes

$$
U(r)=U_{o}-W_{s 1}-W_{e}
$$

$W_{e}$, the work done in expanding against the external pressure, is actually a negative quality, work being done by the negative pressure. At the equilibrium radius,

$$
U\left(r_{e q}\right)=U_{o}-4 \pi r_{e q}^{2} \sigma+\frac{4}{3} \pi r_{e q}^{3} P_{n e g},
$$

where $r_{e q}$ is given by Eq. (26) and $P_{n e g}$ by Eq. (27).

The numerical results of evaluating Eq. (28) are shown in Table 10.

The surface energy typically amounts to only about $10 \%$ of the initial internal energy, and almost half of it is provided by the PV work that the negative pressure does on the growing bubble. Therefore, the internal energy at any stage of the growth to the equilibrium radius is little different from that in the simpler, constant $m T$ model. 
Table 10. Initial internal energy, surface energy, and PV work

\begin{tabular}{lcccc}
\hline \multicolumn{1}{c}{ Material } & $\begin{array}{c}\text { Recoil energy, } \\
\text { keV/fJ }\end{array}$ & $U_{o}, \mathrm{fJ}$ & $W_{s l}, \mathrm{fJ}$ & $W_{e}, \mathrm{fJ}$ \\
\hline Isopentane & $101 / 16.18$ & 15.76 & 1.8 & 0.8 \\
Freon 113 & $166 / 26.59$ & 25.94 & 2.8 & 1.3 \\
Freon 113 & $101 / 16.18$ & 15.78 & 1.7 & 0.8 \\
n-hexane & $101 / 16.18$ & 15.88 & 1.3 & 0.6 \\
Acetone & $101 / 16.18$ & 15.78 & 1.7 & 0.8 \\
Trichloroethylene & $101 / 16.18$ & 15.75 & 1.9 & 0.8 \\
Ethylene bromide & $101 / 16.18$ & 15.82 & 1.6 & 0.7 \\
Acetophenone & $101 / 16.18$ & 15.97 & 0.9 & 0.4 \\
Cyclohexanol & $101 / 16.18$ & 15.99 & 0.9 & 0.4 \\
\hline
\end{tabular}

Note that $W_{e}$, which I approximated as $P_{n e g} V$, is small compared with $U_{o}$. Therefore, the effect of making the same approximation in the derivation of Eq. (20), and in other equations following from it, must be small.

\subsection{DYNAMIC TERMS}

Figure 6 showed a strong correlation between the results from Eq. (27) and the measured value of the radiation-induced cavitation threshold when the result from high viscosity cyclohexanol was excluded. However, Fig. 7 shows that when the cyclohexanol result is included, the correlation between measurements and results calculated using only the static bubble formation energy terms is poor. This section gives an approximate treatment, based on simple physical arguments, of the dynamic energy losses.

Riepe and Hahn (1961) estimated the viscous and kinetic energy losses, $W_{5}$ and $W_{4}$ respectively, by assuming that the nucleation center grew at a velocity not exceeding that required to reach the critical radius $r_{c r i t}$ within the thermal relaxation time $\tau_{c r i t}$ of a thermal spike of radius $r_{c r i l}$. They point out that at the end of that time, the heat content of such a spike would have fallen, through thermal conduction, by a factor $1 / \mathrm{e}$. The relaxation time is given by $\tau_{c r i t}=r_{c r i}{ }^{2} / 4 D$ where $D$ is the thermal diffusivity of the medium.

However, in the $m T$ model of cavitation nucleation, there is no exact equivalent to the critical radius in the Seitz bubble chamber theory; it has been replaced by a criterion that the expansive forces exceed the compressive ones at all radii.

Furthermore, the Riepe and Hahn calculations on bubble chamber nucleation energy agreed with the values deduced from their experimental observations to within $10 \%$. Such close agreement is difficult to reconcile with a situation in which a fraction $1-1 / \mathrm{e}$, or more than $60 \%$, of the thermal energy might escape the critical radius before the bubble reaches that size.

In fact, the growth could actually take place in a much shorter time than $\tau_{c r i t}$ without upsetting the energy balance significantly because the dynamic terms are relatively small in most cases-see Tables 1 and 4 -and less thermal energy would be lost in that shorter time. Also, the energy that does escape by 


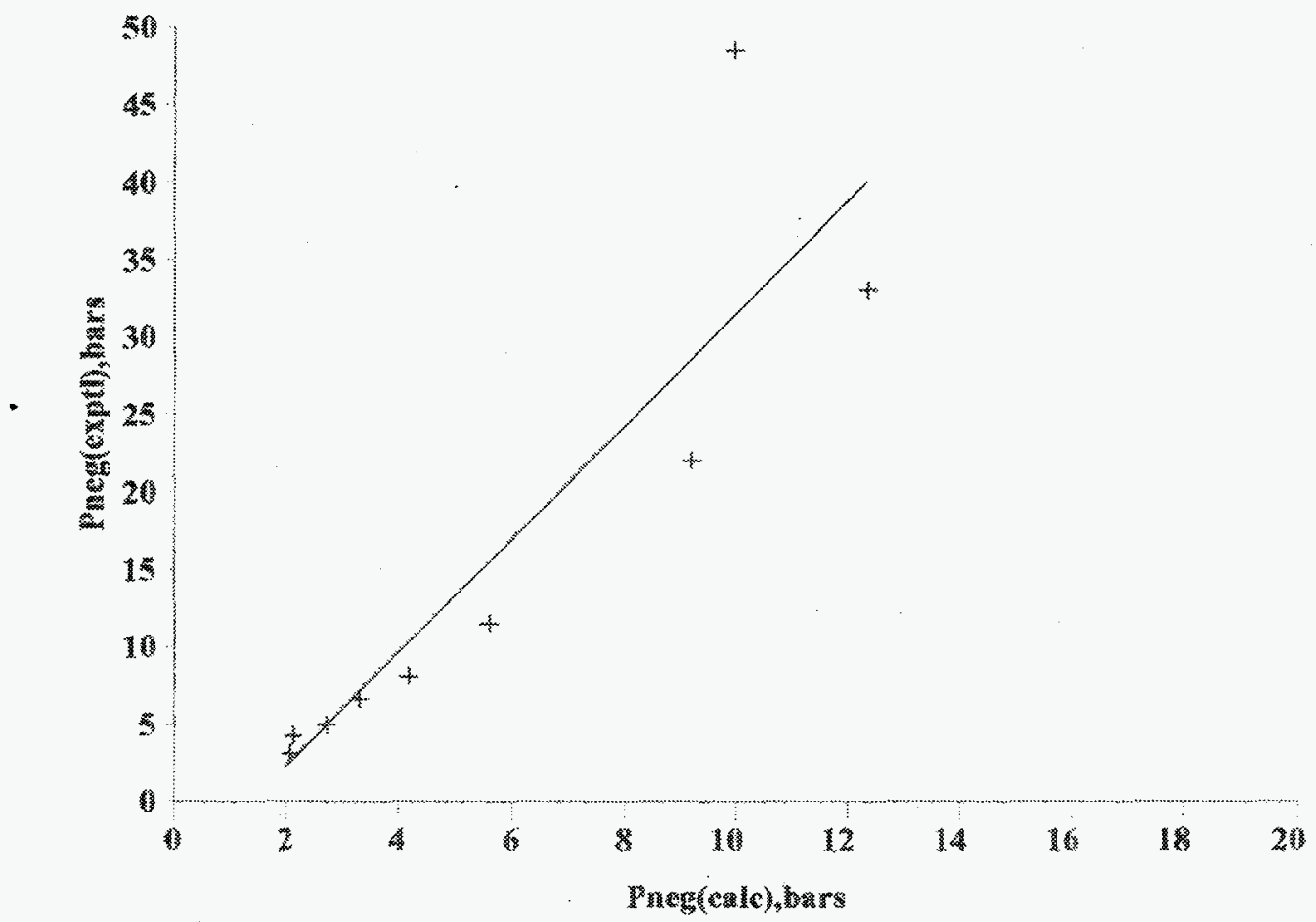

Fig. 7. $\mathbf{P}_{\text {neg }}$ (exptl) vs $\mathbf{P}_{\text {neg }}$ [calc, $\mathbf{m T}$ model, Eq. (27)]. Static terms only. Cyclohexona] included. $R^{\wedge} 2=0.793$.

thermal conduction may continue to facilitate nucleation by heating the liquid around the expanding bubble, thereby reducing its surface tension and the demands on the bubble's internal energy and pressure: i.e., the surface formation is not entirely adiabatic (in which case the additional $T d \sigma / d T$ surface energy term may indeed not be appropriate).

A slightly different model for the dynamic losses is adopted here. Rather than considering only the time $t(r)$ taken to grow to a particular radius, the growth to any radius $r$ is required to take place in a time $\tau(r)$ or less, that is,

$$
t(r) \leq r^{2} / 4 D
$$

and therefore, by differentiation the requirement is

$$
\dot{r}=\frac{d r}{d t} \geq \frac{2 D}{r}
$$

the equality sign being chosen as the limiting case. The viscous loss, which Riepe and Hahn found to be much larger than the kinetic energy loss in most cases, is given in their Eq. (10) as: 


$$
W_{5}=16 \pi \eta \int_{0}^{r} \dot{r} r d r
$$

or, substituting for $\dot{r}$ from Eq. (30),

$$
W_{5}=16 \pi \eta \int_{0}^{r} \frac{2 D}{r} r d r=32 \pi \eta D r
$$

Once again, the integration interval is begun at zero, although the initial radius of the fluid at the critical point could have been used.

The result is different from Riepe and Hahn's Eq. (11), which reads $W_{5}=64 \pi \eta D r$ by a factor of two; the reason is that they assumed a constant growth rate, whereas Eq. (29) allows a lower growth rate in the later stages, when the larger radius would lead to a longer thermal relaxation time.

To calculate the kinetic loss $W_{4}$, the formula used at the critical radius by Riepe and Hahn [Eq. (8) in their paper] is applied here at all radii, with a factor $\mathrm{Mwt} / 10^{3}$ to account for the change from mass to molar density units.

$$
W_{4}=2 \pi \rho_{\ell}\left(M w t / 10^{3}\right) \dot{r}^{2} r^{3}
$$

and substituting for $\dot{r}$ from Eq. (30) gives

$$
W_{4}=8 \pi \rho_{\ell}\left(M w t / 10^{3}\right) D^{2} r
$$

Again, this differs from Riepe and Hahn's Eq. (11), this time by a factor of four, because the effect of a varying growth velocity has been included.

Note that $W_{5}$ and $W_{4}$ have the same form and so it is possible, and convenient, to combine them into a single dynamic energy loss term, $W_{d y n}$, where

$$
\begin{aligned}
W_{d y n} & =\left[32 \pi \eta D+8 \pi \rho_{\ell}\left(M w t / 10^{3}\right) D^{2}\right] \cdot r \\
& =32 \pi D\left(\eta+\rho_{\ell} D\left(M w t / 10^{3}\right) / 4\right] \cdot r
\end{aligned}
$$

or

$$
W_{d y n}=32 \pi \eta_{e f f} D r
$$


where

$$
\eta_{\text {eff }}=\eta+\rho_{\ell} D M w t /\left(4 \cdot 10^{3}\right)
$$

Equation (33) is the work that would be done against an inwardly directed dynamic pressure $P_{d y n}$ where

$$
P_{d y n}=8 \eta_{e f f} \frac{D}{r^{2}}
$$

because

$$
\int_{0}^{r} \frac{8 \eta_{e f f} D}{r^{2}} \cdot 4 \pi r^{2} d r=32 \pi \eta_{e f f} D r
$$

In confirmation, by substituting from Eq. (29), Eq. (35) can be rewritten

$$
P_{d y n}=4 \eta_{e f f} \frac{\dot{r}}{r}
$$

which is identical in form to Seitz's expression for the effective pressure at the bubble surface due to viscosity [Seitz 1958, Eq. (39)].

When the dynamic energy term is included, Eq. (22), without the Bugg term, becomes

$$
P_{\text {int }}(r)=\frac{P_{c r i i} V_{o}}{U_{o} V(r)} \cdot\left[U_{o}-4 \pi r^{2} \sigma-32 \pi \eta_{e f f} D r+P_{n e g} V(r)\right]
$$

and inclusion of the dynamic pressure term in Eq. (8) gives, for negative external pressures, the following condition for continued growth.

$$
P_{i n i}(r)+P_{n e g} \geq \frac{2 \sigma}{r}+\frac{8 \eta_{e f f} D}{r^{2}} .
$$


Combining Eqs. (36) and (37) yields

$$
\begin{aligned}
& \left(\frac{1}{r}\right)^{3}-8 \eta_{e f f} D \cdot\left(1+3 \frac{P_{c r i t} V_{o}}{U_{o}}\right)\left(\frac{1}{r}\right)^{2} \\
& -2 \sigma \cdot \frac{4 \pi}{3 P_{c r i t} V_{o}} \cdot\left(1+\frac{3}{2} \frac{P_{c r i t} V_{o}}{U_{o}}\right)\left(\frac{1}{r}\right) \\
& +P_{n e g} \cdot \frac{4 \pi}{3 P_{c r i t} V_{o}} \cdot\left(1+\frac{P_{c r i t} V_{o}}{U_{o}}\right) \geq 0 .
\end{aligned}
$$

Given the assumption that $\sigma_{e f f}=\sigma$, the coefficients for $(1 / r)^{3}$ and the constant term are identical to those in Eq. (24). The viscous and kinetic energy effects are contained only in the $(1 / \mathrm{r})^{2} \mathrm{term}$, which was absent from Eq. (24).

Once again, the equality sign in Eq. (38) characterizes the limiting value, or cavitation threshold, of $P_{\text {neg. }}$

Substituting $y$ - $a / 3$ for $x$ in the cubic

$$
x^{3}+a x^{2}+b x+c=0
$$

transforms it into the reduced cubic

$$
y^{3}+p y+q=0
$$

where

$$
p=-a^{2} / 3+b
$$

and

$$
q=2(a / 3)^{3}-a b / 3+c
$$

(See, for example, Korn and Korn 1968).

In this case

$$
a=-8 \eta_{c f f} D \cdot \frac{4 \pi}{3 P_{c r i t} V_{o}} \cdot\left(1+\frac{3 P_{c r i t} V_{o}}{U_{o}}\right)
$$




$$
b=-20 \cdot \frac{4 \pi}{3 P_{c r i t} V_{o}} \cdot\left(1+\frac{3}{2} \frac{P_{c r i t} V_{o}}{U_{o}}\right)
$$

and

$$
c=P_{n e g} \cdot \frac{4 \pi}{3 P_{c r i t} V_{o}} \cdot\left(1+\frac{P_{c r i t} V_{o}}{U_{o}}\right)
$$

The minimum condition for continuous growth is the same as before, viz

$$
(p / 3)^{3}+(q / 2)^{2}=0
$$

Given the fluid properties and the energy available for nucleation, which defines $U_{o}$ through Eq. (18), TK Solver easily calculates $P_{\text {neg }}$ from Eqs. (41) and (43), but a little further algebraic manipulation leads to a single equation that can be evaluated with a pocket calculator (or a slide rule).

Start by rearranging Eq. (43):

$$
\left(\frac{q}{2}\right)^{2}=-\left(\frac{p}{3}\right)^{3}=\left(\frac{-p}{3}\right)^{3}
$$

or

$$
q=2(-p / 3)^{3 / 2}
$$

Substitute for $q$ and $p$ from Eq.s (41a) and (4lb),

$$
\begin{aligned}
2(a / 3)^{3}-a b / 3+c & =2\left(\frac{-a^{2} / 3+b}{3}\right)^{3 / 2} \\
& =2\left(\frac{-a^{2}+3 b}{9}\right)^{3 / 2} \\
& =\frac{2}{27}\left(-a^{2}+3 b\right)^{3 / 2},
\end{aligned}
$$


rearranging

$$
c=\frac{2}{27}\left(-a^{2}+3 b\right)^{3 / 2}-\frac{2 a^{3}}{27}+\frac{a b}{3}
$$

Substituting for $c$ from Eq. (42c), and isolating $P_{\text {neg }}$ on the left hand side yields

$$
P_{n e g}=\frac{3 P_{c r i t} V_{o}}{4 \pi\left(1+P_{c r i t} V_{o} / U_{o}\right)} \cdot \frac{1}{27}\left[2\left(a^{2}-3 b\right)^{3 / 2}-2 a^{3}+9 a b\right],
$$

where $a, b$ are defined by Eqs. (42a) and (42b).

As a check of the manipulations, one can set $a=0$, which means there are no dynamic effects: Eq. (44) then reduces to Eq. (27).

One result from Eq. (44) is surprising: see Table 11. Comparing the calculated thresholds without dynamic effects, Eq. (27), and with dynamic effects, Eq. (44), most of the results show only a small increase, as expected. However, the highly viscous cyclohexanol shows an enormous increase and predicts a threshold almost 50 times greater than the observed value.

There is a simple and plausible physical explanation for this gross overestimation of the cyclohexanol threshold, one which also leads to a different method of calculating the threshold for highly viscous liquids.

Although the $m T$ model of bubble nucleation under negative pressure does not involve a single, critical radius, such as can be identified in the theory of bubble chamber nucleation, there is one "magic" radius that has particular significance for the calculation of dynamic energy losses. Recall that the bubble growth velocity was chosen so that the time taken to grow to a radius $r$ was no greater than the relaxation time of a spherical thermal spike of that radius, thus retaining the thermal energy in the neighborhood of

Table 11. Effect of dynamic terms on the calculated threshold

\begin{tabular}{lcccc}
\hline \multirow{2}{*}{ Material } & $\begin{array}{c}\text { Recoil energy, } \\
\text { keV }\end{array}$ & \multicolumn{3}{c}{ Threshold, bars } \\
\cline { 3 - 5 } & 101 & 2.06 & 2.25 & 3.344 \\
Isopentane & 166 & 2.12 & 2.41 & 4.490 \\
Freon 113 & 101 & 2.71 & 3.21 & 5.207 \\
Freon 113 & 101 & 3.30 & 3.73 & 6.890 \\
n-hexane & 101 & 4.19 & 4.69 & 8.309 \\
Acetone & 101 & 5.59 & 6.54 & 11.754 \\
Trichloroethylene & 101 & 9.20 & 13.06 & 22.190 \\
Ethylene bromide & 101 & 12.32 & 26.66 & 33.235 \\
Acetophenone & 101 & 9.96 & 2,779 & 48.740 \\
Cyclohexanol & & &
\end{tabular}


the bubble to assist the growth. But, as Eq. (9) showed, once the bubble reaches a radius $r^{*}=2 \sigma / P_{\text {neg, }}$ it could continue to grow under the influence of the negative pressure alone, even if no internal energy were left at all. Therefore, a criterion on minimum growth velocity need not be applied to growth beyond a radius of $r^{*}$.

When the dynamical terms are small, the equilibrium radius, at which compressive and expansive pressures are equal, is approximately $4 \sigma / 3 P_{\text {neg }}$, as given by Eq. (26). In such a case, $r^{*}=2 \sigma / P_{\text {neg }}$ is greater than $r_{e q}$ by a factor of about 1.5 , so the growth velocity criterion must be applied all the way up to the equilibrium radius and beyond, and the derivation of Eq. (44) is appropriate in such a case.

However, in a highly viscous liquid the large $1 / r^{2}$ term in Eq. (38) leads to a larger radius being required to reach equilibrium, and indeed the equilibrium radius may be greater than $r^{*}$ : in such cases, by imposing the minimum growth velocity criterion throughout the process, one is calculating viscous losses in the growth between $r^{*}$ and $r_{e q}$, losses that are not necessary because there is no constraint on the time allowed for growth beyond $r^{*}$.

The reduced cubic, Eq. (40), has two equal real roots when

$$
(p / 3)^{3}+(q / 2)^{2}=0
$$

and this case corresponds to the threshold. Those roots are given by

$$
y_{2}=y_{3}=-\sqrt[3]{-\frac{q}{2}}=\sqrt[3]{\frac{q}{2}},
$$

and reversing the transformation $y-a / 3=x$ that was applied between Eqs. (39) and (40) gives

$$
x_{1}=x_{2}=y_{2}-\frac{a}{3}=\sqrt[3]{\left(\frac{q}{2}\right)}-\frac{a}{3} .
$$

Comparing Eqs. (39) and (38) shows that $x_{1}=x_{2}=1 / r_{e q}$,

$$
r_{e q}=1 /\left(\sqrt[3]{\left(\frac{q}{2}\right)}-\frac{a}{3}\right)
$$

where $q$ is given by Eq. (41b) and $a$ is given by Eq. (42a).

The "magic" radius, above which the bubble can grow without further reliance on internal pressure, is given by

$$
r^{*}=2 \sigma / P_{n u g}
$$

The two radii corresponding to the cases listed in Table 11 are shown in Table 12. 
Table 12. Calculated thresholds, equilibrium radius, and unconditional growth radii

\begin{tabular}{lcccc}
\hline \multicolumn{1}{c}{ Material } & $\begin{array}{c}\text { Recoil energy, } \\
\mathrm{keV}\end{array}$ & $\begin{array}{c}\text { Threshold, bars, } \\
\text { Eq. (44) }\end{array}$ & $\begin{array}{c}r_{\text {eq }}, \mathrm{nm} \\
\text { Eq. (46) }\end{array}$ & $\begin{array}{c}r^{*}, \mathrm{~nm} \\
\text { Eq. (47) }\end{array}$ \\
\hline Isopentane & 101 & 2.25 & 92.8 & 133.4 \\
Freon 113 & 166 & 2.41 & 103.9 & 147.1 \\
Freon 113 & 101 & 3.21 & 79.1 & 110.5 \\
n-hexane & 101 & 3.73 & 69.8 & 99.5 \\
Acetone & 101 & 4.69 & 70.8 & 100.9 \\
Trichloroethylene & 101 & 6.54 & 64.2 & 89.9 \\
Ethylene bromide & 101 & 13.06 & 45.6 & 59.4 \\
Acetophenone & 101 & 26.66 & 27.2 & 29.6 \\
Cyclohexanol & 101 & 2,779 & 4.4 & 0.24 \\
\hline
\end{tabular}

Except for cyclohexanol, $r^{*}$ is greater than $r_{e q}$ : thus Eq. (44) is appropriate, the rapid growth criterion being applicable up to and beyond $r_{e q}$. Note also that for the low viscosity, low threshold liquids, the value of $r^{*}$ is roughly $1.5 r_{e q}$ as the simple $m T$ model, with static terms only, predicts.

For cyclohexanol, however, the model has imposed a rapid growth requirement in the size range $0.24 \mathrm{~nm}$ to $4.4 \mathrm{~nm}$, when in fact that requirement existed only during the growth up to $0.24 \mathrm{~nm}$. One is, of course, entitled to wonder if the cyclohexanol bubble really knows the opportunity for a more leisurely growth that is open to it, but the fact remains that beyond $r^{*}$ a slow growth, which the viscosity will tend to promote, would not prevent the bubble from exceeding $r_{e q}$ and growing indefinitely.

And, that is not the only problem with applying the basic $m T$ model to very high threshold liquids: Table 13 compares the equilibrium radius $r_{e q}$ and the magic radius $r^{*}$ with $R_{o}$, the radius that the fluid volume $V_{o}$ would have, at the critical point, if it were spherical.

$$
\begin{gathered}
\frac{4 \pi R_{o}^{3}}{3}=V_{o}=\frac{M_{o}}{\rho_{\text {crit }}} \\
\therefore R_{o}=\sqrt[3]{\frac{3 V_{o}}{4 \pi}}=\sqrt[3]{\frac{3 E_{\text {recoil }}}{4 \pi \rho_{c r i t} H_{c a}}}
\end{gathered}
$$

The implicit assumption that the volume and surface area of the initial nucleation center are small compared with the values during the important stage of growth when $r \sim r_{e q}$ or $r^{*}$ is unrealistic for acetophenone and completely incorrect for cyclohexanol. Furthermore, for cyclohexanol the calculated equilibrium radius and the calculated magic radius are both smaller than the initial radius of the heated fluid, which makes no sense. 
Table 13. Comparison of $r_{e q}, \boldsymbol{r}^{*}$, and $\boldsymbol{R}_{o}$

\begin{tabular}{lccccc}
\hline \multicolumn{1}{c}{ Material } & $\begin{array}{c}\text { Recoil energy, } \\
\mathrm{keV}\end{array}$ & $\begin{array}{c}\text { Threshold, bars, } \\
\text { Eq. (44) }\end{array}$ & $\begin{array}{c}r_{\text {eq }}, \mathrm{nm} \\
\text { Eq. (46) }\end{array}$ & $\begin{array}{c}r^{*}, \mathrm{~nm} \\
\text { Eq. (47) }\end{array}$ & $\begin{array}{c}R_{o}, \mathrm{~nm} \\
\text { Eq. (48) }\end{array}$ \\
\hline Isopentane & 101 & 2.25 & 92.8 & 133.4 & 31.0 \\
Freon 113 & 166 & 2.41 & 103.9 & 147.1 & 35.8 \\
Freon 113 & 101 & 3.21 & 79.1 & 110.5 & 30.3 \\
n-hexane & 101 & 3.73 & 69.8 & 99.5 & 28.9 \\
Acetone & 101 & 4.69 & 70.8 & 100.9 & 27.3 \\
Trichloroethylene & 101 & 6.54 & 64.2 & 89.9 & 27.6 \\
Ethylene bromide & 101 & 13.06 & 45.6 & 59.4 & 25.1 \\
Acetophenone & 101 & 26.66 & 27.2 & 29.6 & 23.5 \\
Cyclohexanol & 101 & 2,779 & 4.4 & 0.24 & 23.2 \\
\hline
\end{tabular}

Although Hahn reported measuring the a-recoil induced cavitation threshold of 28 different compounds, he published the results from only eight of them, as far as I know. There is only one good high viscosity data point to work with, and that one, cyclohexanol, needs to be treated carefully because the measurement is reported as being carried out at a temperature that is below the freezing point. Therefore, I adopted only a very simple, although physically reasonable, approach to calculating the cavitation threshold in such a case, because a large mathematical effort did not seem appropriate for a single data point.

Given the energy available, one can calculate the size (e.g., volume or radius) of a sphere of liquid that can be raised to the critical point, thus providing a region in which homogeneous nucleation and subsequent evaporation will take place. If the negative pressure is high enough that the magic radius, $2 \sigma / P_{n e g}$, is equal to or less than this initial bubble size, then the initial bubble can grow even if the high viscosity causes a low growth rate and therefore loses heat through conduction. A threshold, $P_{n e g}$, can be calculated by imposing this inequality:

$$
\frac{2 \sigma}{P_{n e g}} \leq R_{o}
$$

In the limiting case or threshold, when the equality holds,

$$
P_{n e g}=\frac{2 \sigma}{R_{o}} \text {, }
$$


and substituting for $R_{o}$ from Eq. (48) yields

$$
P_{n e g}=2 \sigma \sqrt[3]{\frac{4 \pi \rho_{c r i t} H_{c a}}{3 E_{\text {recoil }}}} .
$$

This equation can be applied legitimately only to a liquid with high $\eta_{\text {eff }}:$ a nucleation center in other liquids can grow quickly enough to reach its equilibrium radius, before the initial heat has been dissipated, without paying too high a price in dynamic losses, leading to a lower threshold than indicated by Eq. (50).

How is one to decide which liquids are "high viscosity" and which are not? By calculating the thresholds from both Eq. (44) and Eq. (50): if the threshold from Eq. (44) is lower, then that is the appropriate model to use (i.e., the liquid is classed as low viscosity). Otherwise, Eq. (50) is applied. The results are shown in Table 14.

Figure 8 plots the calculated and measured threshold, including the cyclohexanol results, and a linear fit to the data. Comparing Fig. 8 and Fig. 7 shows that the inclusion of dynamic effects has greatly improved the fit of the complete data set (i.e., including cyclohexanol). The correlation coefficient is not as high as for the simpler, static terms only, equations without cyclohexanol, but the slope is much improved; a perfect fit would have a slope of 1, and the slope of Fig. 6 is 2.81 , whereas in Fig. 8 it is 1.46 .

Table 14. Threshold calculated from Eqs. (44) and (50)

\begin{tabular}{lccccc}
\hline & & \multicolumn{4}{c}{ Threshold, bars } \\
\cline { 3 - 6 } \multicolumn{1}{c}{ Material } & $\begin{array}{c}E_{\text {recoil }} \\
\text { keV }\end{array}$ & Eq. (44) & Eq. (50) & $\begin{array}{c}\text { MIN [Eq. (44), } \\
\text { Eq. (50)] }\end{array}$ & Measured \\
\hline Isopentane & 101 & $\mathbf{2 . 2 5}$ & 9.68 & $\mathbf{2 . 2 5}$ & 3.34 \\
Freon 113 & 166 & $\mathbf{2 . 4 1}$ & 9.90 & $\mathbf{2 . 4 1}$ & 4.49 \\
Freon 113 & 101 & $\mathbf{3 . 2 1}$ & 11.68 & $\mathbf{3 . 2 1}$ & 5.21 \\
n-hexane & 101 & $\mathbf{3 . 7 3}$ & 12.83 & $\mathbf{3 . 7 3}$ & 6.89 \\
Acetone & 101 & $\mathbf{4 . 6 9}$ & 17.36 & $\mathbf{4 . 6 9}$ & 8.31 \\
Trichloroethylene & 101 & $\mathbf{6 . 5 4}$ & 21.31 & $\mathbf{6 . 5 4}$ & 11.75 \\
Ethylene bromide & 101 & $\mathbf{1 3 . 0 6}$ & 30.92 & $\mathbf{1 3 . 0 6}$ & 22.19 \\
Acetophenone & 101 & $\mathbf{2 6 . 6 6}$ & 33.65 & $\mathbf{2 6 . 6 6}$ & 33.23 \\
Cyclohexanol & 101 & 2,779 & $\mathbf{2 8 . 9 8}$ & $\mathbf{2 8 . 9 8}$ & 48.74 \\
\hline
\end{tabular}




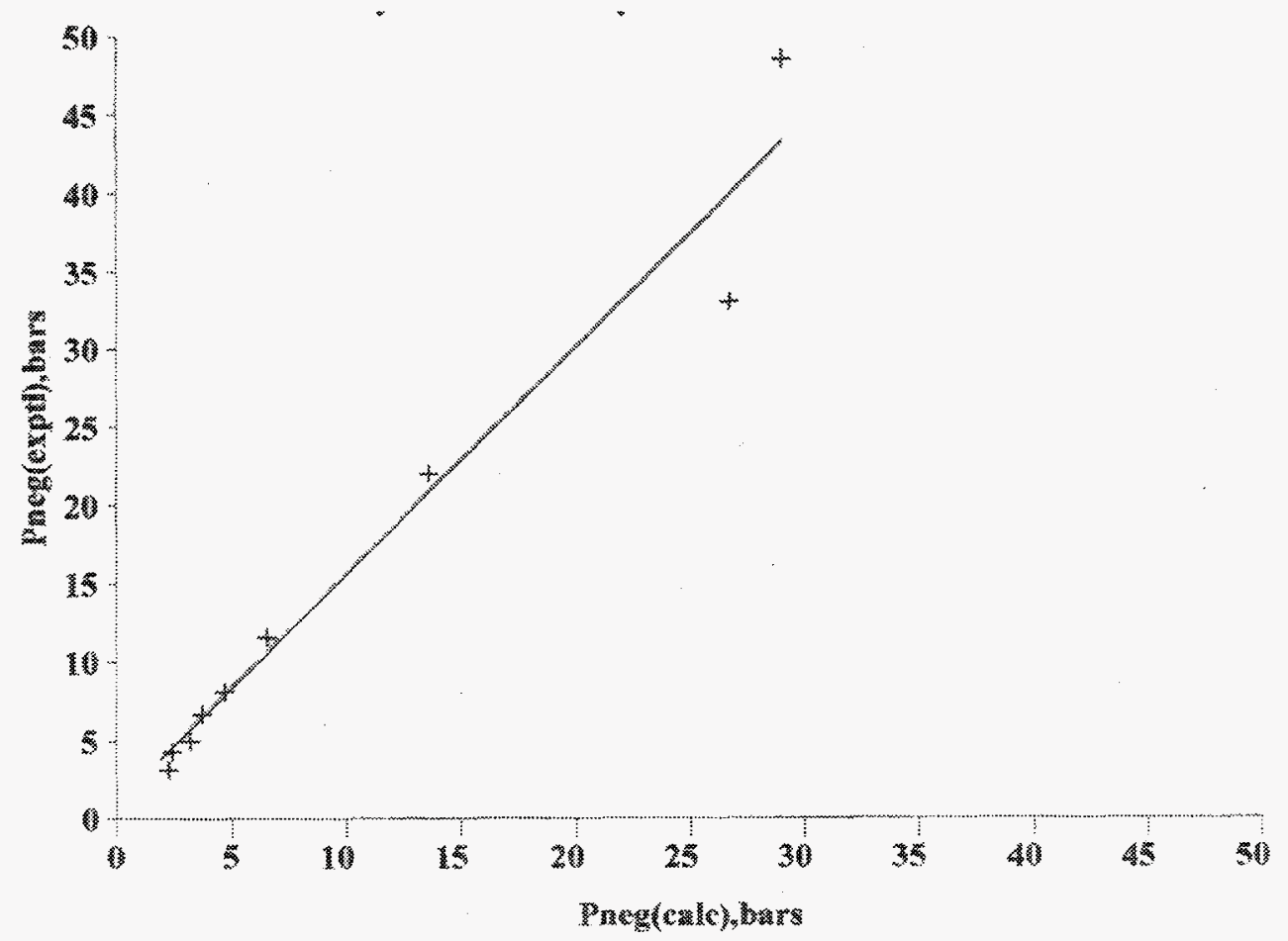

Fig. 8. $P_{\text {neg }}$ (exptl) vs $P_{\text {neg }}$ [calc, variable $m T$ model, Eqs. (44) and (50)|. Static and dynamic terms. Cyclohexonal included. $R^{\wedge} 2=0.960$. 


\section{AVAILABLE ENERGY}

So far, I have assumed that all of the recoil energy is available for bubble nucleation. However, there are some hints in the results presented earlier that this may not be so.

\subsection{ENERGY DISCREPANCIES}

The first observation is that the measured thresholds in Freon 113 with two very different recoil energies (166 keV and $101 \mathrm{keV}$ ) differ by a factor of only 1.16 (according to my measurements, which were necessarily not very precise, from Hahn's published graphs), whereas the values calculated from Eq. (44) differ by a factor 1.33. This would be consistent with several possible explanations, including one that involves less than the full energy of the more energetic recoil being available to a single nucleation center.

The second observation is that all of the calculated values in, for example, Table 14 are lower than the corresponding measured values. This, too, is consistent with a situation in which less than the full recoil energy is actually available. But it is consistent with several other possibilities too.

\subsection{LINEAR RATE OF ENERGY LOSS}

Riepe and Hahn calculated the available energy by considering the energy deposited by the recoiling nucleus and the alpha particle within a length equal to the critical bubble diameter. In the $m T$-model, there is no single, critical bubble size, and so a different approach is needed.

The linear rate of energy loss, $d E / d x$, of the heavy, slow, recoiling nucleus is one to two orders of magnitude higher than that of the ejected alpha particle, and in the following calculations, any contribution to the nucleation energy from the alpha is neglected.

The heavy (mass $>200 \mathrm{amu}$ ) recoils from natural a-decay all have initial velocities less than electron orbital velocities, and a simple, although approximate, expression for their rate of energy loss is the Bohr formula

$$
\frac{d E}{d x}=\frac{\pi \hbar^{2}}{\mu} Z_{p}^{2 / 3} Z_{\ell} N \rho_{\ell}
$$

where $\mu$ is the electron mass $\left(9.109 \times 10^{-31} \mathrm{~kg}\right)$; $\hbar$ is the Planck constant divided by $2 \pi\left(1.055 \times 10^{-34} \mathrm{~J}\right)$, $Z_{p}$ is the charge number of the recoil nuclei ( 82 for ${ }^{210} \mathrm{Po}$ and ${ }^{212} \mathrm{Po}$ decays), $Z_{\ell}$ is the charge number of the liquid molecules, $N$ is Avogadro's number $\left(6.022 \times 10^{23} \mathrm{~mol}^{-1}\right)$, and $\rho_{\ell}$ is the molar density of the liquid.

This version of the formula was taken, with a change of symbols and units, from Bohr's book (Bohr 1948); the same formula was used by Riepe and Hahn (1961). Note that according to Eq. (51), in this regime the rate of energy loss, as calculated from the Bohr formula, is independent of energy.

Substituting the physical constants into Eq. (51) yields

$$
\frac{d E}{d x}=4.36 \times 10^{-13} \rho_{\ell} Z_{\ell}
$$

The units of $d E / d x$ will be joules/metre, if $\rho_{\ell}$ is expressed in $\mathrm{mols} / \mathrm{m}^{3}$. 
Remember, this formula applies only to the recoils from the $\alpha$-decay of Po: a different constant would apply to the nuclei of other elements, because $Z_{p}$ would be different.

Apfel and his colleagues (Apfel, Sun, and Ravinda 1992) have made much more detailed studies of energy deposition, with computer simulations of both thermal and mechanical effects, than the simple approach of this report.

\subsection{NUCLEATION CENTER FORMATION}

As a simplified model, consider that this linear rate of energy deposition could create a cylinder of fluid at the critical temperature and pressure. In the nomenclature of the precious sections, if $d$ is the average diameter of the heated cylinder, then

$$
\frac{\pi}{4} d^{2} \rho_{c r i t} H_{c a}=\frac{d E}{d x}=4.36 \times 10^{-13} \rho_{\ell} Z_{\ell}
$$

or

$$
d=2 \sqrt{\frac{d E / d x}{\pi \rho_{c r i t} H_{c a t}}} .
$$

First, suppose that the recoil particle has a range that is long compared with the diameter $d$; actually, in many cases it is not so long, but that situation is easy to deal with. Then, imagine that the long cylinder of heated vapor breaks up into separate bubbles, perhaps because of the severe irregularities in its actual diameter (because the recoil loses its energy in a relatively small number of statistically distributed collisions, the energy deposition in any short segment of the track is likely to differ significantly from the average value and, of course, the axis of the cylinder will not be straight).

If the length of the cylinder deforming into a spherical bubble is short (Fig. 9a), then the diameter of the spherical bubble is greater than that length, and some of the small bubbles will touch and coalesce into larger ones.

If, on the other hand, the length of the cylindrical section is much greater than its diameter (Fig. 9b), the resulting sphere has a diameter smaller than the length of its cylindrical progenitor, and in that case the adjacent spheres will not touch and coalesce.

The limiting case, with the spherical bubblets arrayed like pearls on a string, just touching each other, occurs when

$$
\frac{\pi d^{2}}{4} \ell=\frac{4 \pi}{3}\left(\frac{\ell}{2}\right)^{3}
$$

or

$$
\ell=\sqrt{\frac{3}{2}} d \approx 1.225 d
$$



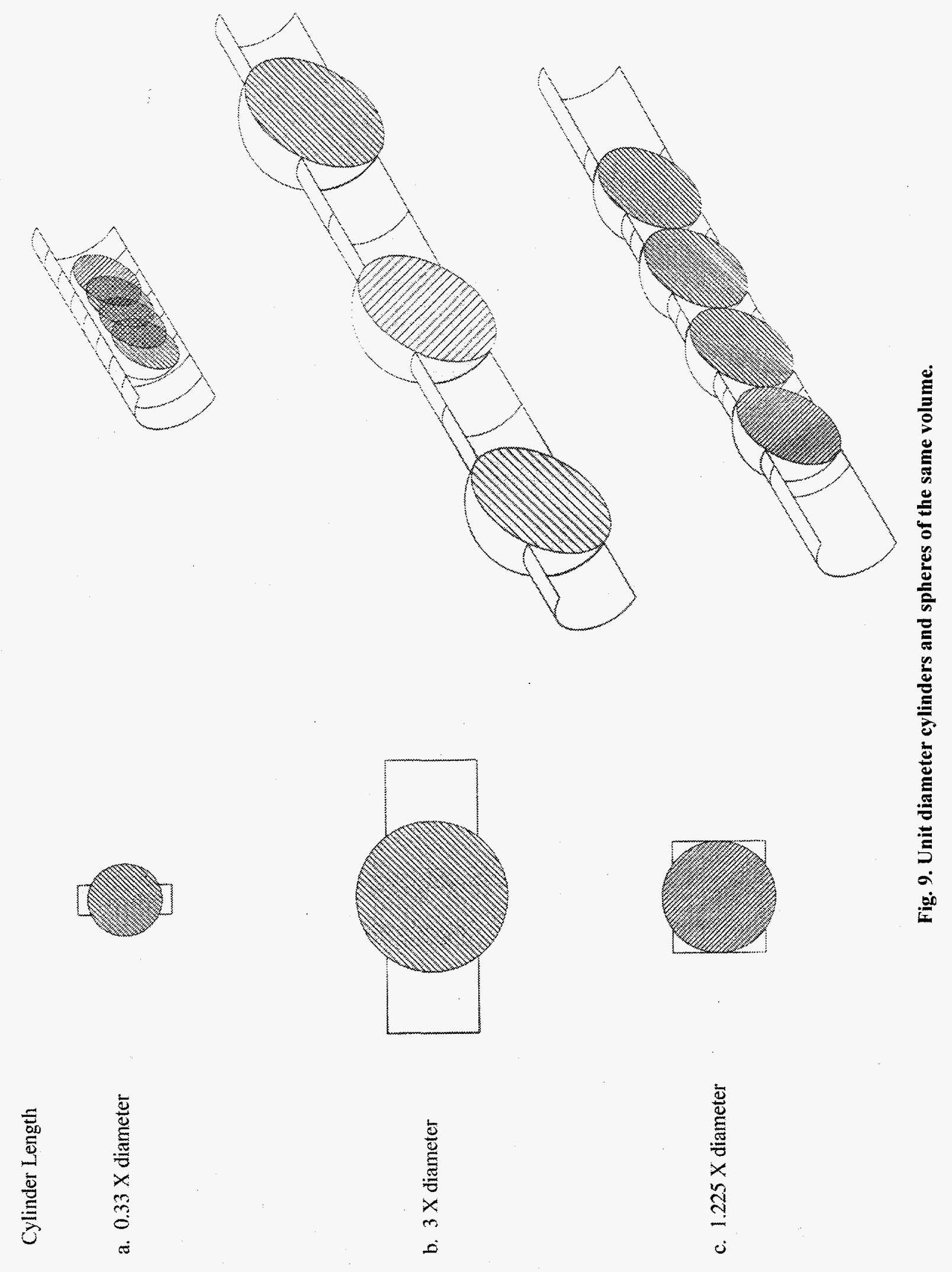
See Fig. (9c). Or, substituting for $d$ from Eq. (53),

$$
\ell=\sqrt{\frac{6 d E / d x}{\pi \rho_{c r i t} H_{c a}}}
$$

The energy available to form this bubble is $\ell d E / d x$, the length of track within the cylindrical section $\times$ the linear energy deposition rate, so

$$
E_{a v}=\ell \frac{d E}{d x}=\sqrt{\frac{6(d E / d x)^{3}}{\pi \rho_{c r i t} H_{c u}}}
$$

The volume of the cylindrical section, and of the spherical bubble formed from it, is

$$
V_{o}=\pi \frac{d^{2}}{4} \ell=\pi \sqrt{\frac{3}{32}} d^{3},
$$

or, substituting for $d$ from Eq. (53),

$$
V_{0}=\sqrt{\frac{6}{\pi}\left(\frac{d E / d x}{\rho_{c r i l} H_{c a}}\right)^{3}} .
$$

Bubbles formed from cylindrical sections shorter than the length defined by Eq. (55) will touch and coalesce, thereby growing. But what about longer sections-could a line of larger, but separated, bubbles form?

My argument is that the irregularities in the recoil particle's track will create localized regions of higher and lower energy deposition, on a scale small compared with the total track length. These localized regions will form tiny overlapping bubbles, each smaller than the size given by Eq. (56). Adjacent bubbles will coalesce, but once a bubble of diameter $\sqrt{3 / 2 d}$ has been formed in this way, it will not be in contact with the adjacent bubble of the same size or smaller. Therefore, there will be no more coalescence. Equation (56) therefore represents the volume of the largest nucleation centers along the particle's track.

The mass of fluid in the bubble is $M_{o}=V_{o} \rho_{c r i t}$

$$
\therefore M_{o}=\sqrt{\frac{6}{\pi \rho_{c r i l}}\left(\frac{d E / d x}{H_{c a}}\right)^{3}} \text {. }
$$


For good physical reasons, exactly the same algebraic results follow from asking the simpler question, "What size of sphere can be raised to the critical point by the energy deposited along a length equal to its own diameter?" In this case, $M_{o} H_{c a}=$ diameter $\times d E / d x$, or

$$
V_{o} \rho_{c r i t} H_{c a}=\sqrt[3]{\frac{6 V_{o}}{\pi}} \cdot d E / d x
$$

therefore,

$$
V_{0}=\sqrt{\frac{6}{\pi}\left(\frac{d E / d x}{\rho_{c r i t} H_{c a}}\right)^{3}},
$$

which is the same as Eq. (58).

The energy that might be used in place of the full recoil energy, in the equations derived earlier in this report, is $\ell d E / d x$, given by Eq. (57). However, in some cases the actual track length of the recoil, according to Bohr's formula, is less than the length $\ell$. In that event, the quantity $\ell d E / d x$ would be greater than $E_{\text {recoil }}$, but of course only the recoil energy is actually available. In the language of TK Solver, this can be written

$$
E_{a v}=\operatorname{MIN}\left(\ell d E / d x, E_{\text {recoil }}\right)
$$

or, in words, the available energy is the lesser of $\ell d E / d x$ and $E_{\text {recoil }}$. Substituting for $\ell d E / d x$ from Eq. (57) yields

$$
E_{a v}=M I N\left(\sqrt{\frac{6(d E / d x)^{3}}{\pi \rho_{c r i t} H_{c a}}}, E_{\text {recoil }}\right)
$$

To show the impact of these considerations, Table 15 compares the recoil energy with $\ell d E / d x$, and $E_{a,}$, calculated as above, for the liquids whose cavitation threshold was reported by Hahn. 
Table 15. Energy available for bubble formation

\begin{tabular}{lccc}
\hline \multirow{2}{*}{ Material } & \multicolumn{3}{c}{ Energy, keV } \\
\cline { 2 - 4 } & $E_{\text {recoil }}$ & $\begin{array}{c}\text { edE/dx } \\
\text { Eq. (54) }\end{array}$ & $\begin{array}{c}E_{a v} \\
\text { Eq. (61) }\end{array}$ \\
\hline Isopentane & 101 & $\mathbf{4 7}$ & $\mathbf{4 7}$ \\
Freon 113 & 166 & $\mathbf{1 3 9}$ & $\mathbf{1 3 9}$ \\
Freon 113 & $\mathbf{1 0 1}$ & 139 & $\mathbf{1 0 1}$ \\
n-hexane & 101 & $\mathbf{4 7}$ & $\mathbf{4 7}$ \\
Acetone & 101 & $\mathbf{5 2}$ & $\mathbf{5 2}$ \\
Trichloroethylene & $\mathbf{1 0 1}$ & 110 & $\mathbf{1 0 1}$ \\
Ethylene bromide & $\mathbf{1 0 1}$ & 158 & $\mathbf{1 0 1}$ \\
Acetophenone & 101 & $\mathbf{5 8}$ & $\mathbf{5 8}$ \\
Cyclohexanol & 101 & $\mathbf{5 6}$ & $\mathbf{5 6}$ \\
\hline
\end{tabular}

\subsection{CALCULATION OF CAVITATION THRESHOLD}

Write

$$
\begin{gathered}
\frac{d E}{d x}=\frac{\pi \hbar^{2}}{\mu} Z_{p}^{2 / 3} Z_{\ell} N \rho_{\ell} \\
V_{o}=\sqrt{\frac{6}{\pi} \cdot\left(\frac{d E / d x}{\rho_{c r i t} H_{c a}}\right)^{3}} \\
E_{a v}=M I N\left(\sqrt{\frac{6(d E / d x)^{3}}{\pi \rho_{c r i t} H_{c a}}}, E_{\text {recoil }}\right) \\
U_{o}=E_{a v}-\rho_{c r i t} V_{o}
\end{gathered}
$$

from Eq. (51),

from Eq. (58),

from Eq. (61),

from Eq. (18), 


$$
\begin{aligned}
& a=-8 \eta_{e f f} D \cdot \frac{4 \pi}{3 P_{c r i t} V_{o}} \cdot\left(1+3 \frac{P_{c r i t} V_{o}}{U_{o}}\right) \\
& b=-2 \sigma \cdot \frac{4 \pi}{3 P_{c r i t} V_{o}} \cdot\left(1+\frac{3}{2} \frac{P_{c r i t} V_{o}}{U_{o}}\right)
\end{aligned}
$$

from Eq. (42b).

Then the calculated thresholds for low and high viscosity situations are derived by substituting the above expressions into Eqs. (44) and (50). From Eq. (44),

$$
P_{n e g}(62)=\frac{3 P_{c r i t} V_{o}}{4 \pi\left(1+P_{c r i t} V_{o} / U_{o}\right)} \cdot \frac{1}{27}\left[2\left(a^{2}-3 b\right)^{3 / 2}-2 a^{3}+9 a b\right],
$$

and from Eq. 50, substituting $E_{a r}$, for $E_{\text {recoil }}$

$$
P_{n e g}(63)=2 \sigma \sqrt[3]{\frac{4 \pi \rho_{c r i t} H_{c u t}}{3 E_{c v}}}
$$

The calculated negative pressure threshold for radiation-induced cavitation is

$$
P_{\text {neg }}(\text { threshold })=\operatorname{MIN}\left[P_{\text {neg }}(62), P_{\text {neg }}(63)\right]
$$

Table 16 shows the results from these equations, including $E_{a r}, P_{n e g}(62)$, and $P_{\text {neg }}(63)$.

The calculated thresholds [Eq. (64)] and the experimental values are plotted in Fig. 10: there is a reasonable straight line fit, with a slope of almost exactly unity and only a small intercept.

The details of the fit are not as good as some of the earlier, simpler equations - in particular, the calculated values for isopentane and Freon 113 are badly out of order-but the high viscosity cyclohexanol has been successfully brought into the fit. And the average slope is now right.

It is perhaps worth remarking that the Bohr formula for the $d E / d x$ of slow, heavy particles is well recognized to be only an approximation. Riepe and Hahn quoted results from another formula differing from the Bohr approximation by as much as $15 \%$ and also experimental results that differed from the calculations by more than $50 \%$. Such a difference, for example, would change the calculated values of some thresholds by as much as $30 \%$.

Furthermore, it is an assumption of Bohr's range calculation that the mass of the energetic recoil particle is very much greater than the mass of the nuclei in the medium it is traversing; otherwise, the particle would essentially diffuse rather than pursue a definite track. This assumption is probably valid 
Table 16. Calculated and measured cavitation thresholds

\begin{tabular}{lccccc}
\hline \multirow{2}{*}{ Material } & $\begin{array}{c}\text { Available energy } \\
(\mathrm{keV})\end{array}$ & $P_{\text {neg }}(62)$ & $P_{\text {neg }}(63)$ & $P_{\text {neg }}(64)$ & Exptl. \\
\cline { 3 - 5 } & 47 & $\mathbf{3 . 4 2}$ & 12.46 & $\mathbf{3 . 4 2}$ & 3.34 \\
Isopentane & 139 & $\mathbf{2 . 6 6}$ & 10.49 & $\mathbf{2 . 6 6}$ & 4.49 \\
Freon 113 & 101 & $\mathbf{3 . 2 1}$ & 11.68 & $\mathbf{3 . 2 1}$ & 5.21 \\
Freon 113 & 47 & $\mathbf{5 . 8 1}$ & 16.60 & $\mathbf{5 . 8 1}$ & 6.89 \\
n-hexane & 52 & $\mathbf{6 . 8 7}$ & 21.69 & $\mathbf{6 . 8 7}$ & 8.31 \\
Acetone & 101 & $\mathbf{6 . 5 4}$ & 21.31 & $\mathbf{6 . 5 4}$ & 11.75 \\
Trichloroethylene & 101 & $\mathbf{1 3 . 0 6}$ & 30.92 & $\mathbf{1 3 . 0 6}$ & 22.19 \\
Ethylene bromide & 58 & 45.51 & $\mathbf{4 0 . 4 4}$ & $\mathbf{4 0 . 4 4}$ & 33.23 \\
Acetophenone & 56 & 8925.87 & $\mathbf{3 5 . 3 5}$ & $\mathbf{3 5 . 3 5}$ & 48.74 \\
Cyclohexanol & & & &
\end{tabular}

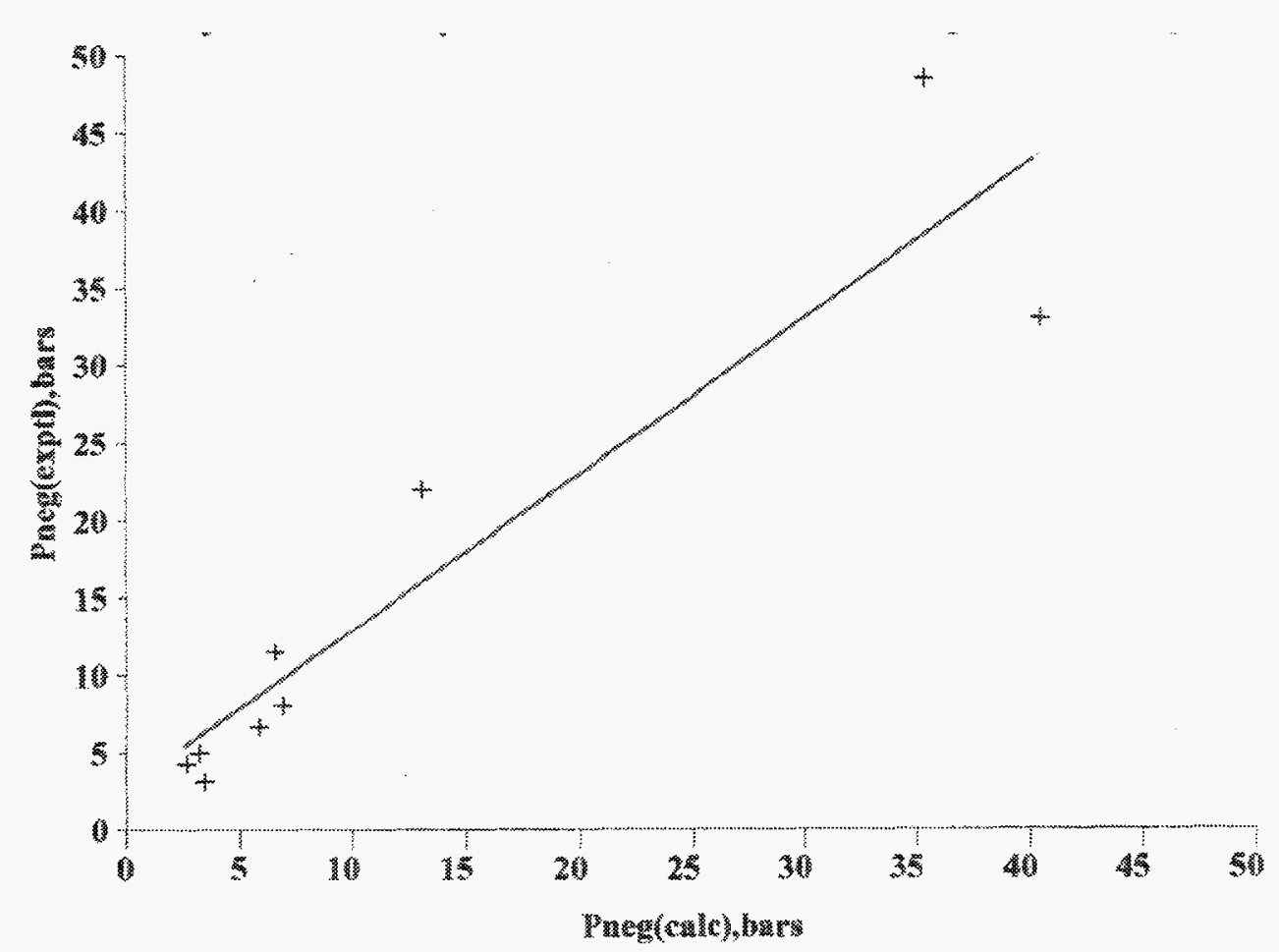

Fig. 10. $P_{\text {neg }}$ (exptl) vs $P_{\text {neg }}$ [calc, variable mT model, Eq. (64), using $E_{\text {av }}$ ]. Static and dynamic terms. Cyclohexonal included. $R^{\wedge} 2=0.960$, slope $=1.01$, intercept $=2.9$. 
for the liquids containing only hydrogen, carbon, and oxygen. It is not really valid for liquids containing chlorine or bromine atoms. Therefore, one might expect my calculation of $E_{a r}$ to be even more suspect for Freon, trichloroethylene, and ethylene bromide than for the other liquids. It is possible that this observation is relevant to the fact that Eq. (64) wrongly orders the thresholds for isopentane and Freon 113, while also significantly underestimating the thresholds for trichloroethylene and ethylene bromide.

Considering the number of effects to be considered (including homogeneous nucleation thresholds, bubble growth thermodynamics, dynamic effects, and the energy deposition rates of nuclear particles), I regard Fig. 10 as a good result, especially in comparison with the earlier model that produced Fig. 4, which excluded the high viscosity cyclohexanol case and still had a slope of 14 with a correlation coefficient of only 0.66 .

For interest, Table 17 shows the continuing improvement in the agreement between calculated and experimental results, in terms of the slope of a graph of one against the other, as the successively more comprehensive models in this report are applied. It is, however, interesting, and somewhat puzzling, that the correlation coefficient does not continuously improve, although it probably remains acceptable.

The fact that the intercept of the graphs is not zero is less troublesome. At low thresholds $\left(P_{n e g} / 2<P_{v a p}\right)$, the models would not be applicable anyway. Certainly the final model's incorrect predictions that the Freon threshold would be lower than the isopentane one and that the threshold for trichloroethylene would be lower than for acetone, is more disturbing than the nonzero intercept or the lower correlation coefficient.

Table 17. Evolution of the model

\begin{tabular}{lcccccccc}
\hline Model & Equation & Figure & $\begin{array}{c}\text { Cyclohexanol } \\
\text { included? }\end{array}$ & $\begin{array}{c}\text { Dynamic } \\
\text { effects? }\end{array}$ & $\begin{array}{c}d E / d x \\
\text { effects? }\end{array}$ & & & \multicolumn{2}{c}{ Straight-line fit to experiment } \\
\hline$R_{c r i t}$ & & 4 & No & No & No & 13.9 & -13.9 & 0.66 \\
$m T$ & $(17)$ & 5 & No & No & No & 2.9 & -2.5 & 0.99 \\
$m T$ & $(27)$ & 6 & No & No & No & 2.8 & -2.6 & 0.99 \\
$m T$ & $(44),(50)$ & 8 & Yes & Yes & No & 1.5 & 1.2 & 0.96 \\
$m T$ & $(64)$ & 10 & Yes & Yes & Yes & 1.0 & 2.8 & 0.86 \\
\hline
\end{tabular}




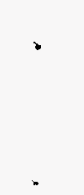




\section{SUMMARY}

In 1961, Georg Riepe's Ph.D. research at the University of Fribourg had shown that nucleation of bubbles in the superheated liquid of a bubble chamber was quantitatively explained by the Sietz thermal spike theory - at least for the case of bubble formation by the heavy, slow nuclei recoiling from alpha decay (Riepe and Hahn 1961).

Two years later, another paper from the same laboratory reported that in cold liquids, "superheated" by application of a tensile stress, there was an order of magnitude discrepancy between the experimental results and the predictions of the same theory that had served Riepe so well (Hahn and Peacock 1963).

In 1967, a new report, from a different laboratory, provided a physical model of the criteria for bubble formation that offered a reason for the difference in behavior under irradiation of hot superheated liquids and cold ones, but the quantitative predictions for bubble nucleation under negative pressures, although improved over the earlier theory, were still in poor agreement with the experimental data (West 1967).

The present report amends and extends the 1967 theory, here called the $m T$ model. Predictions and experimental data, from the few measurements available of bubble formation by slow, heavy particles in liquids under negative pressure, are now in reasonably good agreement, even for those liquids where dynamic effects (viscous and kinetic energy losses) are significant or dominant. For this author, it provides some satisfaction to see progress in a puzzle that has been bothersome for more than 30 years.

The initial impetus for the work described here arose from the Spallation Neutron Source (SNS) Project. The SNS will have a liquid mercury target which may, under certain circumstances, be subject to negative pressure transients. I plan a separate, shorter report applying the above theory specifically to mercury. 


\section{ACKNOWLEDGMENTS}

I am most grateful for Dr. Georg Riepe's interest in this work, for his helpful advice and insights-his observation, one day, that in an ideal gas the pressure is proportional to the internal energy per unit volume led me, on later reflection, to the realization that the first $m T$ model had not been physically self consistent-and for his comments on the drafts of this report. Dr. Robert Apfel also made helpful and thoughtful comments on a draft.

Many colleagues at Oak Ridge National Laboratory have been kind enough to listen to descriptions of this work and to offer helpful criticism, advice, and ideas. I thank them for their help and interest. D. M. Williams kindly prepared the drawings in Fig. 9. L. K. Mansur recognized, and pointed out to me, the analogies between the original $m T$ model and a theory later developed to describe onset of swelling in irradiated solids and its dependence upon the helium created in neutron-induced transmutation reactions.

Because of the potential significance of radiation-induced cavitation in the liquid mercury target of

the proposed new SNS, John Haines of that project's target team kindly provided encouragement for the work and support for the publication of this report. 


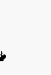

. 


\section{REFERENCES}

Apfel, R. E. (1979): “The Superheated Drop Detector." Nucl. Instr. and Meth. 162, 603-608.

Apfel, R. E. (1972): “The Tensile Strength of Liquids.” Scientific American 227, 6, 58-71, December.

Apfel, R. E. (1971): "A Novel Technique for Measuring the Strength of Liquids." Inl. Acoustical Soc. Am. 49, 1(Part2), 145-155.

Apfel, R. E., Sun, Y. Y. and Ravinda, Nath (1992): "Transient Thermal and Mechanical Response of Water Subject to Ionizing Radiation.” Radiat. Res. 131, 124-132.

ASTM (1992): "Standard Practice for the Use of the International System of Units (SI)..." E380-92.

Bertanza, L., Franzini, P., Martelli, G. and Tallini, B. (1956): "An Attempt to Control a Bubble Chamber by Counters." CERN Symposium on High Energy Accelerators and Pion Physics, Geneva, 11-23 June, 1956, 29-30.

Berthelot, M. (1850): "Sur Quelques Phénomènes de Dilatation Forcée des Liquides." Ann. de Chimie et de Physique, 3rd Serie, Tome XXX, 232-237 and Plate II.

Bohr, N. (1948): "Penetration of Atomic Particles Through Matter." Det Kgl. Danske Vidensabernes Selskab., Mathematisk-Gysiske Meddalelser XVIII, 8.

Briggs, L. J. (1949): “A New Method for Measuring the Limiting Negative Pressure in Liquids." Science 109, 440, April 29.

Bugg, D. V. (1959): "The Bubble Chamber." Progress in Nucl. Phy. 7, 1-52, O. R. Frisch, ed., Pergamon Press.

Carey, Van P. (1992): "Liquid-Vapor Phase-Change Phenomena." ISBN 0-89116-836-2, Taylor \& Francis.

Dietrich, L. W. and Connolly, T. J. (1973): "A Study of Fission-Fragment-Induced Nucleation of Bubbles in Superheated Water." Nucl. Sci. and Eng. 50, 273-282.

Donny, M. F. (1846): "Sur la Cohésion des Liquides, et sur leur Adhérence aux Corps Solides." Ann. de Chimie et de Physique 3, XVI, 167-190 and Plate I.

Dufour, L. and Dufay, R. (1963): “Thermodynamics of Clouds." Int. Geophys. Ser. V.006, Academic Press.

El-Nagdi, M. M. and Harris, M. J. (1971): "Experimental Study of Radiation-Induced Boiling in Superheated Liquids." Jnl. Brit. Nucl. Eng. Soc. 10, 2, 131-139.

Finch, R. D. (1964): "Influence of Radiation on the Cavitation Threshold of Degassed Water." Jnl. Acoustical Soc. Am. 36, 12, 2287-2292, December. 
Glaser, D. A. (1964): "Elementary Particles and Bubble Chambers." Nobel Lectures in Physics 1942-1962 (1960 lecture), Elsevier.

Glaser, D. A. (1958): "The Bubble Chamber." Encyclopedia of Physics, vol XLV, Nuclear Instrumentation II, S. Flügge ed., Springer-Verlag.

Glaser, D. A. and Rahm, D. C. (1955): "Characteristics of Bubble Chambers." Physical Review 97, 2, 474-479.

Greenspan, M. and Tscheig, C. E. (1967): "Radiation-Induced Acoustic Cavitation; Apparatus and Some Results." Jnl. Res. National Bureau of Standards-C. Engineering and Instrumentation 71C, 4, 299-312, October-December.

Hahn, B. (1961): "The Fracture of Liquids Under Stress Due to Ionizing Particles." Nuovo Cimento 22, $650-653$.

Hahn, B. and Peacock, R. N. (1963): "Ultrasonic Cavitation Induced by Neutrons." Nuovo Cimento 28, 2, 334-340, April 16.

Hugentobler, E., Hahn, B., and Steinrisser, F. (1953): "Relativistischer Zuwachs der Blasendichte von Spuren Schneller Teilchen in einer Freon-Blasenkammer," Helv. Phys. Acta 36, 301.

Hughes, A. L. (1960): "An Exploration of the Possibility of Employing Ultrasonic Radiation to Sensitize a Bubble Chamber." Proc. Intl. Conf. On Instrumentation for High Energy Physics, E. O. Lawrence Radiation Laboratory, Berkeley, California, Sept 12-14, II b.1.

Korn, G. A. and Korn, T. M. (1968): Mathematical Handbook for Scientists and Engineers. 2nd Edition, McGraw-Hill.

Lieberman, D. (1959): "Radiation-Induced Cavitation." Phys. Fluids 2, 4, 466-468.

Lo, Y-C. and Apfel, R. E. (1988): "Prediction and Experimental Confirmation of the Response Function for Neutron Detection Using Superheated Drops." Physical Review A 38, 10, 5260-5266, Nov. 15.

Mansur, L. K. et al. (1986): "Control of Helium Effects in Irradiated Materials Based on Theory and Experiment," Jnl. of Nuclear Materials, 141-143, pp. 633-646.

Milburn, J. and Johnson, R. P. C. (1966): "The Conduction of SAP II. Detection of Vibrations Produced by Sap Cavitation in Ricinus Xylem." Planta (Berlin) 69, 43-52.

Peyrou, Ch. (1967): "Bubble Chamber Principles." Bubble and Spark Chambers, Vol. 1, ChII, 19-58, R. P. Shutt, ed., Academic Press.

Pless, I. A. and Plano, R. J. (1956): "Negative Pressure Isopentane Bubble Chamber." Rev. Sci. Instr. 27, 11, 935-937, November.

Rice-Evans, P. (1973): "Towards the Triggered Bubble Chamber." Nucl. Instr. and Meth. 109, 525-527.

Riepe, G. and Hahn, B. (1961): "Untersuchungen zum Mechanismus der Blasenbildung in Freon-12 und Propan durch Rückstosskerne einiger $\alpha$-Strahler.” Helv. Phys. Acta 34, 8, 865-892. 
Scholander, P. F. et al. (1965): “Sap Pressure in Vascular Plants.” Science 148, 339-345, April 16.

Seitz, F. (1958): “On the Theory of the Bubble Chamber." Phys. Fluids 1, 1, 2-13.

Sette, D. and Wanderlingh, F. (1962): "Nucleation by Cosmic Rays in Ultrasonic Cavitation." Phys. Review 125, 2, 409-417, Jan. 15.

Spadavecchia, A. and Hahn, B. (1967): "Die Rotationskammer and Einige Anwendungen." Helv. Phys. Acta 40, 1063-1079.

Sun, Y. Y., Chu B. T., and Apfel, R. E. (1992a): "Radiation-Induced Cavitation Process in a Metastable Superheated Liquid I. Initial and Pre-bubble Formation Stages." Jnl. Comp. Phys. 103, 116-125.

Sun, Y. Y., Chu B. T., and Apfel R. E. (1992b): "Radiation-Induced Cavitation Process in a Metastable Superheated Liquid II. Interface Formation and Post-interface Formation Stages." Jnl. Comp. Phys. 103, $126-140$.

Tenner, A. G. (1963): "Nucleation in Bubble Chambers." Nucl. Instr. and Meth. 22, 1-42, March.

West, C. and Howlett, R. (1969): "Experimental Measurements on Cavitation Bubble Dynamics." Acustica 21, 112-117.

West, C. and Howlett, R. (1968): "Some Experiments on Ultrasonic Cavitation Using a Pulsed Neutron Source." Brit. Inl. Appl. Phys. (J. Phys. D), Ser 2, Vol 1, 247-254.

West, C. D. (1967): “Cavitation Nucleation by Energetic Particles.” AERE-R5486, June.

Wilson, J. G. (1951): The Principles of Cloud Chamber Technique. Cambridge University Press.

Worthington, A. M. (1892): "On the Mechanical Stretching of Liquids: an Experimental Determination of the Volume Extensibility of Ethyl-Alcohol." Phil. Trans. (A) 183, 355-370 and Plate 10. In this paper, Worthington credits $O$. Reynolds with the invention of a centrifugal method of placing liquids under negative pressure, but I have so far been unable to obtain a copy of, or even an unambiguous reference for, Reynolds' publication on the subject.

Yaws, C. L. (1996): “Floppy Disk Databases of Thermodynamic and Transport Properties." TREI, 685 


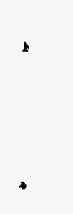




\section{LIST OF SYMBOLS}

Symbol

alpha

$a$

$b$

$c$

$C_{e}$

$d$

$\sigma$

$\sigma_{e f f}$

$D$

$d E / d x$

$E_{a r}$

$E_{\text {recoil }}$

$\hbar$

$H_{c a}$

$H(T)$

$H_{r}$

$H_{r r}$

$H_{\text {yo }}$

$\ell$

$M_{o}$

$M(r)$

Mwt

$N$

$\eta$

$\eta_{\text {eff }}$

$p$

$\rho_{\text {crit }}$

$\rho_{\ell}$

$\rho_{r}$

$P_{c r i i}$

$P_{\text {int }}(r)$

$P_{e x t}$

$P_{\text {neg }}$

$P_{\text {vap }}$

$P_{\text {ir }}$

$P_{\text {rrcrit }}$

$q$

$r$

$\dot{r}$

$r^{*}$

$r_{\text {crit }}$

$r_{e q}$

$R$

$R_{o}$

$R^{2}, \mathrm{R}^{\wedge} 2$

\section{Definition}

Ratio of the vapor pressure over a concave surface of radius $r_{\text {crii }}$ to that over a plane surface Coefficient of the quadratic term in a nonreduced cubic: Eq. (39)

Coefficient of the linear term in a nonreduced cubic: Eq. (39)

Constant in a nonreduced cubic: Eq. (39)

Specific heat of the liquid

Average diameter of heated cylinder

Surface tension

Effective surface tension including the Bugg term

Thermal diffusivity

Linear rate of energy deposition

Energy available to form the nucleation center

Energy of recoil from $\alpha$-decay

Planck's constant $\div 2 \pi$

Enthalpy difference between ambient conditions and the critical point

Enthalpy at temperature $T$

Enthalpy of evaporation

Enthalpy of evaporation from a concave surface of radius $r$

Enthalpy of evaporation from a plane surface

Length of heated cylinder

Quantity (mols) of liquid raised to the critical point

Quantity (mols) of vapor inside the bubble when its radius is $r$

Molecular weight

Avogadro's number

Liquid viscosity

Effective viscosity including kinetic energy losses

Coefficient of linear term in a reduced cubic

Fluid density at the critical point

Liquid density

Vapor density

Critical pressure

Pressure inside the bubble when its radius is $r$

Liquid pressure outside the bubble

Magnitude of the negative pressure in the liquid outside the bubble

Vapor pressure over a plane surface

Vapor pressure over a concave surface of radius $r$

Vapor pressure over a concave surface of radius $r_{\text {crit }}$

Constant in a reduced cubic

Bubble radius

$\mathrm{dr} / \mathrm{dt}$

The "magic" radius, $20 / P_{\text {neg }}$

Critical radius for continued growth: Eq. (1)

In the $m T$ model, the bubble radius at which compressive and expansive terms are equal

Molar gas constant

Radius of a spherical mass $M_{o}$ at the critical point

Correlation coefficient of the linear regression 


$\begin{array}{ll}R_{r} & \text { Recoil range } \\ \tau & \text { Relaxation time of a spherical thermal spike } \\ \tau_{c r i t} & \text { Relaxation time of a spherical thermal spike of radius } r_{c r i t} \\ t & \text { Time } \\ T_{o p} & \text { Operating temperature } \\ T_{c r i} & \text { Critical temperature } \\ \mu & \text { Electron mass } \\ U_{o} & \text { Initial internal energy } \\ U(r) & \text { Internal energy as a function of radius } \\ \mathrm{v}_{c} & \text { Velocity of the bubble wall as it grows to the critical radius } \\ V_{o} & \text { Volume of the mass } M_{o} \text { at the critical pressure and temperature } \\ V(r) & \text { Volume of bubble when its radius is } r \\ W_{s i} & \text { Surface energy } \\ W_{s 2} & \text { Bugg surface energy term } \\ W_{e} & \text { Work done by the expanding bubble on the surrounding liquid } \\ W_{v} & \text { Enthalpy of evaporation of the vapor filling the bubble } \\ W_{4} & \text { Kinetic energy given to the liquid moving away as the bubble expands } \\ W_{5} & \text { Viscous losses in moving away the liquid as the bubble expands } \\ \lambda & \text { Thermal conductivity of the liquid } \\ y_{2}, y_{3} & \text { Real roots of a cubic: Eq. (45) } \\ Z l & \text { Charge number of the liquid molecules } \\ Z p & \text { Charge number of the recoiling nucleus }\end{array}$


APPENDIX A

MEASUREMENTS OF THE PRESSURE THRESHOLD FOR BUBBLE NUCLEATION BY VARIOUS PARTICLES IN VARIOUS LIQUIDS 
,

\section{.}

. 


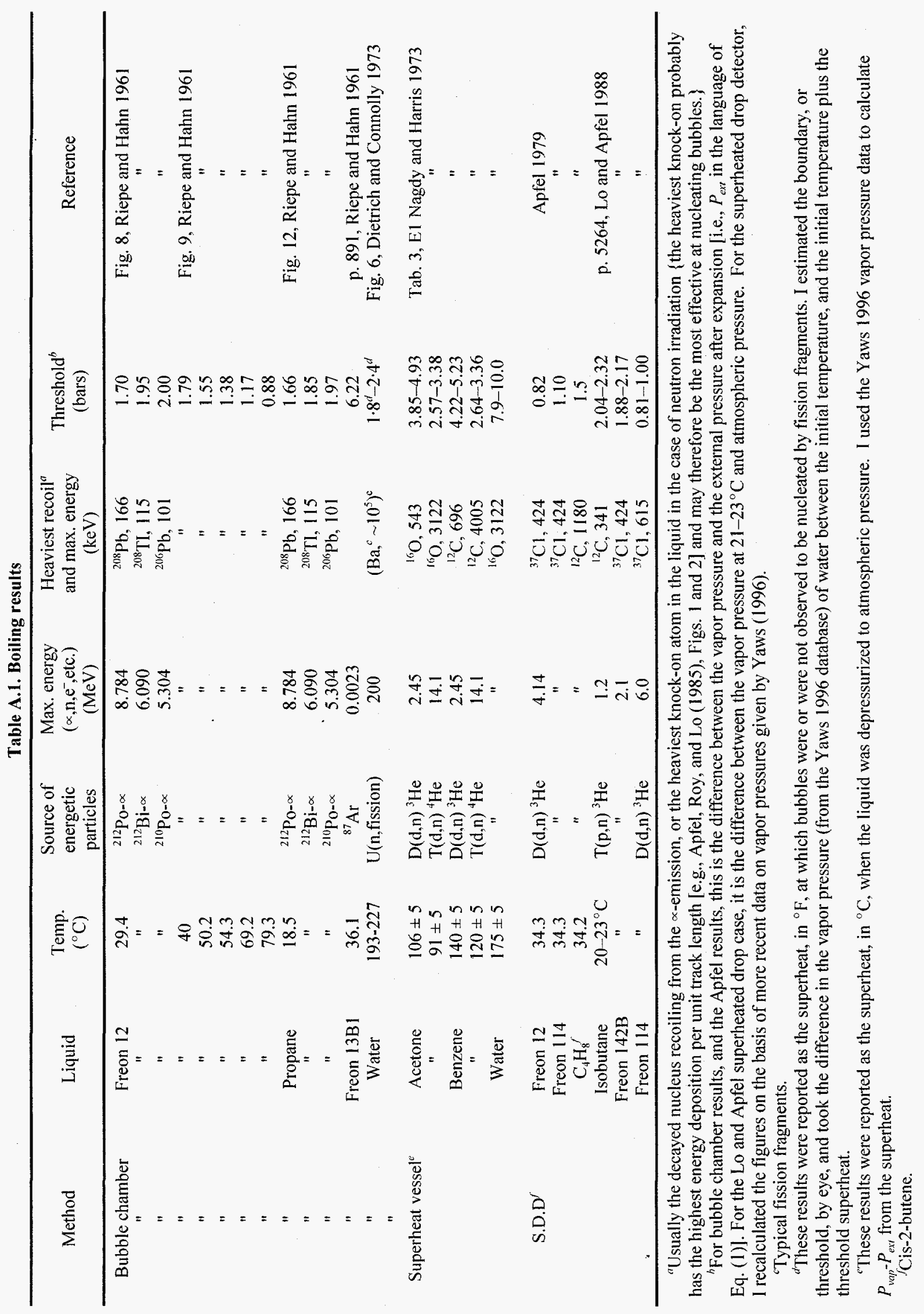




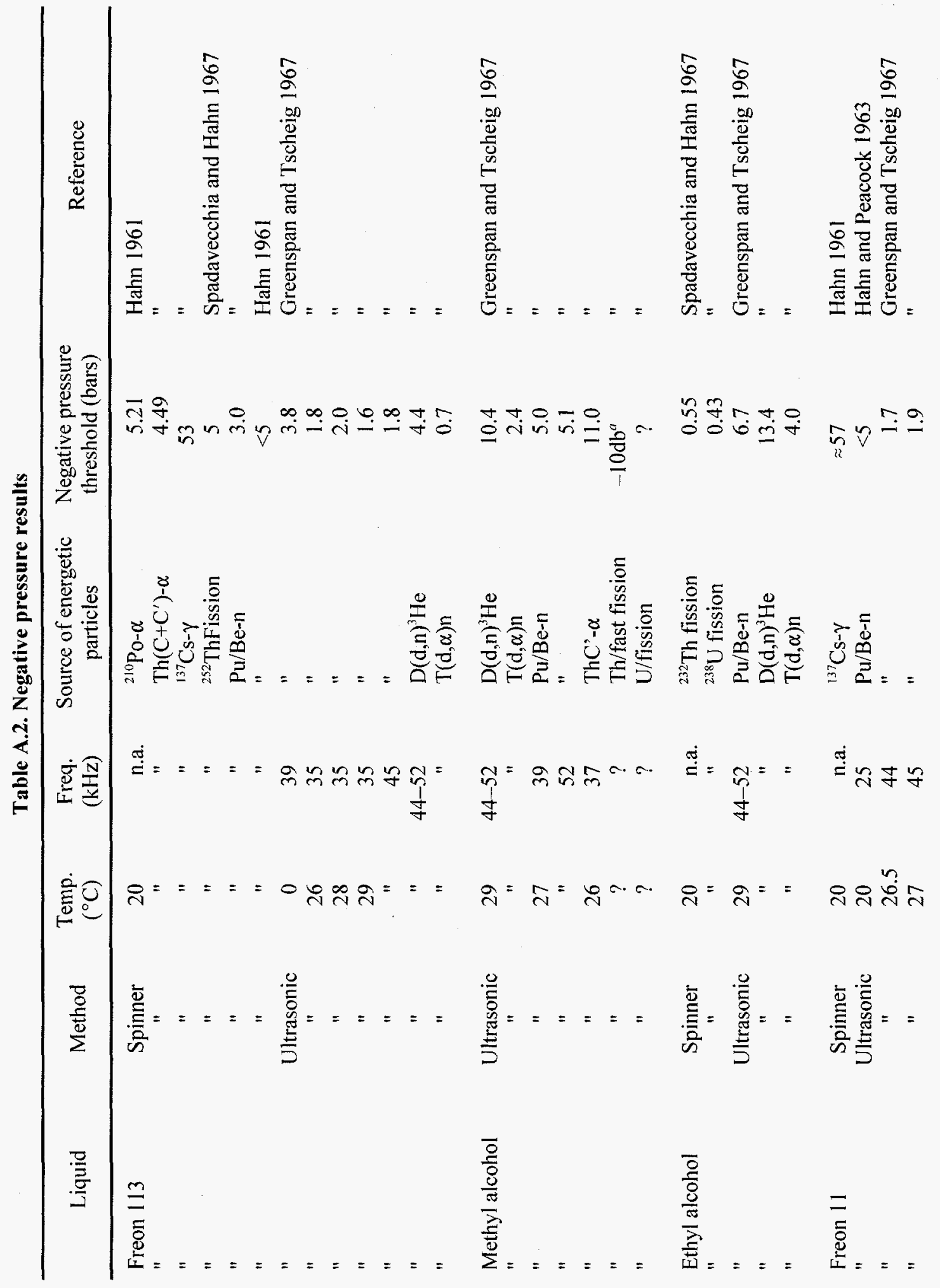




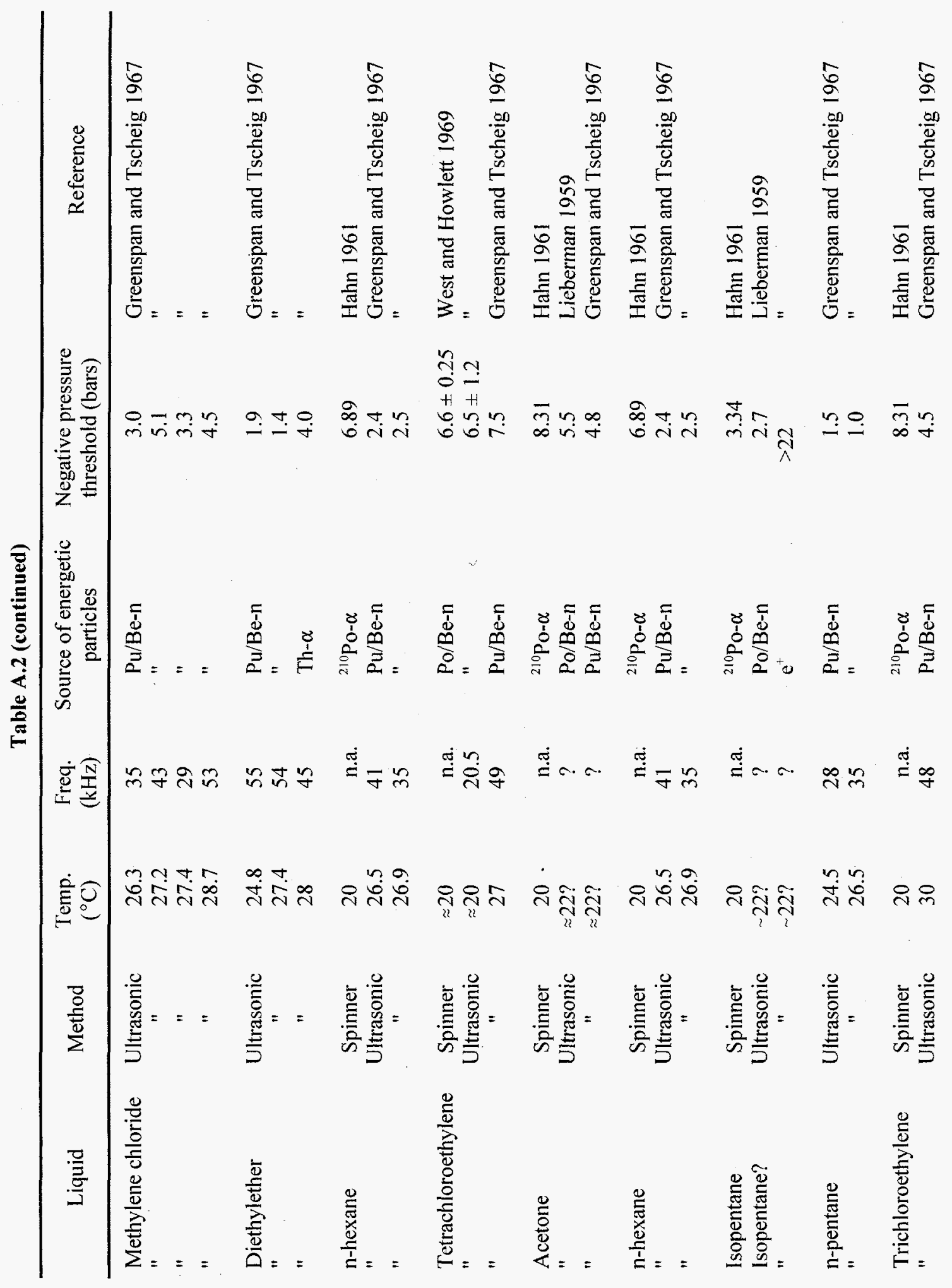




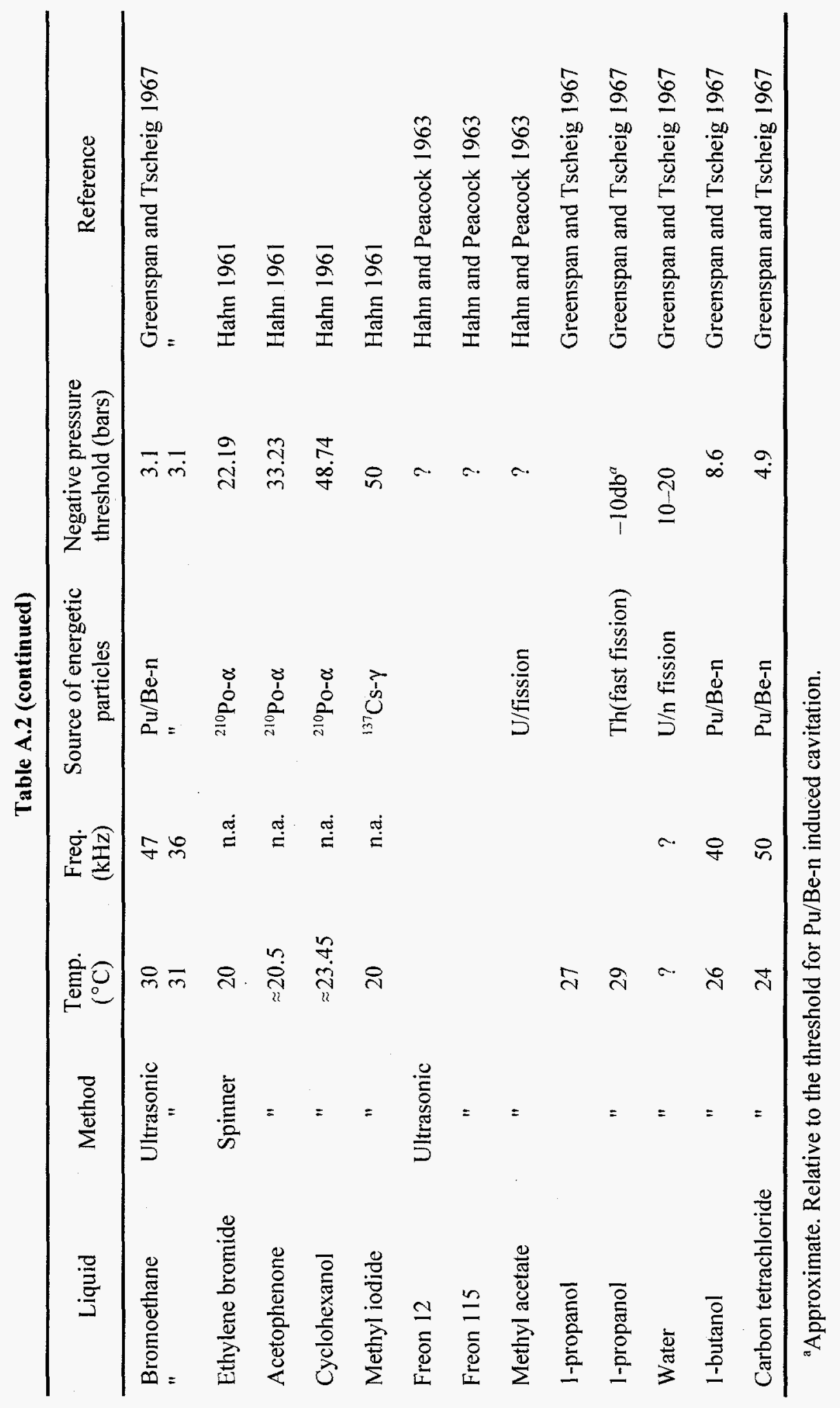


APPENDIX B

EFFECT OF SURFACE CURVATURE ON ENTHALPY OF EVAPORATION 
2

\section{.}

. 


\section{APPENDIX B. EFFECT OF SURFACE CURVATURE ON ENTHALPY OF EVAPORATION}

Not only is the equilibrium vapor pressure higher over the curved surface of a small droplet, compared with a plane surface, but the enthalpy of evaporation is reduced. If the same curvature effects do take place inside a bubble, with the opposite sign, then the enthalpy of evaporation would be increased. However, it seems that the quantitative change would be very small.

Using the formula 8.48 in Dufour and Defay (1963), with a change of nomenclature and substituting $1 / \rho_{\ell}$ for the specific volume of the liquid, one may write, for a concave surface of radius $r$,

$$
H_{v r}=H_{v \infty}+2 \sigma /\left(\rho_{\varphi} r\right)
$$

Enthalpy of evaporation from a surface of radius $r=$ enthalpy of evaporation from a plane surface + $2 \sigma /\left(\rho_{r} r\right)$.

By inspection, we can see that the effect will be larger for liquids with a high value of $2 \sigma / r$, i.e., in those cases where the $\Delta P$ between the bubble interior and the liquid is greatest. Therefore, as an extreme example, take the case of the cyclohexanol results reported in Tables 2 and 3.

$$
\begin{aligned}
H_{v r c r i t}-H_{v o \infty} & =\frac{2 \sigma}{r_{c r i t} \rho_{\ell}} \\
& =\frac{2 \times 33.58 \times 10^{-3}}{13.78 \times 10^{-9} \times 9.605 \times 10^{3}} \\
& =5.1 \times 10^{2}
\end{aligned}
$$

The correction is only $0.5 \mathrm{~kJ} / \mathrm{mol}$ compared with an $H_{v \infty}$ value of $61 \mathrm{~kJ} / \mathrm{mol}$, a correction of less than $1 \%$. In other cases listed in Table 2 , the correction is even smaller. This effect has been ignored in calculating the $W_{p}$ energy term. 


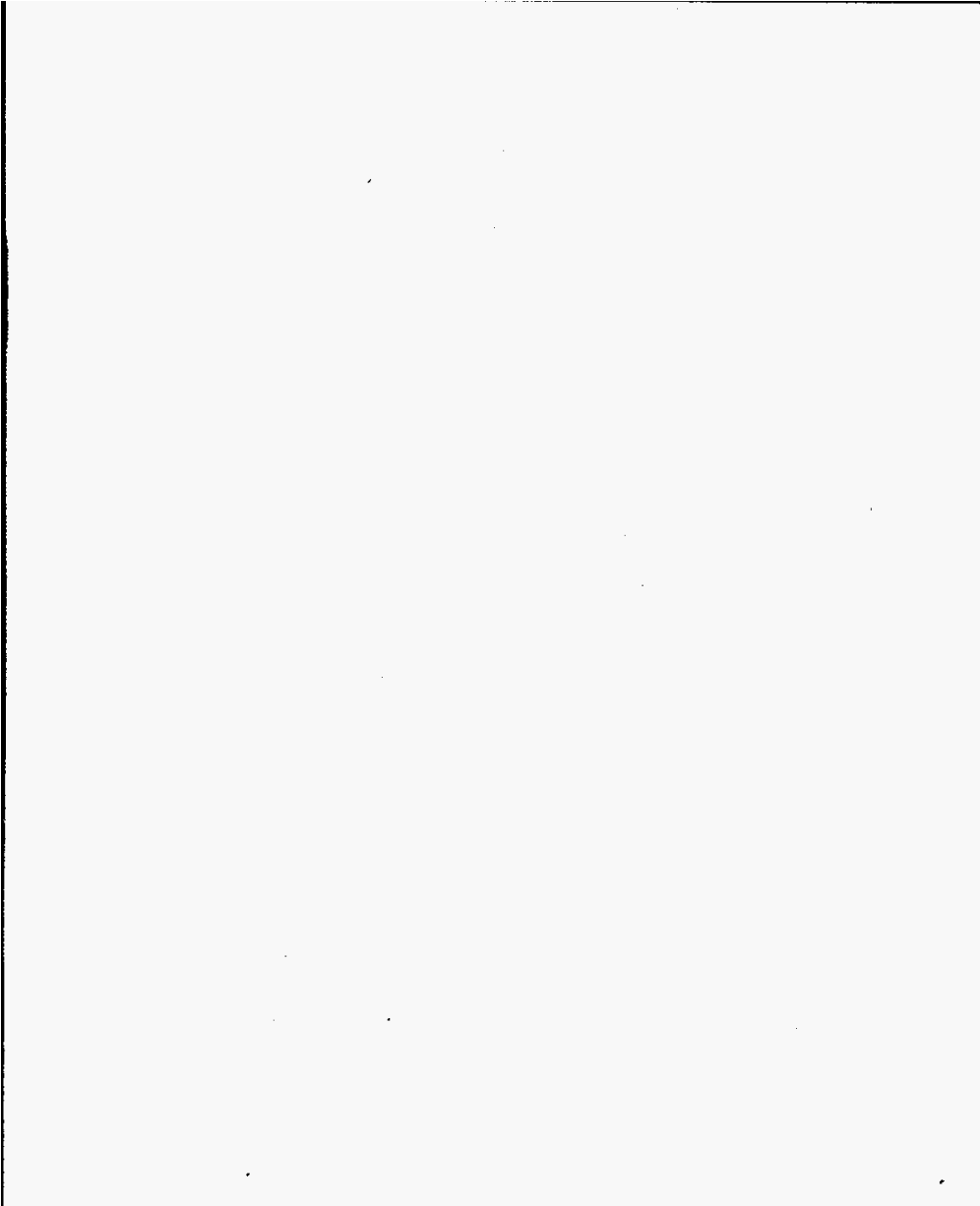




\section{APPENDIX C}

CALCULATIONS ON RIEPE AND HAHN'S BUBBLE CHAMBER EXPERIMENT RESULTS AND COMPARISONS WITH THEIR CALCULATIONS 


\section{APPENDIX C. CALCULATIONS ON RIEPE AND HAHN'S BUBBLE CHAMBER EXPERIMENT RESULTS AND COMPARISONS WITH THEIR CALCULATIONS}

As a check of my own methods, I have recalculated the critical radii and the energy terms using modern values of the liquid and vapor properties (Yaws 1996). I do not know how Riepe and Hahn solved the two nasty simultaneous Eqs. (3) and (4) for the critical radius, but by their standards I probably had it easy, using the automatic iterative solution finder in TK Solver.

This close to the critical temperature, the vapor density used in Eq. (5b) is significantly different from the ideal gas value P/RT. Under the conditions shown in Table 1, the vapor densities given by Yaws are $15-20 \%$ higher than the ideal gas calculation.

First, from Eq. (4) of the main text,

$$
P_{v r c r i t}=P_{v \infty \infty} \exp \left[-2 \sigma /\left(R T \rho_{\ell} r_{c r i t}\right)\right],
$$

and for convenience write

$$
P_{\text {vrcrit }}=\text { alpha } \times P_{\text {vo }} .
$$

Then, by inspection of Eq. (C.1),

$$
\text { alpha }=\exp \left[-2 \sigma /\left(R T \rho_{\ell} r_{c r i l}\right)\right] \text {, }
$$

which allows one to rewrite Eq. (3) from the main text of this report as

$$
r_{c r i l}=2 \sigma /\left(a l p h a \times P_{\nu \infty}-P_{e x t}\right),
$$

and in the Riepe and Hahn experiments, $P_{\text {ext }}$ is equal to the initial (i.e., vapor) pressure of the chamber minus the measured pressure drop, $\Delta P$, resulting from the expansion (i.e., $\Delta P$ is the pressure drop measured by Riepe and Hahn). Therefore,

$$
r_{c r i l}=2 \sigma /\left[\text { alpha } \times P_{\nu \infty}-\left(P_{v \infty}-\Delta P\right)\right]
$$

or

$$
r_{c r i t}=2 \sigma /\left[\Delta P-(1-\text { alpha }) P_{v \infty}\right] .
$$


Given a reasonable guess, or estimate, as a starting point, TK Solver can iteratively solve the two simultaneous Eqs. (C.3) and (C.5) for $r_{c r i t}$ and alpha. I normally used alpha $=1.0$ as that guess. Once alpha and $r_{\text {crit }}$ are known, $P_{\text {rrcrit }}$, the vapor pressure expected inside the critical bubble, is easily evaluated from Eq. (C.2). The vapor density can then be obtained from the Yaws data base. Table C.1 summarizes the results for the two liquids shown in Table 1 of the main text.

The actual TK Solver models and the input data are shown at the end of this appendix. The results are summarized in Table C.1, which also shows, in the last two lines, the difference between the Yaws value for the vapor density and the ideal gas value, $\mathrm{P} / \mathrm{RT}$, at the same temperature and pressure.

In a separate calculation, one can then compute the vapor content of the bubble and evaluate Eqs. (5a) through ( $5 \mathrm{~d}$ ) for comparison with Table 1. The properties needed for these computations are shown in Table C.2: I have converted the Yaws data to SI units where necessary, using the conversion factors in ASTM (1992).

Table C.1. Calculated parameters of critical bubbles

\begin{tabular}{|c|c|c|}
\hline \multicolumn{3}{|c|}{ Material } \\
\hline Name & Freon 12 & Propane \\
\hline Composition & $\mathrm{CCl}_{2} \mathrm{~F}_{2}$ & $\mathrm{C}_{3} \mathrm{H}_{8}$ \\
\hline \multicolumn{3}{|c|}{ Conditions } \\
\hline Temperature, ${ }^{\circ} \mathrm{C}$ & 29.4 & 18.5 \\
\hline Measured $\Delta P, \mathrm{~Pa}$ & $200 \times 10^{3}$ & $197 \times 10^{3}$ \\
\hline \multicolumn{3}{|c|}{ Properties (Yaws) ${ }^{a}$} \\
\hline Molecular weight & 120.913 & 44.096 \\
\hline Surface tension, $\mathrm{N} / \mathrm{m}$ & $8.23 \times 10^{-3}$ & $7.78 \times 10^{-3}$ \\
\hline Liquid density, mols $/ \mathrm{m}^{3}$ & $10.680 \times 10^{3}$ & $11.407 \times 10^{3}$ \\
\hline Vapor pressure, ${ }^{b} \mathrm{~Pa}$ & $722.6 \times 10^{3}$ & $806.5 \times 10^{3}$ \\
\hline \multicolumn{3}{|c|}{ Calculated values } \\
\hline alpha & 0.9928 & 0.9931 \\
\hline$r_{c r i,}, \mathrm{~m}$ & $84.52 \times 10^{-9}$ & $81.28 \times 10^{-9}$ \\
\hline$P_{\text {vrerit }}{ }^{c} \mathrm{~Pa}$ & $721.35 \times 10^{3}$ & $800.94 \times 10^{3}$ \\
\hline Vapor density, ${ }^{d} \mathrm{mols} / \mathrm{m}^{3}$ & 336.1 & 373.4 \\
\hline$P_{\text {vrerit }} / \mathrm{RT}, \mathrm{mols} / \mathrm{m}^{3}$ & 286.8 & 330.3 \\
\hline
\end{tabular}

aConverted by this author to SI units where necessary, using the factors in ASTM (1992).

${ }^{b}$ Over a plane surface.

'Over a concave spherical surface of radius $r_{\text {crit }}$

"At the temperature shown and pressure $P_{\text {vrcrir }}$. 
Table C.2. Properties of Freon 12 and propane

\begin{tabular}{|c|c|c|}
\hline \multicolumn{3}{|c|}{ Material } \\
\hline Name & Freon 12 & Propane \\
\hline Composition & $\mathrm{CCl}_{2} \mathrm{~F}_{2}$ & $\mathrm{C}_{3} \mathrm{H}_{8}$ \\
\hline \multicolumn{3}{|c|}{ Conditions } \\
\hline Temperature $\mathrm{T},{ }^{\circ} \mathrm{C}$ & 29.4 & 18.5 \\
\hline Measured $\Delta P,{ }^{a} \mathrm{~Pa}$ & $200 \times 10^{3}$ & $197 \times 10^{3}$ \\
\hline$P_{e x t}{ }^{b}$ & $522.6 \times 10^{3}$ & $609.5 \times 10^{3}$ \\
\hline \multicolumn{3}{|c|}{ Vapor properties (Yaws) } \\
\hline Pressure $P_{\text {vap }}{ }^{c} \mathrm{~Pa}$ & $722.6 \times 10^{3}$ & $806.5 \times 10^{3}$ \\
\hline Pressure $P_{\text {vrcrip }}{ }^{d} \mathrm{~Pa}$ & $721.35 \times 10^{3}$ & $800.94 \times 10^{3}$ \\
\hline Density, ${ }^{e} \mathrm{mols} / \mathrm{m}^{3}$ & 336.1 & 373.4 \\
\hline \multicolumn{3}{|c|}{ Liquid properties (Yaws) } \\
\hline Surface tension, $\mathrm{N} / \mathrm{m}$ & $8.23 \times 10^{-3}$ & $7.78 \times 10^{-3}$ \\
\hline Density, mols $/ \mathrm{m}^{3}$ & $10.680 \times 10^{3}$ & $11.407 \times 10^{3}$ \\
\hline Enthalpy of evap., J/mol & $16.54 \times 10^{3}$ & $15.25 \times 10^{3}$ \\
\hline Specific heat, $\mathrm{J} / \mathrm{mol} \cdot \mathrm{K}$ & 122.70 & 115.24 \\
\hline Thermal conductivity; $\mathrm{W} / \mathrm{m} \cdot \mathrm{K}$ & 0.0731 & 0.1627 \\
\hline Viscosity, $\mathrm{Pa} \cdot \mathrm{s}$ & $0.255 \times 10^{-3}$ & $0.107 \times 10^{-3}$ \\
\hline Thermal diffusivityf & $55.8 \times 10^{-9}$ & $123.7 \times 10^{-9}$ \\
\hline
\end{tabular}

${ }^{a}$ For ${ }^{210}$ Po recoils.

${ }^{b} P_{\text {vap }}-\Delta P$.

'Over a plane surface.

¿Vapor pressure over the concave curved surface of the critical bubble-see

Table C.1.

${ }^{e}$ At the temperature listed $(T)$ and a pressure of $P_{\text {vrcrit }}$.

${ }^{f}$ Calculated as thermal conductivity/(density $\times$ specific heat).

The two calculation steps could easily be combined into a single TK model, but for flexibility and ease of cross-checking, I chose not to do that.

Using these values of the properties and the values of $r_{c r i t}$ shown in Table C.1, the vapor content of the bubble, the speed of expansion, and the various energy terms are recalculated and compared with Riepe and Hahn's results in Table C.3.

The present calculations of overall bubble nucleation center formation energy are within a few percent of the Riepe and Hahn results. The only significant disagreement, and that only in percentage terms, is in the small $W_{5}$ term for propane, and for that term Riepe and Hahn explicitly write that they had no precise data on thermal conductivity or viscosity. 
Table C.3. ${ }^{210}$ Po recoils

\begin{tabular}{|c|c|c|c|c|}
\hline \multirow{2}{*}{ Liquid temperature } & \multicolumn{2}{|c|}{$\mathrm{CCl}_{2} \mathrm{~F}_{2}\left(29.4^{\circ} \mathrm{C}\right)$} & \multicolumn{2}{|c|}{$\mathrm{C}_{3} \mathrm{H}_{8}\left(18.5^{\circ} \mathrm{C}\right)$} \\
\hline & Riepe and Hahn & West & Riepe and Hahn & West \\
\hline Calculated critical radius, $\AA$ & 861 & 845 & 829 & 813 \\
\hline Growth velocity, $\mathrm{cm} / \mathrm{s}$ & 304 & 264 & 610 & 609 \\
\hline No. of molecules in critical bubble & $5.55 \times 10^{5}$ & $5.12 \times 10^{5}$ & $5.52 \times 10^{5}$ & $5.06 \times 10^{5}$ \\
\hline Surface energy, $W_{s 1}, \mathrm{keV}$ & 4.9 & 4.6 & 4.3 & 4.0 \\
\hline PV work, $W_{e}, \mathrm{keV}$ & 8.7 & 8.2 & 8.9 & 8.6 \\
\hline Latent heat, $W_{v}, \mathrm{keV}$ & 94.7 & 87.8 & 89.0 & 80.0 \\
\hline Kinetic energy, $W_{4}, \mathrm{keV}$ & 0.3 & 0.2 & $\sim 0.4$ & 0.4 \\
\hline Viscous work, $W_{5}, \mathrm{keV}$ & 1.8 & 1.5 & $\sim 2.6$ & 1.4 \\
\hline Total energy, keV & 110.4 & 102.3 & 105.2 & 94.4 \\
\hline
\end{tabular}

Riepe and Hahn's results and calculations showed that Seitz' thermal spike theory of bubble chamber operation is in quantitative agreement with the observed boiling nucleation behavior of $\alpha$-recoils (i.e., of heavy, slow moving energetic particles). 


\begin{tabular}{|c|c|c|c|c|c|}
\hline$\$$ & 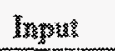 & Nैarme & Oxtzente & Unais & 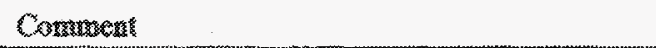 \\
\hline & & & & & 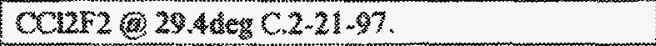 \\
\hline & 8,3145 & X & & Imastik & Nols \\
\hline & 302.55 & 管 & & X & 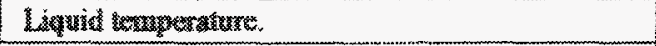 \\
\hline & .00823 & 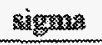 & & Nha & Strof \\
\hline & 10680 & 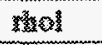 & & 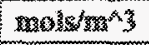 & 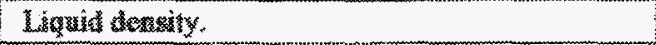 \\
\hline & 726000 & 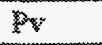 & & (2) & 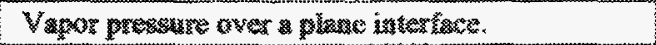 \\
\hline & $20000 \mathrm{~s}$ & 1) & & s; & 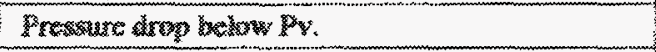 \\
\hline & & aggks & .992777225 & & 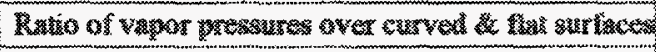 \\
\hline & & serix & 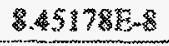 & 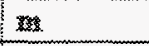 & 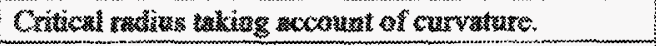 \\
\hline & & sy & 721353.932 & s: & 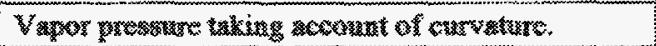 \\
\hline & & & & & \\
\hline & & & & & \\
\hline & & & & & \\
\hline & & & & & \\
\hline & & & & & \\
\hline
\end{tabular}

Varichle Shest

S1

\begin{tabular}{|c|}
\hline rlogs \\
\hline 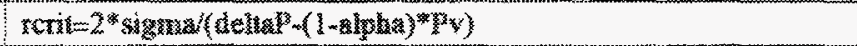 \\
\hline 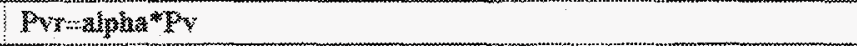 \\
\hline 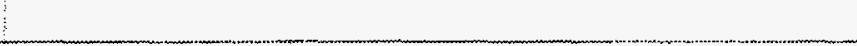 \\
\hline \\
\hline
\end{tabular}

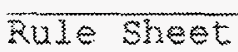

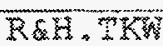

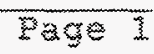




\begin{tabular}{|c|c|c|c|c|c|}
\hline 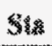 & 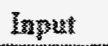 & Naxice & Grfout & Unia & 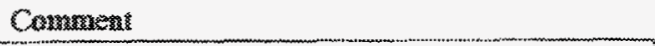 \\
\hline & & & & & 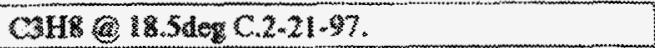 \\
\hline & 8.3145 & R & & Yhaol K & 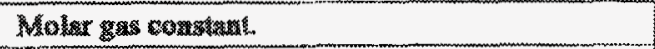 \\
\hline & 291.65 & $T$ & & 勧 & 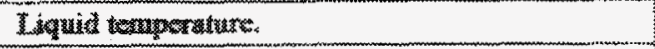 \\
\hline & $.0077 \%$ & rymata & & M/rom & 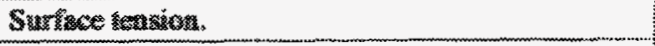 \\
\hline & 11483 & 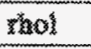 & & $\max \left\{x^{\mathrm{A}} 3\right.$ & 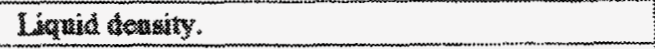 \\
\hline & 806,60 & (2) & & 鹳 & 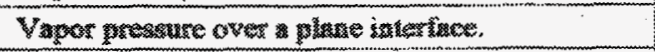 \\
\hline & 99703 & aeskas & & P & 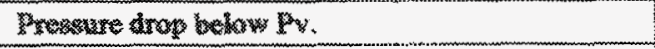 \\
\hline & & 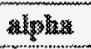 & .993103031 & & 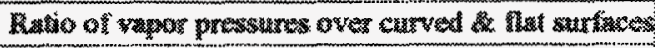 \\
\hline & & acrit & $8.12797 \mathrm{~B}-8$ & 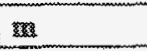 & 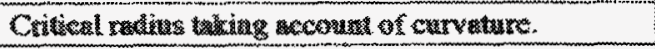 \\
\hline & & Py & 904937.67 & 臹 & 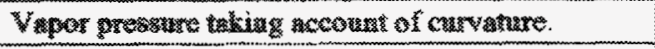 \\
\hline & & & & & \\
\hline & & & & & \\
\hline & & & & & \\
\hline & & & & & \\
\hline & & & & & \\
\hline
\end{tabular}

stinge

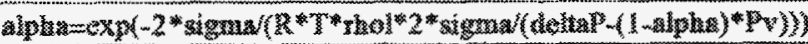

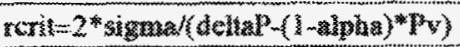

Wy 


\begin{tabular}{|c|c|c|c|c|c|}
\hline$\$ \mathrm{ta}$ & Lagyt & Namec & Ozfput & Uxits & Combanen \\
\hline & & & & & COLP2@29.4C \\
\hline & 209.913 & 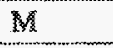 & & & 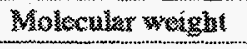 \\
\hline & $\$ 22600$ & Pax & & $x_{3}$ & 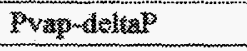 \\
\hline & 5.452148 & rexi & & $\mathrm{x}$ & \\
\hline & .00823 & sigmes & & N/max & \\
\hline & $10 \leqslant 80$ & rtsol & & molsims & \\
\hline & 16940 & $M Y$ & & $3 / \mathrm{mx} x \mathrm{x}$ & \\
\hline & 822.7 & 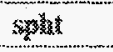 & & 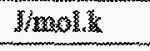 & \\
\hline & .673 & A & & Wims. & \\
\hline & 00255 & ste & & Pas: & \\
\hline & 336.1 & Show & & molsing & \\
\hline & & $D$ & 5.5768 & & \\
\hline & & Win & $7.388 \mathrm{l}-16$ & 3 & \\
\hline & & We & $3.327 \%-15$ & 3 & \\
\hline & & $W_{8}$ & $1.66 \%-1 / 4$ & 3 & \\
\hline & & W4 & $3.4432 \times 17$ & $\frac{7}{3}$ & \\
\hline & & ws & 2.4173516 & 3 & \\
\hline & - & & & & \\
\hline
\end{tabular}

St Ru

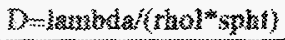

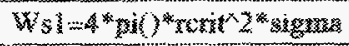

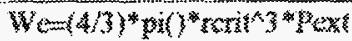

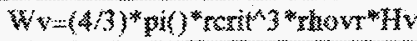

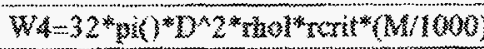

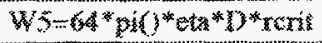




\begin{tabular}{|c|c|c|c|c|c|}
\hline$\$$ & I & Naxtse & Guखqux & Cuniti & Cxzruxarescat \\
\hline & & & & & $\mathrm{C} 3 \mathrm{H} 8(a) 18.5 \mathrm{C}$ \\
\hline & 4.996 & $M$ & & & Molecular weight \\
\hline & 605500 & Bexi & & Pa & 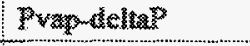 \\
\hline & 2.128 .8 & 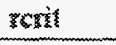 & & 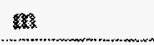 & \\
\hline & .00778 & siggrma & & W/xa & \\
\hline & 11407 & r sey & & xals/mis & \\
\hline & 15250 & $\mathrm{Kv}$ & & Yixnol & \\
\hline & 115.24 & $3 g^{k}$ & & W/rank & \\
\hline & .1627 & Laxnibda & & W/me & \\
\hline & .000107 & es & & 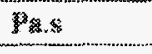 & \\
\hline & 373,13 & $r \operatorname{los} 4 x$ & & 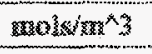 & \\
\hline & & I & $3.237695-3$ & & \\
\hline & & Wa & $6.459 \mathrm{~B}^{36}$ & $y$ & \\
\hline & & We & $3799 E^{\prime} 5$ & $y$ & \\
\hline & & Wy & $3.2808 \mathrm{z}-4$ & $y$ & \\
\hline & & W & 0.2962513 & 3 & \\
\hline & & 5 & 2. $363 \mathrm{E}-16$ & 3 & \\
\hline & & & & & \\
\hline
\end{tabular}

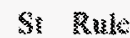

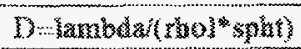

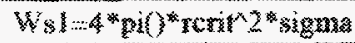

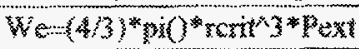

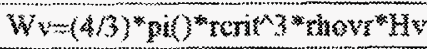

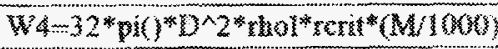

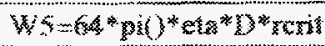


APPENDIX D

AN ADDITIONAL SURFACE ENERGY TERM? 



\section{APPENDIX D. AN ADDITIONAL SURFACE ENERGY TERM?}

Bugg (1959) introduced an additional surface energy term. This was also reported on by Tenner (1963), Hugentobler et al (1963), and Peyrou (1967). Using Peyrou's notation, there is an additional surface energy, $W_{s 2}$, needed to account for the extra internal energy needed by the vapor in the bubble in order to form the surface in an adiabatic way (i.e., without input from anything but the energy of the vapor).

$$
W_{s 2}=-4 \pi r^{2} T \partial \sigma / \partial T
$$

At least in most cases, $-T \partial \sigma / \partial T$ is greater than $\sigma$, so Bugg's term would be a large part of the surface energy.

In the Yaws data base, surface tension at temperature $T$ Kelvin is represented by a correlation of this form:

$$
\sigma(T)=(A+B T)^{n}
$$

therefore,

$$
T \frac{\partial \boldsymbol{\sigma}}{\partial T}=n B T(A+B T)^{n-1}
$$

and it is easy to compute the value of $W_{s 2}$, using the values of $A, B$, and $n$ from Yaws. Between the melting point and the critical point, $T$ is always positive and $\partial \sigma / \partial T$ negative, so that $-T \partial \sigma / \partial T$ is positive and adds to the surface energy. Table D. 1 is an extension of the West figures and the West columns in Table C.3 to include the $W_{s 2}$ energy: one does not know values of $\sigma$, to say nothing of $\partial \sigma / \partial T$, Riepe and Hahn would have used if they were to have calculated this term, and so no comparison with their results is possible.

The calculated total energy is still satisfactorily close to the recoil and alpha energy from the ${ }^{210} \mathrm{Po}$ decay, although it must be said that the addition of the $W_{s 2}$ term has not improved the agreement.

Of the $T \partial \sigma / \partial T$ term, Peyrou (1967) wrote, "The author, not being a specialist in thermodynamics, must confess that he is somewhat puzzled by this term."*

*This sentence in Peyrou's 1967 paper was footnoted as follows: "Since this paper was written, it has become clear to the author that, indeed, the adiabaticity of the process inside the bubble has nothing to do with the adiabaticity of surface formation; that is why extra energy is needed to take this fact into account. However, since heat diffusion is very fast around a little spherical surface (see Section III.D) it is still not clear that surface formation is indeed an adiabatic process." 
Table D.1. Extension of West figures and columns in Table C.3

\begin{tabular}{lcc}
\hline \multicolumn{1}{c}{ Temperature } & $\begin{array}{c}\mathrm{CCl}_{2} \mathrm{~F} \\
29.4^{\circ} \mathrm{C} / 302.55 \mathrm{~K}\end{array}$ & $\begin{array}{c}\mathrm{C}_{3} \mathrm{H}_{8} \\
18.5^{\circ} \mathrm{C} / 291.65 \mathrm{~K}\end{array}$ \\
\hline$A$ (from Yaws) & 24.6498 & 26.4582 \\
$B$ (from Yaws) & -0.06403 & -0.07154 \\
$n$ (from Yaws) & 1.267 & 1.192 \\
$\sigma$ (from Yaws), N/m & 8.23 & 7.78 \\
$T \partial \sigma / \partial T, \mathrm{~N} / \mathrm{m}$ & -38.37 & -34.61 \\
$W_{s 1}$ from Table C.3, keV & 4.6 & 4.0 \\
$W_{s 2}$ from Eqs. (C.1) and (C.3), keV & 21.4 & 17.8 \\
$W_{e}$ from Table C.3, keV & 8.2 & 8.6 \\
$W_{v}$ from Table C.3, keV & 87.8 & 80.0 \\
$W_{4}$ from Table C.3, keV & 0.2 & 0.4 \\
$W_{5}$ from Table C.3, keV & 1.5 & 1.4 \\
Total energy, $\mathrm{keV}$ & 123.7 & 112.2 \\
\hline
\end{tabular}


APPENDIX E

FLUID PROPERTIES FOR EVALUATIONS OF ENERGY TERMS AND PRESSURE THRESHOLD FOR HAHN'S SPINNER EXPERIMENTS 



\section{APPENDIX E: FLUID PROPERTIES FOR EVALUATIONS OF ENERGY TERMS AND PRESSURE THRESHOLD FOR HAHN'S SPINNER EXPERIMENTS}

The properties of the fluids in Hahn's spinner experiments were obtained from the Yaws database (Yaws 1996) and converted as necessary to the units used in this report. In a few cases (e.g., the viscosity of liquid acetophenone and cyclohexanol), the correlations used by Yaws were extrapolated a few degrees outside their applicable temperature range.

The data listed in Table E.1 are rounded to fit in the available space. The properties calculated from Yaws, such as molar densities, carried more significant figures in the TK solver models than in the table.

Table E.1. Liquid and vapor properties; 10-5-98

\begin{tabular}{|c|c|c|c|c|c|c|c|c|c|}
\hline & $\xi$ & 2 & 3 & st & 5 & $\xi$ & 7 & 8 & 3 \\
\hline 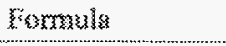 & ऊSRL2 & $0 \mathrm{crcs} \times 3$ & $(20335$ & G6I14 & $3 \times 60$ & $52 \operatorname{ses} 3$ & $233 \mathrm{Br} 2$ & 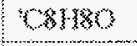 & 66120 \\
\hline & & & & & & & & & \\
\hline Erecond & $10 k$ & 366 & 101 & 101 & 100 & $10 \xi$ & 30 & m & 161 \\
\hline Exacil, 1 & 16182 & 26,996 & 16,382 & 16182 & 96.182 & 36,182 & 16.82 & 16.882 & 16.882 \\
\hline $7 p$ & 82 & 82 & $\$ 2$ & 82 & 82 & 82 & 82 & 82 & 82 \\
\hline Trane, $x_{0}$ & 293,15 & 29315 & 293,15 & 293.15 & 293.15 & 293.15 & 293,35 & 29365 & $29: 60$ \\
\hline 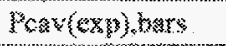 & 3.34 & 4.8 & 5.23 & 6.89 & 8.3 & 11.75 & 22.19 & 33.23 & 48.74 \\
\hline \multicolumn{10}{|c|}{ From Yows bata } \\
\hline $\mathrm{MSWE}$ & 72.150 & 187.175 & 187.35 & 86177 & 58.980 & 131,388 & 187.362 & 120.351 & $10 \% 18$ \\
\hline $2 k$ & 42 & 9 & 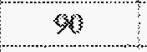 & 30 & 32 & 8 & $\$$ & 6 & 56 \\
\hline 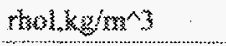 & 621 & $15 ?$ & 1576 & 663 & 791 & 3466 & 2176 & 1023 & 962 \\
\hline sigma, $m$ Mn/m & 1498 & 37.72 & 17.72 & 18.4 & 23.66 & 29.40 & $38: 2$ & 39,48 & 33.58 \\
\hline 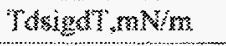 & -31.73 & .33 .16 & -33.16 & -32.56 & -36.26 & -38.8 & $.356,38$ & -33.69 & $-3\} .41$ \\
\hline Cpligylonel. & 157.03 & 168.26 & 36826 & 191.40 & 126.66 & 23.05 & $\{31.03$ & 19931 & 237.80 \\
\hline 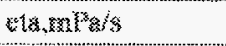 & .225 & .734 & .734 & .310 & .322 & 571 & 1.749 & 1.391 & 29.540 \\
\hline Klus.wim & $1.16 \mathrm{a}-1$ & $7.71 \mathrm{E}-2$ & $7.3 \leq 2=2$ & $3.2 \times E-1$ & 1,6324 & \left.1\} .3 E_{*}\right\}$ & $3 .\{\} \mid \xi-1$ & $1.755, n$ & $1.34 \mathrm{~F}$ \\
\hline Pcrix, bars & 33.81 & $3 \times 15$ & 3415 & 30.12 & 4732 & 89.16 & 5477 & 38.40 & 37.45 \\
\hline Triz, $K$ & 460,43 & 487.35 & 487,25 & 507.43 & $58 \% .28$ & $\$ 71,00$ & 650.15 & 791.00 & 625.15 \\
\hline thorri, , kim 3 & 235.3 & 5760 & 5760 & 233.0 & 279.9 & 513.2 & $71<2$ & 3196 & $3\}\{.3$ \\
\hline 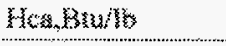 & 237.18 & $\{0326$ & 10,28 & 285.78 & 29534 & 1543 & 346.18 & 463,20 & 429.20 \\
\hline 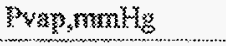 & 57525 & $27 \% 75$ & 270,75 & 122.39 & 184,3 & 38.3 & 1018 & 0.23 & 0.66 \\
\hline 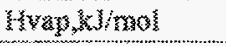 & 25.27 & 28.86 & 2886 & 32.28 & 32.56 & 35.27 & 3238 & 33.89 & $\$ 1.99$ \\
\hline \multicolumn{10}{|l|}{ 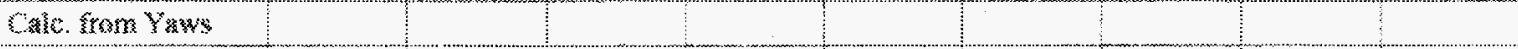 } \\
\hline 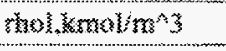 & 8.607 & 8411 & 8.411 & .670 & 13.616 & 11.35 & 13.599 & 8.556 & 9.605 \\
\hline 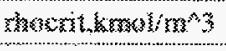 & 3,276 & 3.078 & 3.074 & 2.704 & 4785 & 3.906 & 3.323 & 2660 & 3.106 \\
\hline 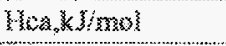 & 39.78 & $449 \%$ & 3497 & 39.35 & 39.37 & 47.07 & 63.93 & 112.61 & 99,95 \\
\hline$D_{n} m^{*} 2 / n$ & $5.553 \mathrm{~B} .8$ & $5.4485-8$ & $5.4898-1$ & $8,3448-8$ & 9.4498 & $8.565 \%$ & $6.6655 \mathrm{~J}-8$ & $1.323 \% \%$ & $\% 25 \mathrm{~L}$ \\
\hline Pvog & $7.6 \% \mathrm{k}$ & $3.613-1$ & 3.435 & $\left\{.63 \mathrm{~S}_{m}\right\}$ & $2,65-1$ & $7.756,2$ & $1.966-2$ & $3.73 \% 4$ & $8.80 \mathrm{~L}-4$ \\
\hline Sigent,roNing & 46.72 & 50.88 & 50,88 & 51.38 & 59.92 & 68.28 & 77.93 & 72.55 & 60.39 \\
\hline 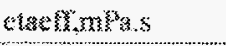 & $2.383 E-1$ & $3.55 \mathrm{se}, \mathrm{s}$ & $7.555 \mathrm{E}-1$ & $3.238 \mathrm{E}-3$ & $3,4978-1$ & $6024 \mathrm{E}$ & 1.785 & 1.917 & 99.555 \\
\hline
\end{tabular}

ThT TRER: properties 



\section{INTERNAL DISTRIBUTION}

1. J. R. Alonso

2. J. B. Ball

3. L. A. Charlton

4. T. A. Gabriel

5. J. R. Haines

6. M. Siman-Tov

7. R. P Taleyarkhan
8-10. C. D. West

11. J. Whealton

12. D. M. Williams

13-14. Central Research Library

15. Laboratory Records Department 16-17. OSTI

\section{EXTERNAL DISTRIBUTION}

18. Prof. R. E. Apfel, Yale University, 9 Hillhouse Avenue, New Haven, CT 06520-8286

19. Dr. G. Bauer, Paul Scherrer Institute, CH5232, Villigen, Switzerland

20. Prof. F. d'Errico, Yale University School of Medicine, Department of Therapeutic Radiology, Division of Radiological Physics, 333 Cedar St., HRT-219, New Haven, CT 06510

21. Herr Dr. Georg Riepe, Im Schmidtenloch 59, D-53894 Mechernich, Germany

22. Dr. Carl L. Yaws, TREI, 685 Birchwood, Port Neches, Texas 77651

23. D. K. Wilfert, Energy Programs, U.S. Department of Energy, Oak Ridge Field Office, SNS Building, MS-8218, P.O. Box 2009, Oak Ridge, TN 37831-8218 